University of Rhode Island

DigitalCommons@URI

Open Access Master's Theses

1968

\title{
A Preliminary Study of the Effects of an Imidazolecarboxyhydrazide on Blood Pressure, Monoamine Oxidase, and Locomotor Activity
}

Robert Louis Procaccini

University of Rhode Island

Follow this and additional works at: https://digitalcommons.uri.edu/theses

\section{Recommended Citation}

Procaccini, Robert Louis, "A Preliminary Study of the Effects of an Imidazolecarboxyhydrazide on Blood Pressure, Monoamine Oxidase, and Locomotor Activity" (1968). Open Access Master's Theses. Paper 218.

https://digitalcommons.uri.edu/theses/218

This Thesis is brought to you for free and open access by DigitalCommons@URI. It has been accepted for inclusion in Open Access Master's Theses by an authorized administrator of DigitalCommons@URI. For more information, please contact digitalcommons-group@uri.edu. 
A PFELIMINAKY SIUDY OF THE EFFECHE OE AN IMIDAZOLFCARBOXYTYURAZILE ON SBNOL PRESSURE, MONOAMINE OXISASH, AND LOCONOFOK ACITVITY

$B Y$

ROBERT LOUIS PROCACCINI

A THESTS SUBMITTED IN PARTIAT FUIEIILMENT OF TFE FEQUIREMENTS FOR THF DEGREE OF

MASTER OF SCIENCE

IN

PHARMACCIOGY

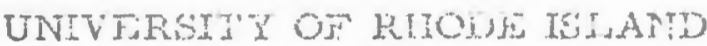

19088 


\begin{abstract}
Imidazole-4, 5-dicarboxylic acid, di-2-methylhydrazide (JNIVa), exemplary of several recently synthesized dihydrazides, was investigated for possible monoamine oxidase inhibiting properties. A significant alteration of systemic blood pressure, measured both directly and indirectly, was not evident during either single of repeated administxation of JNIVa at low doses. Monoamine oxidase, as determined spectrophotometrically, was inhibited in vitro, but not in vivo by this compound. The degree of enzyme inhibition was shown to be dependent upon preincubation time. Compound JNIVa was less effective in inhibiting monoamine oxidase in vitro than was phenelzine, a known inhibitor of moisoamine oxidase both in vivo and in vitro. When measured 1.0 hour and 2.5 hours after drug administration, phcrelzine increased gross locomotor activity at both time intervals, whereas JNIV a significantly decreased spontaneous activity at the 1.0 hour time interval.
\end{abstract}




\section{MASTER OF SCIENCE THESIS}

OF

ROBERT LOUIS PROCACCINI

Approved:

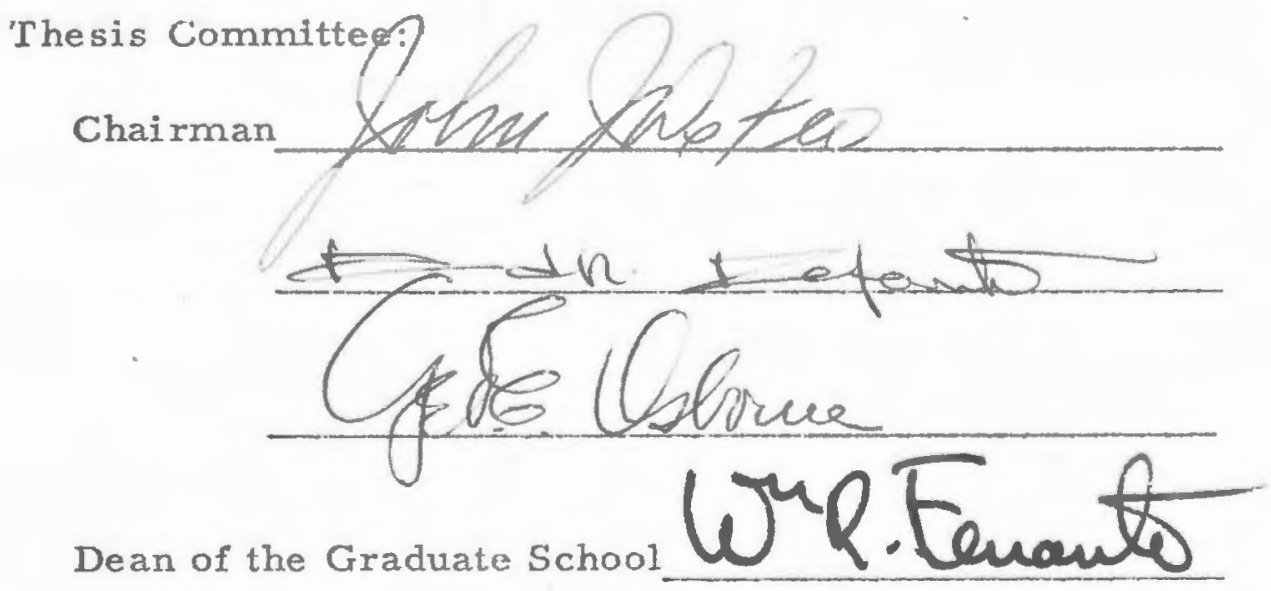

UNIVERSITY OF RHODF. ISLAND

1968 


\section{ACKNOWLEDGEMENTS}

The author wishes to express sincere appreciation for the advice and encouragement afforded to him by Dr. John J. DeFeo.

The author would like to thank Mr. Angelo Benedict Mendillo, III, for his generous assistance both in and out of the laboratory.

The author would like to express his gratitude and appreciation for the encouragement afforded to him by his parents, Mr. and Mrs. Domenic Procaccini, whose kind help has made the attainment of their son's goals possible. 
ACKNOWLEDGEMENTS .................... iii

ABSTRACT $\ldots \ldots \ldots \ldots \ldots \ldots \ldots \ldots \ldots \ldots \ldots \ldots \ldots \ldots \ldots \ldots \ldots$

TABLE OF CONTENTS .................... v

LIST OF TABLES ...................... vi

LISI OF FIGURES. .................... viii

I. INTRODUCTION .................... 1

II. SURVEY OF THE LITERATURE .............. 3

A. HYDRAZIDES: HEMODYNAMIC EFFECTS ..... 10

B. MAO INHIBITORS: BEHAVIORAL CHANGES .... 12

III. INVESTIGATION .................. 20

A. OBJECTIVES .................... 20

B. MATERIALS AND METHODS ........... 21

1. Blood Pressure study ............ 21

2. Monoamine oxidase studies ......... 25

3. Activity studies ................ 34

IV. RHSULTS ..................... 37

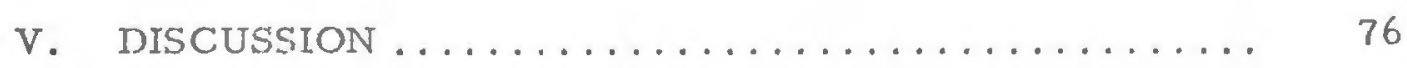

vI. SUMMARY AND CONCLUSIONS .............. 92

VII. REFERENCES ...................... 94 


\section{LIST OF TABLES}

Page

XII. The effect of JNIVa and phenelzine treatment on gross locomotor activity in male albino mice. Incidence of significant difference between phenelzine-treated and vehicle-treated groups of mice at the one hour time interval..............................

XIII. The effect of JNIVa and phenelzine treatment on gross locomotor activity in male albino mice. Incidence of significant difference between phenelzine-treated and velicle-treated groups of mice at the 2.5 hour time

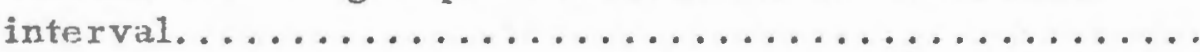




\section{LIST OF FIGURES}

Page

1. The effect of JNIVa and phenelzine on terminal monoamine oxidase activity. In vivo drug activity expressed as turnover rate of monoamine oxidase obtained from liver homogenates of rats pretreated with vehicle, JNIVa or phenelzine .....................

2. The effect of JNIV a and phenelzine on terminal monoamine oxidase activity. In vivo drug activity expressed as turnover: rate of monoamine oxidase obtained from brain homogenates of rats pretreated with vehicle,

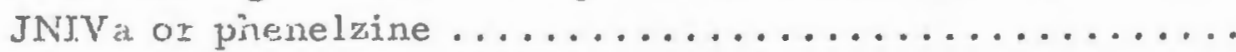

3. The effects of JNIV a on monoamine oxidase activity. Graph represents degree of enzyme inhibition produced by increased concentrations of inhibitor............

4. The effects of phenelzine dihydrogen sulfate on monoamine oxidase activity. Graph represents degree of enzyme inhibition produced by increased concentrations of

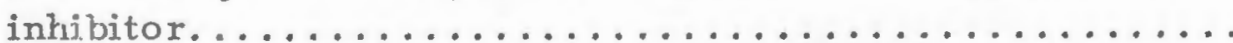

5. The effect of increased preincubation time on the degree of inhibition of monoamine oxidase by compound JNIVa

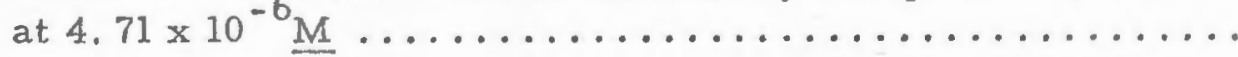

6. Actophotometric recording of gross locomotor activity generated by vehicle-treated mice, one hour after injection.

7. Actophotometric recording of gross locomotor activity generated by phenelzine-treated mice, one hour after

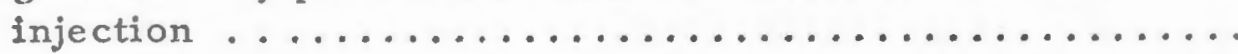

8. Actophotometric recording of gross locomotor activity

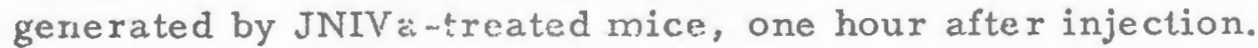

9. Actophotometric recording of gross locomotor activity generated by phenelzine-treated mice, 2.5 hours after

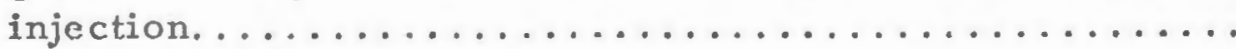

10. Actophotometric recording of gross locomotor activity generated by JNIVa-treated mice, 2.5 hours after

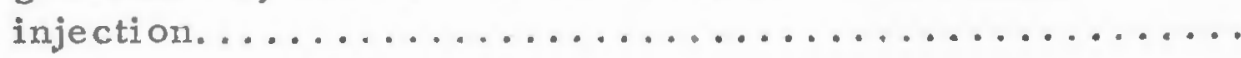




\section{LIST OF FIGURES}

11. Actophotometric recording of gross locomotor activity generated by vehicle-treated versus JNIVa-treated

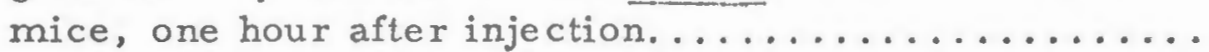

12. Actophotometric recording of gross locomotor activity generated by vehicle-treated versus phenelzine-treated mice, one hour after injection................

13. Actophotonatric recording of gross locomotor activity generated by vehicle-treated versus JNIVa-treated mice, 2.5 hours after injection..............

14. Actophotometric recording of gross locomotor activity generated by vehicle-treated versus phenelzine-treated mice, 2.5 hours after injection...............

15. Actophotometric recording of gross locomotor activity generated by JNIVa-treated versus phenelzine-treated Inice, one hour after injection................

16. Actophotometric recording of gross locomotor activity generated by JNIVa-treated versus phenelzine-treated mice, 2.5 hours after injection...............

17. Actophotometric recording of gross locomotor activity generated by JNIVa-treated versus phenelzine-treated mice, one hour and 2.5 hours, respectively, after

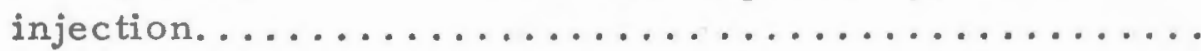

18. Actophotometric recording of gros locomotor activity generated by JNIVa-treated versus phenelzine-treated mice, 2.5 hours and one hour, respectively, after

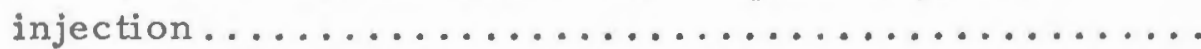

19. Actophotometric recording of gross locomotor activity generated by two JNIVa-treated groups of mice, one hour and 2.5 hours, respectively, after injection......

20. Actophotometric recording of gross locomotor activity of vehicle-treated, JNIVa-treated and phenelzinetreated mice, one hour after injection............ 


\section{LIST OF FIGURES}

Page

21. Actophotometric recording of gross locomotor activity generated by vehicle-treated, JNIVa-treated and phenelzine-treated mice, 2.5 hours after injection......

22. Actophotometric recording of gross locomotor activity generated by vehicle-treated versus two groups of JNIVa-treated mice, one hour and 2.5 hours, respectively,

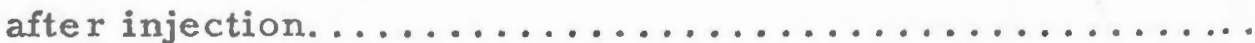

23. Actophotometric recording of gross locomotor activity gererated by vehicle-treated versus two groups of pherelzine-treated mice, one hour and 2.5 hours,

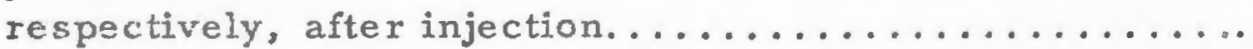




\section{INTRODUC'TION}

In 1964, Dr. Jay Nematollahi* synthesized a series of imidazole acid hydrazides. Comparison of the molecular structures of these imidazolecarboxhydrazides with known hydrazide-type inhibitors of monoamine oxidase (MAO) suggested the hypothesis that this series of compounds might exhibit similar biological activity. In order to test the validity of the hypothesis, an approach was made based on several assurmptions: experiments with these compounds should provide comparisons with the pharmacological activities of known inhibitors of MAO, e.g., the prolongation or potentiation of the effects elicited by vaxious biogenic amines to produce the type of action that may manifest itself by an alteration in systemic blood pressure; second, the cxperiments should include both in vivo and in vitro studies of liver monoamine oxidase in rats pretreated with sufficient doses of hydrazide MAO inhibitors, since these compounds have shown that the activity of this enzyme system is either greatly depressed or inhibited completely; and the experiments should allow for observations of behavioral changes (usually an increase in locomotor activity) such as have been observed in several animal species treated with MAO inhibitors.

\footnotetext{
*University of Texas; Drug-Plastic Research and Toxicology Laboratories, Balcones Research Center, Austin, Texas
} 
Consequently, test procedures were designed with the purpose of determining which, if any, of these physiological alterations could be demonstrated in animals treated with new compounds from this series of acid hydrazides. 


\section{SURVEY OF THE LITERATURE}

The preliminary observations of Zeller et al. (1952) of two antitubercular drugs, isonicotinic acid hydrazide (INH) and l-isonicotinyl2 -isopropyl hydrazide (IIH) proved to be the initiating stimulus for subsequent studies of hydrazides and their effect on the enzyme, monoamine oxidase. Teller and his coworkers noted that the two acit hydrarides produced marked in vitro inhibition of mammalian monoamine oxidase, and attributed the euphoria observed in patients during clinical trials with these drugs, to sympathetic stimulation resulting from interference of normal amine metabolism.

Studies on the cellular localization of monoamine oxidase (Hawkins, 1952) revealed that enzyme activity was largely present in the mitochondria. Following this observation, Zeller and Barsky (1952) postulated that administration of 1-isonicotinyl-2-isopropyl hydrazine (Iproniazid), followed by isolation of tissue mitochondria for determination of monoamine oxidase activity, would provide an indication of any in vivo enzyme inhibition. Under these conditions, Iproniazid produced an irreversible inhibition of liver monoamine oxidase, both in vitro and in vivo. Based on these findings, Zeller stated:

"The elimination of monoamine oxidase activity in vivo should prove of value in the investigation of the physiological function of the enzyme, particularly with regard to its possible role in the degradation of epinephrine and nor epinephrine. INH may well become of the same importance as has eserine in the analysis of the cholinergic system. The above results may also offer an explanation for the 
sympathetic and general mental stimulation observed afte $r$ administration of isonicotinyl-hydrazicles... in that the blocking of monoamine oxidase activity could lead to an accumulation of sympathetic amines with ensuing effects on the autonomic nervous system."

Schayer and Smile (1953), using $\alpha$-laballed ${ }^{14} \mathrm{C}$-epinephrine, demonstrated the ability of iproniazid to alter epinephrine metabolism in the intact $r$ at. In a later study, Schayer (1953), using ${ }^{14}$ C-tyramine, further demonstrated that, in contrast to epinephrine, tyramine is metabolized almost solely by monoarnine oxidase; consequently, by administering radioactive tyramine to rats pretreated with a hydrazide MAO inhibitor, and measuring the quantity of unmetabolized tyramine present in the urine, he was able to measure the degree of in vivo MAO inhibition. Schayer noted with interest the obvious failure of compounds capable of inhibiting MAO in vitro to perform the same function in vivo and attributed this loss of activity to the inability of the drug to reach the site of action because of rapid destruction or of permeability problems. He suggested the possibility that in vitro preparations underwent some alteration of the active portion of the enzyme, effecting a response different from that scen in an Intact preparation.

Subsequent investigations have revealed a number of factors which could conceivably alter the activity of hydrazide MAO inhibitors, depending upon the type of experimental system involved. The work of Aebi (1962) demonstrated that the degree of MAO activity and MAO 
inhibition involved in an in vitro preparation is dependent upon the structural state of the mitochondria. Referring to inconsistent values reported by investigators using both in vivo and in vitro systems for studying $\mathrm{MAO}$, Aebi noted that, "It is very difficult to extrapolate figures for an enzymatic activity obtained from lysed preparations to the intact cell, if the enzyme is structurally bound." In relation to in vivo studies of $\mathrm{MAO}$ activity and MAO inhibition, Horita (1965) reported that red blood cells are capable of antagonizing the actions of various monoamine oxidase inhibitors. This factor alone might account for variations in the response to hydrazide inhibitors, since mitochondrial preparations, properly prepared, do not contain red blood cells.

Zeller et al., (1955) later elucidated the mechanisms involved in the process of MAO inhibition. Zeller reported certain characteristics of hydrazide-type MAO inhibitors which would subsequently prove to be almost universal for this class of compounds. He noted that the degree of inhibition of monoamine oxidase activity depended upon whether the inhibitor used, in this case 1-isonicotinyl-2-isopropyl hydrazide, was added to the system prior to or simultaneously with the substrate. In additional experiments, preparations of mitochondrial monoamine oxidase were preincubated with the inhibitor for various time intervals prior to the addition of substrate. From this work, Zeller was able to demonstrate clearly that 
the degree of inhibition of mitochondrial MAO was dependent upon the length of time the inhibitor was allowed access to the enzyme in the absence of substrate. The MAO activity of liver homogenates was reported to be relatively unaffected by iproniazid. This apparent insensitivity to agents capable of inhibiting monoamine oxidase in vivo was attributed to the presence of a substance or substances in the cellular iractions of the homogenate. Since iproniazid was known to produce a potent, irreversible inhibition of $\mathrm{MAO}$ in vivo (Zeller, et al., 1952), it seemed that these interfering substances did not come.into play in the intact animal.

The work of Briesmer and Wells (1956) described the ability of iproniazid to decrease epinephrine inactivation by intact liver slices from cats pretreated with the inhibitor. However, these authors concluded that the drug was relatively impotent when used in an in vitro enzyme preparation.

Mechanism of action: iproniazid. Although numerous investigators had utilized the hydrazide MAO inhibitors as tools in studies associated with this enzyme, little was actually known about the mechanism of action of these drugs prior to the publication of the work of Davison (1957). He extended Zeller's original observations, proposing oxygen as a necessary requirement for iproniazid, if the drug is to exhibit irreversible inhibition of mitochondrial monoamine oxidase. This activity is absent under anaerobic conditions. In accordance with 
previous observations, he found that progressive inhibition of enzyme activity was less pronounced in liver suspensions as compared to mitochondrial preparations. The facts that the inhibition reaction proved to be first-order and possessed a high energy of activation, strongly suggested the occurrence of a chernical reaction involving the hydrazide moiety.

Maitre (1967) studied the effects of various MAO inhibitors on brain, liver and heart, using two substrates, tyramine and 5-hydroxytryptamine. In order to gain a more complete picture of inhibitor potencies, he determined MAO activity in vivo as well as in vitro. In his study. in vivo effects of iproniazid on brain MAO proved to be relatively more potent than those elicited in vitro. A selected accumulation or a slow metabolic rate of the inhibitor in the brain were mechanisms thought to be responsible for this action. However, a different theory is presently favored by the majority of investigators: ipronazid and related hydrazine drugs could undergo a cleavage of the parent molecule, leading to the formation of an active metabolite; the metabolite then could disappear more slowly from the brain than from peripheral tissues (organs). Research in this area has been extensive. Davison (1958) reported that iproniazid and presumably other hydrazide MAO inhibitors react at the active center of the enzyme in a manner similar to substrate oxidation. Once attached to the active center of the enzyme, the drug undergoes dehydrogenation and reacts 
further with the enzyme to produce the final inhibition. The following mechanism was postulated:

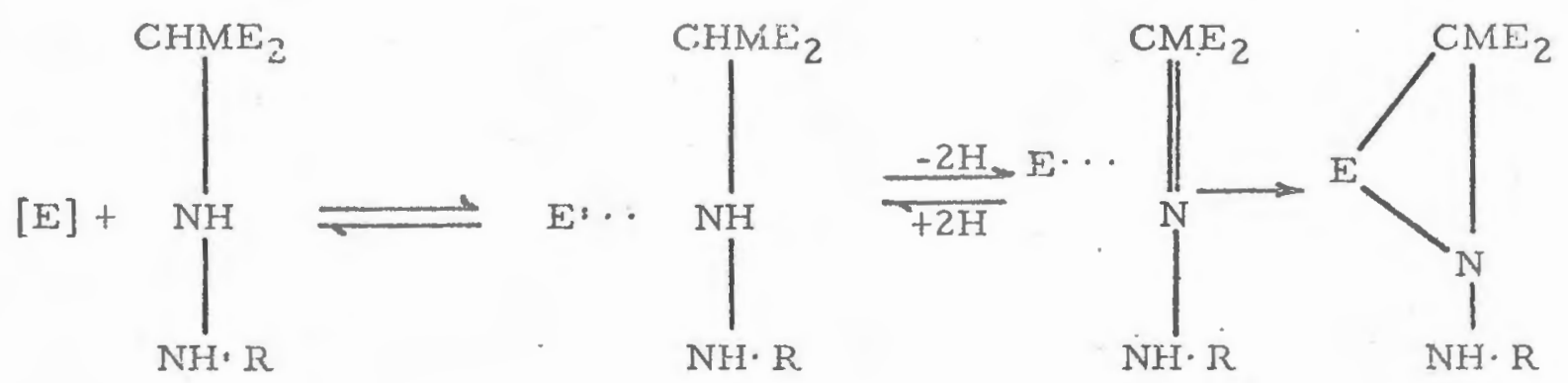
ENZYME IPRONIAZID
REVERSIBLE
IRREVERSIBLE
COMPLEX
COMPLEX

$$
(\mathrm{R}=\text { ISONICOTINYL) }
$$

Following this work, Smith et al. (1962) presented evidence that, during the preircubation periods with the enzyme required for maximal inhibition, iproniazid was hyclrolysed to form a volatile compound believed to be the active inhibitor of the enzyme. The reaction was thought to be non-enzymatic. Monoamine oxidase was not implicated in this reaction since the formation of active inhibitor is accomplished in the absence of active enzyme. Isopropylhydrazine, a metabolite of iproniazid Kíoechlin and Iliev, 1959) with MAO inhibitory properties (Biel et al. , 1959; Nair, 1959), is believed to be the active inhibitor.

A mechanism analagous to the one proposed for iproniazid has been reported by Schwartz (1962), who suggested that isocarboxazid (Marplan) exerts its MAO inhibition by undergoing hydrolysis to benzylhydrazine, during preincubation with the enzyme. When benzylhydrazine was used alone, no preincubation period was necessary to attain maximal 
inhibition of the enzyme, in vitro. He concluded that the parent molecule must be hydrolysed to the active moiety before inhibition of the enzyme can be accomplished.

Support for a hydrolytic mechanism involving monoamine oxidase has been presented by Seiden and Westley (1963), who used a preparation of lysed brain mitochondria to show that addition of iproniazid to a functioning $\mathrm{NAO}$ reaction resulted in an inhibition of that system only after a definite delay period. In the same system, isopropylhydrazine, the proposed active moiety of iproniazid, proved to be ten times as potent as the active compound. Except for the absence of any delay phenomenon, isopropylhydrazine elicited the same type of inhibition as that seen with iproniazid. The postulated mechanism is summarized in the following reactions:

(1) IPRONIAZID $+\mathrm{H}_{2} \mathrm{O} \ldots \ldots . . \rightarrow$ ISONICOTINIC ACID

$+$

ISOPROPYLHYDRAZINE
(2) ISOPROPYLHYDRAZINE + MAO $\rightarrow$ INACTIVE FORM OF MAO

According to the scheme, iproniazid is first modified enzymatically to form an inhibitory product, with subsequent inhibition of the enzyme by the product. This proposed mechanism of action could explain several characteristics associated with hydrazineinduced inhibition of monoamine oxidase. 
Hydrazides: Hemodynamic Effects

The effect of hydrazide MAO inhibitors on systemic blood pressure is not well understood. Sjoerdsma stated (1960) that the simultaneous drug-induced decreased blood pressure and increased tissue levels of norepinephrine "constituted an intriguing paradox".

Following clinical reports of the antihypertensive effects produced by various hydrazides, Gertner $(1959 ; 1961)$ found that certain hy.drazide MAO inhibitors blocked ganglionic transmission. Goldberg et al., (1960) noted that the se compounds exerted a selective inhibitory action on the sympathetic synapse without depressing parasympathetic ganglia. He speculated that this sympathetic inhibition could be the mechanism responsible for hypotension in man after administration of MAO inhibitors. Gessa et al. , (1963) postulated another theory conccrning hypotensive effects produced by hydrazide MAO inhibitors. These workers noted that hydrazine MAO inhibitors elicit certain bretylium-like properties, that they prevent guanethidine from releasing heart norepinephrine, and that they also prevent sympathetic nerve impulses from releasing norepinephrine onto receptor sites. These findings substantiated the work of Davey et al. (1963), who reported that the MAO inhibitor nialamide reduced the amount of nor epin ephrine released from splenic nerves by electrical stimulation. These effects appeared to be independent of the MAO inhibitory properties exhibited by these compounds. According to Gessa et al. , 
(1963), blockade of this enzyme system could be regarded as an undesirable side effect of these drugs in their use as hypotensive agents. Clinical investigation by Assali and Kanakbcena (1960) led them to conclude that the hypotension as sociated with the use of iproniazid represented a side effect of the drug, probably caused by venous pooling and a decrease in cardiac output. An alternate mechanism for the production of hypotension was postulated by Sjoerdsma (1960). In studies with various hydrazire and non-hydrazine MAO inhibitors he observed a uniform hypotensive effect when evidence of MAO inhibition was apparent, exclusive of the type of inhibitor used. These findings offered evidence of a causal relationship between MAO inhibition and reduction of blood pressure. Further, he postulated that an accumulation of an amine, such as serotonin, 5-hydroxytryptamine (5-HT), in sympathetic ganglia could be responsible for the effects seen in man. Consequently, dopamine, an excellent substrate for $\mathrm{MAO}$ and a weak pressor substance could accummulate at nerve endings and competitively block the action of released norepinephrine. Kopin et al., (1965) have dernonstrated the existence of a weak pressor amine, octopamine (norsynephrine), which could produce partial sympathetic blockade by replacement of norepinephrine. Thus octopamine could act as a false, inactive neurotransmitter. The appeal of this theory has been augmented by the fact that the formation of octopamine is enhanced during inhibition of MAO. Sjoerdsma (1966), while discussing the relationship existing 
between inhibition of a given enzyme and concurrent pharmacologic effects, stated that "such a relationship seems established with the MAO inhibitors." Pletscher (1966) noted that only those hydrazine, MAO inhibitors capable of exerting a potent inhibiting action on MAO induced hypotension in man. A number of investigators have failed to establish any correlation between MAO inhibition and pharmacological effects in mais. Their failure does not imply that a relationship does not exist, however, since MAO activity in man has been measured only in peripheral tissues.

MAO inhibitors: Behavioral changes

Gylys et al., (1967) stated that:

"The monoamine oxidase inhibitors as a pharmacological group exhibit heterogeneous and unpredictable effects on spontaneous motor activity..... It is conceivable that such heterogeneous responses might be partially due to the chemical diversity of MAO inhibitors as a group and the experimental design, i.e., dose selection, time of testing, duration of activity recording."

Since 1959, extensive work has been undertaken in an attempt to clarify the mechanism of action of hydrazine and non-hydrazine MAO inhibitors in relation to central stimulation.

The extent to which the therapeutic effects of the inhibitors, particularly antidepressant actions, may be attributed to the irreversible blockade of MAO and the consequent accumulation of brain amines has been and remains the question at hand. Feldstein (1965) in his discussion concerning MAO inhibitors and their clinical application 
posed the question, "Is MAO inhibition a general pharmacologic property of these agents, or is it'specifically related to relief of depression?"

Numerous investigators working on hydrazine-type MAO inhibi: tors have attempted to correlate clinically observed behavioral effects with several biochemical changes produced by these drugs, particularly increases in brain amine levels.

Clinically; the mood elevating or antidepressant actions of hydrazine MAO inhibitors accompanied by a corresponding increase in certain brain amines is readily demonstrated. Feldstein (1965) used the conversion of orally administered ${ }^{14} \mathrm{C}$-Serotonin to ${ }^{14} \mathrm{C}-5$-hydroxy indolacetic acid, as a quantitative index of MAO inhibition in human subjects, all of whom were being treated for psychiatric disorders. Following treatment with phenelzine, isocarboxazid, and nialamide, all hydrazine-type MAO inhibitors, Feldstein was able to demonstrate a direct correlation between the degree of drug induced MAO inhibition and clinical improvement. Pare (1966) was able to measure serotonin brain levels directly and antidepressant activity of MAO inhibitors in 44. patients dying of terminal illnesses. He found that brain serotonin levels rose at the same time that the antjdepressant effect of the drug occurred.

Studies in animal behavior associated with brain amine levels have been inconclusive. Spector et al, (1960) studied the effects of 
several hydrazine MAO inhibitors, including iproniazid, on brain levels of norepinephrine and serotonin in various animal species. They concluded from this study that any central excitation elicited by these compounds, per se or by any accurnulation of brain serotonin alone, was unlikely. In rabbits, single doses of inhibitor had produced a marked rise in brain serotonin levels. However, behavioral changes durirg this period were not evident. Dally doses of inhibitor, although not increasing sorotonin levels significantly higher than single doses, did produce a higher norepinephrine level. It was further noted that, when peak norepinephrine levels were obtained, the rabbits elicited signs of hyperexcitability. The inhibitors increased brain serotonin levels but failed to raise norepinephrine levels significantly in cats and dogs. It was of interest, then, to note that the inhibitors failed to elicit increased psychomotor activity in either of the se species.

The effects of iproniazid, along with other hydrazine-type MAO inhibitors, on locomotor activity in mice remains unclear. Greig et al., (1961) reported that iproniazid and b-phenylisopropyl hydrazine (JB 516) failed to increase spontaneous motor activity when administered to mice. B-phenylisopropyl hydrazine, a hydrazine analog of amphetamine has been shown to elicit central excitation and convulsions In rabbits (Spector, et al., 1960; Maling et al., 1962). Greig et al., (1961) reported that this drug failed to increase spontaneous motor activity in mice. However, Plummer et al., (1963), using a modified 
jiggle cage to measure gross locomotor activity, noted that JB-516 sharply augmented spontaneous activity in mice at the $20 \mathrm{mg} / \mathrm{kg}$ dose level. This effect, they believed, was apparently unrelated to the MAO inhibitory properties of the drug, since this slimulatory action disappeared after one hour, whereas MAO inhibition remained. Nardil. (phenelzine) has been shown to raise brain serotonin levels in mice at a steady state of $0.43 \mathrm{ug} / \mathrm{g}$ of brain wet weight (Dubnick et al., 1959). Adrninistered in single doses, phenelzine produced central stimulation in mice, but failed to elicit similar responses in rabbits, dogs, rats, and monkeys (Chessin et al., 1959).

Recently, Garattini et al. , (1967) reported a change in turnover rate of 5-hydroxy-tryptamine in grouped and isolated aggresive mice treated with a MAO inhibilor. An increase in turnover time of se rotonin of about $57 \%$ in isolated mice as compared to grouped mice was noted. It was further demonstrated that changes in 5-HT turnover are not necessarily reflected in the level of brain 5-HT. Under isolated conditions, all mice became aggressive, suggesting a possible correlation between behavioral changes and central metabolism of 5-HT. Randall and Bagdon (1959) reported that in mice pretreated with ipronfazid, the central excitatory effects of 5-hydroxytryptophan and DOPA wore potentiated, whereas the drug falled to elicit an excitatory response in these animals when administered alone. Similarly, Green (1962) demonstrated that even after repeated oral administration 
of iproniazid in high doses $(100 \mathrm{mg} / \mathrm{kg})$, no significant or consistent effect upon the motor activity pattern of the drug-treated animals was observed. Conversely, Chessin et al., (1959) reported that administration of a single dose of Nardil (phenelzine) produced stimulation of the central nervous system in mice, but failed to do so in rabbits, dogs, cats, and monkeys. Recently, it has been reported that marked stimulation prociuced by at least one MAO inhibitor and characterized by hyperactiyity is better developed and hence more readily demonstrated in mice than in rats (Gylys et al. , 1967).

Furguiele (1962) measured the changes both in spontaneous and forced motor activity in mice following administration of iproniazid and phenylisopropylhydrazine (PIH). Potent stimulatory effects on gross locomotor activity were seen after PIH administration, whereas iproniazid greatly depressed spontaneous activity, at high dose levels. Both of the hydrazides, howeve $r$, decreased forced activity, as measured by "rotorod performance time." These data supported existing theories concerning the mechanism of action of the hydrazides. Increased spontaneous activity produced by phenylisopropyl hydrazine coincided with reports of a dual mechanism of this drug; that is, an amphetamine-like direct stimulation of the central nervous system accompanied by MAO inhibition in the brain (Brodie et al. , (1959).

In general, exploratory behavior in rats is used as the qualitative measurement in determining the effects of centrally acting drugs. 
Marriott and Spencer (1965) used a specially designed Y -shaped box to te st behavioral changes in rats following administration of phenelzine and other drugs. By this method, the count of the number of complete entries with all four feet of the animal into the arms of the .. box is taken as a measurement of exploratory activity. A period of 35 minutes is allowed to elapse following administration of drug before the animal is placed into one arm of the box and observed continually for five minutes. Under these test conditions, phenelzine was. shown to reduce exploratory activity in rats at intermediate dose levels of $5-10 \mathrm{mg} / \mathrm{kg}$, intraperitoneally. The author states: "It is possible that the antidepressant actions of these drugs are mediated through changes in the metabolism of centrally acting catecholamines and may therefore increase the susceptibility of rats to environmental stimuli."

Hall's open-field test (1934) is the one generally accepted as a valid measure of animal behavior, particularly exploratory activity. The "field" consists of a circular base which is divided by painted squares. During the allotted observation period, the total number of squares traversed and the number of central squares entered by the animals are counted. The " $t$ " test is then used to compare values generated by drug-injected animals with corresponding control values. Using this test, Brimblecombie (1962) was able to demonstrate that phenelzine decreased ambulatory activity. 
To study the effects of antidepressant drugs on learning, Latz et al., (1967) placed mice in a single-T water maze. Following administration of various drugs, including iproniazid and phenelzine, they demonstrated that phenelzine was capable of impairing response acquisition, whereas iproniazid was not.

A seemingly biphasic action of several MAO inhibitors on locomolor activily has recently been reported by Gylys and Muccia (1967). Initially, pheneizine-treated mice exhibited a decrease in spontaneous activity as measured by photocell equipped activity chambers. However, the initial depression was followed by a second phase characterized by hyperactivity. When compared to the action of d-amphetamine, it was noted that the secondary excitatory effects of the MAO inhibitors were dissimilar to the immediate excitatory response exhibited by this drug. This secondary action of the MAO inhibitors suggests the possibility of an indirect action of this class of drugs, unrelated to their MAO inhibitory properties. Concurrent with this idea, it was further noted that doses of the inhibitors capable of producing hyperactivity were higher than those doses required fox MAO inhibition alone.

The foregoing review of the literature makes it apparent that, although a substantial amount of information concerning hydrazide monoamine oxidase inhibitors has been published during the past decade, many facts concerning this class of drugs remain both 
elusive and obscure. At present, the trend of research in this field seems to be foward the clucidation of pharmacological effects elicited by these drugs but which a re now believed to be unrelated to their MAO inhibitory properties. 


\section{INVESTICATION}

A. Objectives

During the past decade, numerous hydrazide analogs have been synthesized and extensively tested to determine any possible inhibitory action on the monamine oxidase enzyme system. It is well established that numerous compounds possessing the hydrazide moeity are capable of irreversibly inhibiting MAO. As a consequence, several hydrazicle compounds have established themselves on the current market as psychotherapeutic drugs.

Specifically, the object of this investigation was to determine whether a newly synthesized class of compounds, imidazolecarboxhydrazides, were capable of inhibiting MAO in vivo, in vitro, or both. At attempt was made to correlate any in vivo inhibition of MAO activity with blood pressure changes in the event that hemodynamic alterations became evident.

While a direct correlation between MAO inhibition and blood pressure changes has not been established, many researchers believe that the hemodynamic alterations seen following the administration of hydrazide MAO inhibitors could conceivably have been produced by an action unrelated to inhibition of this enzyme system.

Preliminary observations have demonstrated the ability of at least one member of the dihydrazide compounds to alter locomotor activity. Therefore the present study has included quanlitative 
alterations of central nervous system activity.

\section{B. Materials and Methods}

\section{Blood Pressure Study}

a. Direct blood pressure measurement: Male, adult albino rats of the Sprague-Dawley $\operatorname{strain}^{1}$ weighing between 200-250 gms. were aresthetized with Urethan ${ }^{2}, 1.25 \mathrm{gms} / \mathrm{kg}$., administered intraperitoneaily. Blood pressure was obtained by direct cannulation of the left carotid artery; a saline-filled tube extending from the cannula ss rved to transmit pulse pressure variations to a standard mercury manometer. A glass rider, resting on the mercury meniscus transferred this information into a continuous recording on a smoked kymograph drum. Heparin ${ }^{3}$ was introduced into a soft rubber tube directly adjecent to the cannula in order to reduce clot formation. Tracheotomy was performed immediately following cannulation of the artery.

All drugs to be administered I. V. were dissolved in normal saline. Drig solutions we re prepared in sufficient concentrations so that no volume greater than $0.50 \mathrm{ml}$. was injected. All drugs were administered by slow infusion into the right femoral. vein. Blood pressure was recorded for a maximum period of two hours.

1. Charles River Breeding Farins, North Wilmington, Massachusetts.

2. Mexck \& Co., Inc, Rahway, Now Jersey.

3. Panheprin, Abbott Laboratorjes, North Chicago, Illinois. 
b. Indirect blood pressure measurement: Male, adult albino rats of the Sprague-Dawley strain were grouped into two and distributed in standard animal housing cages ${ }^{1}$. Room temperature, throughout the study, was maintained at $23^{\circ} \mathrm{C}$, as measured by a Tempscribe recording thermomete ${ }^{2}$. The room housing the animal cages was illuminated for a minimum of 10 hours daily.

Approximately $20 \mathrm{gms}$ of Purina ${ }^{3}$ rat food was offered to each animal daily at noon. Water was provided ad libitum by means of an inverted bottle with a tubular outlet.

All drugs were administered intraperitoneally during this study. The animals were weighed dally on a Ohaus animal balance ${ }^{4}$, and injected daily between 9:00 A. M. -10:00 A. M. for a period of 21 days. Hydrazide compounds to be tested were dissolved in glass-distilled wate $r$ in concentrations of $10 \mathrm{mg} / \mathrm{ml}$ and $20 \mathrm{mg} / \mathrm{ml}$. At the time of injection, animals received drugs according to the following regimen:

COMPOUND JN IVa (imidazole-4,5-dicarboxylic acid, di-2-methylhydrazide)
$5 \mathrm{mg} / \mathrm{kg}$, intraperitoneally daily $20 \mathrm{mg} / \mathrm{kg}$, intraperitoneally daily $40 \mathrm{mg} / \mathrm{kg}$, intraperitoneally daily

1. Wahmann Mfg. Co., Baltimore, Maryland.

2. Bacharach, Pittsburgh, Pennsylvania.

3. Ralston Purina, St. Louis, Missouri.

4. Ohaus Scale Corp., Union, New Jersey. 
COMPOUND JN II (imidazole-4, 5-dica rboxylic acid, di-2-dimethylhydrazide)

VEHICLE, glass distilled water
$5 \mathrm{mg} / \mathrm{kg}$, intraperitoneally daily $20 \mathrm{mg} / \mathrm{kg}$, intraperitoneally daily $40 \mathrm{mg} / \mathrm{kg}$, intraperitoneally daily

The effects of the dihydrazide compounds on systolic blood pressure were determined by indirect measurement. Prior to the actual reading, the animal cages were removed from their normal habitat ard puced. in an Environtrol constant temperature chamber maintained at $30^{\circ} \mathrm{C}$. The design of this chamber allows the maintenance of low humidity at relatively high temperatures. Following their introduction into the chamber, the animals were allowed one hour for acclimation prior to blood pressure determinations.

The tail cuff method for determination of systolic blood pressure was utilized. An inflatable, circular tail cuff ${ }^{1}$ attached to a pressure system, was slid up the length of the tail and placed approximately one inch from the base. A Beckman microphone transduce ${ }^{2}$ enclosed in a small clear plastic holder was slid onto the tail, adjacent to the rubber tail-cuff. The plastic holder of the transducer incorporated a screw clamp. By manipulating this clamp, pressure was applied to the $r$ at tail, forcing it into contact with the microphone transducer. The anatomical structure of the tall itself required considerable

1. Harvard Instruments, Cambridge, Massachusetts.

2. Beckman Co., Palo Alto, California. 
manipulation to ensure accurate readings. A lead from the phonotransducer was fed into a Beckman. Infraton ${ }^{1}$ signal divider; the output lead of this instrument was then attached to a HP oscilloscope 2 set at a $20 \mathrm{msec} / \mathrm{cm}$ sweep time.

Basically, pressure fluctuations picked up by the phonotransduce $x$ and $x u b s e q u e n t l y$ converted into electronic signals were observed as scarl lines on an oscilloscope. These lines, or "blips", seen as a series of peaks, could be obliterated by inflating the rubber tail-cuff which effectively stopped tail circulation. Careful manipulation of a screw valve decreased the pressure in the manometer system, allowing the return of circulation. As circulation was restored, the "blips" reappeared on the oscilloscope screen. The pressure reading, taken directly from the manometer at the precise moment the "blips" reappcared, was considered to be systolic blood pressure.

Before blood pressures were recorded, the animals were placed in a neating box maintained at $40^{\circ} \mathrm{C}$ for approximately 20 minutes. In this manner, peripheral blood vessels could be dilated somewhat, the reby facilitating the reading. Immediately following the heating period, each rat was placed into a plastic chamber ${ }^{3}$, designed such

1. Beckman Co., Palo Alto, California

2. Model 130B, Hewlett-Packar.cl Co., Palo Alto, California.

3. Designed and constructed by Mr. David Coates, Dept. of Pharmacology, University of Rhode Island. 
that a piston-like apparatus constituted one end, while the opposite end was removable. Thus, by moving the piston toward the removable partition, it was possible to vary the chamber length to correspond to the size of the animal. The movable partition was put into place and the piston length adjusted, leaving only the rat's tail extending from the chamber. Generally, a few minutes were required before the rat became sufficiently calm to allow readings to be taken.

Blood pressure recordings were taken as the average of three or more successive determinations. The time elapsed between two successive determinations varied depending upon the general behavior of the animal.

For the purpose of this preliminary study, 28 rats divided into seven groups of four each underwent the daily protocol previously described. Blood pressures were recorded three days prior to the administration of drug. Beginning on the second day of drug administration, blood pressure was recorded every third day throughout a 21 day period.

2. Monoamine oxidase studies

A preeminent characteristic of hydrazide MAO inhibitors is that the majority of the se compounds exhibit MAO inhibition either in vivo or in vitro but not in both. That is, a compound showing pronounced $\mathrm{MAO}$ inhibitory power in an in vivo system may in fact have 
little or no effect in an in vitro system. The refore, both in vivo and In vitro MAO studies were performed.

a. In vivo MAO study: 48 rats we re divided into eight equal groups as follows:
Group 1 : received Nardi1 ${ }^{1}$ (phanelzine dihydrogen sulfate) $40 \mathrm{mg} / \mathrm{kg}$ body weight, i. p. in glass-distilled water. sacrifice: 2 hours after injection.

Group II : received glass-distilled water, $1 \mathrm{ml} / \mathrm{kg}$ body weight, i.p.

1 sacrifice: 2 hours after injection.

Group III : received carboxymethylcellulose, $2 \%$ suspension, $1 \mathrm{ml} / \mathrm{kg}$ body weight, i. p. sacrifice: 40 minutes after injection.

Group IV : received compound JN IVa $(250 \mathrm{mg} / \mathrm{kg})$, in carboxy-methyl-cellulose vehicle, $250 \mathrm{mg} / \mathrm{kg}$ body weight, i. p. sacrifice: 40 minutes after injection.

Group V : recelved carboxymethylcellulose, $2 \%$ suspension in glass-distilled water, $1 \mathrm{ml} / \mathrm{kg}$ body weight, i. p. sacrifice: 2 hours after injection

Group VI : received compound JN IVa in carboxymethy1cellulose vehicle, $250 \mathrm{mg} / \mathrm{kg}$ body weight, i. p. sacrifice: 2 hours after injection.

Immediately following the time alloted to each group for drug activity, the animals were decapitated ${ }^{2}$. Both liver and brain tissue

1. Generously supplied by Warner-Chilcott Laboratories, Morris Plains, N. J.

2. Guillotine, Harvard Instruments, Cambridge, Massachusetts. 
were rapidly removed and homogenized. A Tri-R Homogenizer ${ }^{1}$ equipped with a Teflon pestle was used for this purpose. Since Horita (1965) had demonstrated the ability of red blood cells to antagonize the actions of known inhibitoxs of MAO, it was necessary to exsanguinate the liver prior to homogenizing this organ. This was accomplished in situ by canrulating the hepatic artery and perfusing the entire organ with cold $0.25 \mathrm{M}$ sucrose solution. The organ homogenates from each rat were placed in standard $12 \mathrm{ml}$ glass tubes and frozen at $-40^{\circ} \mathrm{C}$ until needed. At the time of assay, the tubes were placed in a cold water bath until the homogenates had thawed completely.

1. Assay of monoamine oxidase activity.

a) Methodology. A modification of the spectrophotometric MAO assay of Weissbach et al., (1960) was used for the determination of monoamine oxidase activity both in vivo and in vitro MAO studies. The basis for the assay is the enzymatic breakdown of kynuramine ${ }^{2}$, a synthetic amine.

In the presence of monoamine oxidase, kynuramine is

1. Tri-R Instruments, Jamaica, New York.

2. Kynuramine dihydrobromide, Regis Chemical Company, Chicago, Illinois. 
degraded in the following manner:<smiles>NCCCNCCN</smiles>

Kynuramine

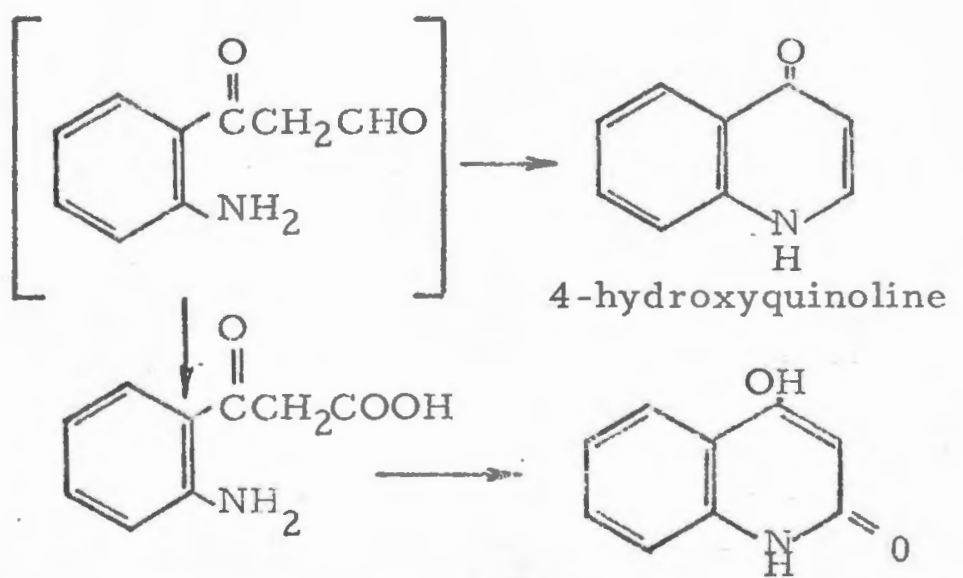

2, 1-dihydroxyquinoline

Absorbance of kynuramine is seen to increase sharply and maximally at $360 \mathrm{mu}$. This enzymatic degradation of kynuramine by MAO may readily be followed by spectrophotometric analysis, and is seen as a decrease in absorbance at $360 \mathrm{mu}$. Conversely, as kynuramine absorbance at $360 \mathrm{mu}$ decreases, the absorbance peak of the product develops at 310-335 mu. This new peak is thought to be the spectrum of 4-hydroxyquinoline, the postulated end product of MAO-degraded ky nuramine.

b) Procedure. The tubes of frozen homogenates were thawed and placed in an insulated containe $r$ filled with crushed ice. This procedure was adhered to largely as a precautionary measure, for it has been demonstrated that $\mathrm{MAO}$ is an extremely stable enzyme.

A Beckman DB Spectropholometer ${ }^{l}$ equipped with a $10^{\prime \prime}$ record 1. Beckman Instruments, Inc., Fullerton, California. 
ing accessory ${ }^{1}$ attachment was used to follow the enzyme reaction. A temperature of $30^{\circ} \mathrm{C}$ was maintained in the cuvette chamber of the spectrophotometer by use of a Haake ${ }^{2}$ constant temperature and circulating apparatus. Accordingly, all components of the reaction medium, exclusive of the enzyme, were kept in a water bath ${ }^{3}$ maintained at epproxirnately $30^{\circ} \mathrm{C}$.

At the time of assay, each component of the incubation mixture was pipetted into standard, two-sided silica cuvettes. The following scheme represents a typical reaction mixture:

\section{Component}

Phosphate buffer, $0.5 \mathrm{M}, \mathrm{pH} 7.4$ Kynuramine, 0.3 um Wate ${ }^{\circ}$, glass-distilled Homogenate (enzyme source)

Total volume
Reaction A Reaction B Blank Experimental

\begin{tabular}{|c|c|}
\hline $0.3 \mathrm{ml}$ & $0.3 \mathrm{ml}$ \\
\hline--- & $0.1 \mathrm{ml}$ \\
\hline $2.6 \mathrm{ml}$ & $2.5 \mathrm{ml}$ \\
\hline $0.1 \mathrm{ml}$ & $0.1 \mathrm{ml}$ \\
\hline $3.0 \mathrm{ml}$ & $3.0 \mathrm{ml}$ \\
\hline
\end{tabular}

Preliminary studies were performed to determine the volume of tissue homogenate required to produce a minimum change in absorbance of .100 units per hour. For purposes of the in vivo MAO study, the activity of $0.1 \mathrm{ml}$ of homogenate prepared from tissues of glass-

1. Beckman Instruments, Inc., Fullerton, California.

2. Haake, Gerruder, Berlin, Germany.

3. Arthur H. Thomas, Philadelphia, Pa. 
distilled water vehicle-injected rats was taken as standard activity. A graphical representation of the enzyme reaction taking place was produced directly by the recording instrument. The line obtained from this graph represented the change in absorbance per unit time (minutes). Data recorded for the initial 5-10 minutes was discarded due to recording interfcrence caused by particles settling in the reaction mediurr. This problem did not occur during the in vitro studies, when rnitochondrial suspensions were used as the enzyme source.

In accordance with the prescribed methodology, it was necessary to demonstrate a linear relationship between absorbance versus concentration of kynuramine. This was accomplished by preparing a series of solutions of varying concentrations of kynuramine and measuring absorbance of the se concentrations at $360 \mathrm{mu}$. A curve was then constructed by plotting optical density (absorbance) readings on the ordinate versus kynuramine concentration on the abcissa. In this study, the existence of a linear relationship between concentration and absorbance was substantiated.

b. In vitro MAO study: The original procedure of Weissbach et al., (1960) for the determination of MAO activity utilized tissue -homogenates as a source of this enzyme. However, various workers have shown that the greatest amount of MAO activity is localized in the mitochondria (Kopin, 1959; Davison, 1957; Hawkins, 1952). For 
this reason, rat liver mitochondrial suspensions were used as the enzyme source throughout the in vitro MAO studies.

1. Preparation of liver mitochondria: Five rats were killed separately by cervical dislocation. The hepatic artery was isolated and the entire liver was perfused with cold $0.25 \mathrm{M}$ sucrose solution. The liver was placed in a chilled $150 \mathrm{ml}$ beaker and washed until the decanted superuatant remained clear, then placed in $50 \mathrm{ml}$ glass tube.s. The liver was then homogenized using approximately a 1:4 mixture of tissue and sucrose solution. The homogenates were pooled, distributed in equal volumes to eight $50 \mathrm{ml}$ polypropylene tubes, and centrifuged ${ }^{1}$ at $3,000 \mathrm{rpm}$ for 10 minutes. The resulting supe rnatant was decanted, divided into eight additional tubes and centrifuged at 3,000 rpm for 10 minutes. The supernatant was carefully decanted, distributed to eight tubes and centrifuged a third time at 7,000 $\mathrm{rpm}$ for 10 minutes. The supernatant was discarded and the resultant pellet washed with $2.0 \mathrm{ml}$ of $.25 \mathrm{M}$ sucrose. A total of $20 \mathrm{ml}$ of sucrose was.used to transfer the pellets into two tubes which were then centrifuged at $11,500 . r p m$ for 10 minutes. The supernatant was discarded and the pellet resuspended in $48 \mathrm{ml}$ of $0.05 \mathrm{M}$ phosphate buffer, $\mathrm{pH}$ 7.4. The final suspension was redistributed into $2 \mathrm{ml}$ aliquots, placed in standard $12 \mathrm{ml}$ glass tubes and stored at $-40^{\circ} \mathrm{C}$.

1. Servall Refrigerated Centrifuge, Model RC-2, Sorvall, Inc., N.J. 
2. In vitro MAO Assay:

At the time of assay, one or more tubes containing mitochondrial suspension we re allowed to thaw $i_{1}$ a cold water bath. Certain modifications in preparing the reaction mixture were required. All components of the reaction mixture, excluding the substrate, kynuramine, were incubated with either known inhibitor or compound IVa for a specified period prior to the addition of substrate.

3. Protein content determination: The method of Gornall et al. , (1949) was used for the colorimetric determination of the protein present in an aliquot portion of mitochondrial suspension. This method proved to be particularly useful in determining protein content in crude tissue homogenates. At the time of assay, $1.0 \mathrm{ml}$ of mitochondrial suspension was pipetted into a standard $12 \mathrm{ml}$ glass tube, to which was added $4.0 \mathrm{ml}$ of biuret reagent. The contents were mixed $d^{1}$, allowed to stand for at least 20 minutes, and then placed in silica cuvettes. Readings were taken on the $\mathrm{DB}$ spectrophotometer ${ }^{2}$ at $540 \mathrm{mu}$ against a blank containing $1.0 \mathrm{ml}$ of water in place of the mitochondrial suspension.

Bovine serum albumin ${ }^{3}$ was used in the preparation of standard

1. Vortex Junior, Scientific Industries, Inc., Springfield, Mass.

2. Beckman Instruments, Inc., Fullerton, California.

3. Armour Pharmaceutical Co., Kankakee, Illinois. 
curves. This was accomplished by preparing several concentrations of standard protein as follows

Reagent

Serial Dilutions

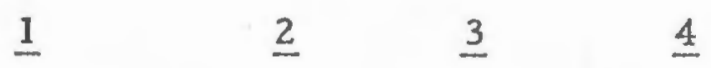

Bovine albumin $(10 \mathrm{mg} / \mathrm{ml}) \quad 0.1 \mathrm{ml} \quad 0.2 \mathrm{ml} \quad 0.3 \mathrm{ml} \quad 0.4 \mathrm{ml}$

Water, glass distilled $\quad 0.9 \mathrm{ml} \quad 0.8 \mathrm{ml} \quad 0.7 \mathrm{ml} \quad 0.6 \mathrm{ml}$

Biuret reagent $\quad 4.0 \mathrm{ml} \quad 4.0 \mathrm{ml} \quad 4.0 \mathrm{ml} \quad 4.0 \mathrm{ml}$

The readings obtained from this series were plotted on graph paper, and a standard curve was constructed from which the protein content of all other samples could be determined.

The method for determining protein content of homogenate samples prepared during the in vivo MAO assays followed the procedure described above.

Calculation of Turnover Rate. The change in absorbance over a 20 minute period was read directly from the plot obtained from the recorder during a typical reaction period. By simple extrapolation, the change in absorbance per hour was calculated. This value, divided by the slope of the kynuramine standard curve ${ }^{1}$, expressed the change in absorbance per micro-mole of kynuramine free base. This value, when subsequently divided by the protein concentration in a particular sample, represents a rate of substrate turnover expressed

1. See Assay of MAO activity; Procedure, page 28 
as $\mu$ mole kynuramine/hr/mg protein.

\section{Activity Studies}

To measure locomotor activity in mice, and drug-induced changes therein, a photoelectrically equipped chamber ${ }^{1}$ was enployed. This chamber, a circular cage, contained 12 symmetrically placed aperatures, each located approximately one-half inch above the grid-like flooring. Six of these openings were equipped to emit electric light beams, each of which crossed the diameter of the chamber, and focused on one of the six receiver aperatures, where the signal was picked up by photoelectric cell lying directly behind the receiver. Thus, six separate and complete photo-electric circuits existed in the chamber. An electric counting mechanism ${ }^{1}$ was attached to the Actophotometer unit. As long as the six photoelectric circuits remained intact, nothing was registered on the counter. However, if any circuit was broken by an interruption of the light beam, a signal was sent to the digital counting mechanism and was registered as a numerical change.

Procedure: Male, albino mice ${ }^{2}$ weighing 20-25 grams were used throughout the study. Each experimental group of five mice was housed in separate cages; water and food were provided

1. Actophotometer, Metro Scientific, Inc. Carle Place, L.I., N.Y.

2. Charles River Breeding Farms, North Wilmington, Mass. 
ad libitum, except when specified by the experimental design. All groups used on any particular day were fasted 24 hours prior to treatment.

Recording periods during both Series I and Series II extended through 11:00 A. M. - 1:00 P.M. In Series II, when the time interval froin trcatmenf to recording of locomotor activiiy was 2.5 hours, animals were injected from 10:00 A.M. to 10:30 A. M. in order that i actual recording periods would coincide with those of Series I. Following drug or vehicle treatment, animals from each treated group were returned to their respective cages. Both drugs (JNIVa and Phenelzine) and vehicle (carboxymethylcellulose) were administered intraperitoneally. Phenelzine and JNIVa we re suspended in a 2 per cent solution of carboxymethylcellulose and were kept frozen unti] needed.

In Series I, 1 hour was allowed to elapse for drug activity, if any, to take place. In Series II, 2.5 hours was allowed prior to recording. Immediately following this allotted period, the five animals of each group we re placed into the Actophotometer; the counter was started and recording of activity commenced. Total cumulative counts were recorded every 5 minutes throughout the 30 minute observation period. At the termination of each counting period, each experimental group was returned to its 
respective cage. Following its entry (use) in the Actophotometer, no group was scheduled for reuse for at least three days. 
IV. RESULTS

ALL TABLES AND FIGURES ARE CON'TAINED IN THIS SECTION. 
TABLE I

TERMINAL MONOAMINE OXIDASE ACTIVITY: IN VIVO DRUG ACTIVITY

A. RAT LIVER HOMOGENATE

\begin{tabular}{|c|c|c|c|c|c|}
\hline Group & $\begin{array}{c}\text { Drug } \\
\text { Administration } \\
\end{array}$ & Dose & $\begin{array}{c}\text { Elapsed time } \\
\text { before } \\
\text { sacrifice }\end{array}$ & $\begin{array}{l}\text { Protein } \\
\text { content of } \\
\text { homogenate } \\
(\mathrm{mg} / \mathrm{ml})\end{array}$ & $\begin{array}{c}\text { Terminal } \\
\text { MAO activity } \\
\text { umol kynuramine/ } \\
\mathrm{hr} / \mathrm{mg} \text { protein }\end{array}$ \\
\hline $1 a-I$ & Phenelzine & $40 \mathrm{mg} / \mathrm{kg}$, & 2 hours & 3.20 & 0 \\
\hline$I b-L$ & & i.p. & & 3.40 & 0 \\
\hline $2 a-L$ & & & & 3.75 & 0 \\
\hline $2 b-I$ & & & & 4.60 & 0 \\
\hline $3 a-L$ & & . & & 3.50 & 0 \\
\hline $3 b-L$ & & & & 2.75 & 0 \\
\hline $4 a-L$ & & & & 3.25 & 0 \\
\hline $4 b-L$ & & & & 2.55 & 0 \\
\hline $5 a-L$ & VEHICLE: & $1 \mathrm{ml} / \mathrm{kg}$, & 2 hours & 1.70 & 20.4 \\
\hline $5 b-L$ & water, glass & i.p. & & 3.50 & 9.3 \\
\hline $6 a-L$ & distilled & & & 1.55 & 21.0 \\
\hline $6 b-L$ & & . & & 2.95 & 13.2 \\
\hline $7 a-L$ & & & & 2.80 & 13.1 \\
\hline $7 b-L$ & & & & 3.25 & 9.7 \\
\hline $8 a-L$ & & & & 4.30 & 9.8 \\
\hline $8 b-L$ & & & & 3.90 & 10.7 \\
\hline $9 a-L$ & VEHICLE: & $1 \mathrm{ml} / \mathrm{kg}$, & $40 \mathrm{~min}$. & 3.20 & 10.5 \\
\hline $9 b-L$ & carboxy - & i.p. & & 2.95 & 10.7 \\
\hline $10 a-L$ & methylcellulose & & & 3.30 & 11.4 \\
\hline $10 b-L$ & $(2 \%)$ & & & 2.90 & 13.4 \\
\hline $11 a-L$ & & & & 2. 80 & 13.2 \\
\hline $11 b-L$ & & & & 3.90 & 11.7 \\
\hline
\end{tabular}


TABLE I (Continued)

TERMINAL MONOAMINE OXIDASE ACTIVITY: IN VIVO DRUG ACTIVITY

A. RAT LIVER HOMOGENATE

\begin{tabular}{|c|c|c|c|c|c|}
\hline Group & $\begin{array}{c}\text { Drug } \\
\text { Administration } \\
\end{array}$ & Dose & $\begin{array}{c}\text { Elapsed time } \\
\text { before } \\
\text { sacrifice }\end{array}$ & $\begin{array}{l}\text { Protein } \\
\text { content of } \\
\text { homogenate } \\
\text { (mg/ml) }\end{array}$ & $\begin{array}{c}\text { Terminal } \\
\text { MAO activity } \\
\text { umol kynuramine/ } \\
\text { hr/mg protein }\end{array}$ \\
\hline $\begin{array}{l}12 a-L \\
12 b-L \\
13 a-L \\
13 b-L \\
14 a-L \\
14 b-L \\
15 a-L\end{array}$ & JNIVa & $\begin{array}{l}250 \mathrm{mg} / \mathrm{kg} \text {, } \\
\text { i. p. }\end{array}$ & $40 \mathrm{~min}$ & $\begin{array}{l}2.95 \\
2.70 \\
2.20 \\
2.90 \\
2.50 \\
2.95 \\
2.60\end{array}$ & $\begin{array}{l}13.1 \\
12.9 \\
18.6 \\
15.1 \\
15.2 \\
12.8 \\
14.1\end{array}$ \\
\hline $\begin{array}{l}16 a-L \\
16 b-L \\
17 a-L \\
17 b-L \\
18 a-L \\
18 b-L \\
19 a-L \\
19 b-L\end{array}$ & $\begin{array}{l}\text { VEHICLE: } \\
\text { carboxy- } \\
\text { methylcellulose }\end{array}$ & $\begin{array}{l}\text { I } \mathrm{ml} / \mathrm{kg} \text {, } \\
\text { i. } \mathrm{p} \text {. }\end{array}$ & 2 hours & $\begin{array}{l}4.10 \\
2.60 \\
2.40 \\
3.40 \\
3.50 \\
3.70 \\
3.90 \\
3.40\end{array}$ & $\begin{array}{l}09.6 \\
12.6 \\
13.4 \\
11.7 \\
11.6 \\
10.4 \\
10.4 \\
12.0\end{array}$ \\
\hline $\begin{array}{l}20 a-L \\
20 b-L \\
21 a-L \\
21 b-L \\
22 a-L \\
23 a-L \\
23 b-L\end{array}$ & JNIVa & $\begin{array}{l}250 \mathrm{mg} / \mathrm{kg} \text {, } \\
\text { i. p. }\end{array}$ & 2 hours & $\begin{array}{l}2.70 \\
2.20 \\
3.40 \\
2.40 \\
3.25 \\
4.40 \\
2.90\end{array}$ & $\begin{array}{r}12.9 \\
13.8 \\
10.7 \\
15.8 \\
11.9 \\
8.5 \\
13.7\end{array}$ \\
\hline
\end{tabular}


TABLE II

SUMMARY OF TABLES I AND II

MONOAMINE OXIDASE ACTIVITY: IN VIVO DRUG ACTIVITY

A. RAT LIVER HOMOGENATE

\begin{tabular}{|c|c|c|c|c|c|c|}
\hline & Group I & Group'II & Group III & Group IV & Group V & Group VI \\
\hline $\begin{array}{l}\text { Dirug } \\
\text { treatment }\end{array}$ & phenelzine & $\begin{array}{l}\text { vehicle: } \\
\text { water }\end{array}$ & $\begin{array}{l}\text { vehicle: } \\
\text { CMC }\end{array}$ & JNIVa & $\begin{array}{l}\text { vehicle; } \\
\text { CMC }\end{array}$ & JNIVa \\
\hline Time & $2 \mathrm{hrs}^{\mathrm{e}}$ & $2 \mathrm{hrs}$ & $40 \mathrm{~min}^{f}$ & $40 \mathrm{~min}$. & 2 hrs. & $2 \mathrm{hrs}$. \\
\hline$N^{b}$ & 8 & 8 & 6 & 6 & 8 & 7 \\
\hline $\mathrm{X} \pm \mathrm{S} \cdot \mathrm{D} \cdot \mathrm{c}^{\mathrm{c}}$ & $0.34^{+}-4.72$ & $13.4 \pm 4.7$ & $11.8 \pm 1.2$ & $14.6 \pm 2.2$ & $11.4 \pm 1.2$ & $12.4 \div 2.3$ \\
\hline
\end{tabular}

STATISTICAL COMPARISON OF GROUPS ${ }^{\mathrm{d}}$

\section{Comparison}

Group I, phenelzine vs. Group II, Vehicle; water Group II, Vehicle; water vs. Group III, Vehicle; CMC Group III, Vehicle; CMC vs Group IV, JNIVa, T-40

Group IV, JNIVa, T-40 vs. Group VI, JNIVa, T-120

Group V, Vehicle; CMC ys. Group VI, JNIVa, T-120

a. CMC; carboxymethylcellulose, $2 \%$.

b. $N=$ Number of rats.

c. mean $\pm S$. D. of MAO activity expressed in umol kynuramine/hr/mg/protein. N.S. = no significant difference, $\mathrm{P} 0.05$. Sign. = significant difference, $\mathrm{F} 0.05$.

\section{$\underline{\text { Result }}$}

Sign.

N.S.

Sign

N.S.

N.S.

d. Comparisons made by use of Student's "t" test.

e. 120 minutes duration $0 \hat{i}$ action.

f. 40 minutes duration of action 
TABLE III

TERMINAL MONOAMINE OXIDASE ACTIVITY: IN VIVO DRUG ACTIVITY

A. RAT BRAIN HOMOGENATE

\begin{tabular}{|c|c|c|c|c|c|}
\hline Group & $\begin{array}{c}\text { Drug } \\
\text { Administration } \\
\end{array}$ & Dose & $\begin{array}{c}\text { Elapsed time } \\
\text { before } \\
\text { sacrifice } \\
\end{array}$ & $\begin{array}{l}\text { Protein } \\
\text { content of } \\
\text { homogenate } \\
(\mathrm{mg} / \mathrm{ml})\end{array}$ & $\begin{array}{c}\text { Terminal } \\
\text { MAO activity } \\
\text { umol kynuramine/ } \\
\text { hr/mg protein }\end{array}$ \\
\hline $\begin{array}{l}1 a-B \\
1 b-B \\
2 a-B \\
2 b-B \\
3 a-B \\
3 b-B \\
4 a-B \\
4 b-B\end{array}$ & $\begin{array}{c}\text { Phenelzine } \\
\vdots \\
\vdots\end{array}$ & $\begin{array}{l}40 \mathrm{mg} / \mathrm{kg} \text {, } \\
\text { i. p. }\end{array}$ & 2 hours & $\begin{array}{l}2.75 \\
2.85 \\
2.90 \\
3.10 \\
3.00 \\
3.00 \\
2.95 \\
3.25\end{array}$ & $\begin{array}{l}0 \\
0 \\
0 \\
0 \\
0 \\
0 \\
0 \\
0\end{array}$ \\
\hline $\begin{array}{l}5 a-B \\
5 b-B \\
6 a-B \\
6 b-B \\
7 a-B \\
7 b-B \\
8 a-B \\
8 b-B\end{array}$ & $\begin{array}{l}\text { VEHICL: } \\
\text { water, glass } \\
\text { distilled }\end{array}$ & $\begin{array}{l}1 \mathrm{ml} / \mathrm{kg} \text {, } \\
\text { i. } \mathrm{p} \text {. }\end{array}$ & 2 hours & $\begin{array}{l}3.30 \\
2.90 \\
2.90 \\
2.60 \\
2.90 \\
2.50 \\
2.70 \\
2.50\end{array}$ & $\begin{array}{l}2.6 \\
3.0 \\
2.8 \\
2.2 \\
3.3 \\
3.2 \\
2.7 \\
3.3\end{array}$ \\
\hline $\begin{array}{r}9 a-B \\
9 b-B \\
10 a-B \\
10 b-B \\
11 a-B \\
11 b-B\end{array}$ & $\begin{array}{l}\text { VEHICLE: } \\
\text { carboxy - } \\
\text { methylcellulose } \\
(2 \%)\end{array}$ & $\begin{array}{l}1 \mathrm{ml} / \mathrm{kg} \text {, } \\
\text { i. p. }\end{array}$ & $40 \mathrm{~min}$ & $\begin{array}{l}2.95 \\
2.95 \\
2.65 \\
3.00 \\
2.95 \\
2.90\end{array}$ & $\begin{array}{l}3.1 \\
3.0 \\
3.4 \\
3.0 \\
2.8 \\
3.1\end{array}$ \\
\hline
\end{tabular}


TABLE III (Continued)

TERMINAL MONAMINंE OXIDASE ACTIVITY: IN VIVO DRUG ACTIVITY

A. RAT BRAIN FOMOGENATE

\begin{tabular}{|c|c|c|c|c|c|}
\hline Group & Administration & Doge & $\begin{array}{l}\text { Elapsed time } \\
\text { before } \\
\text { sacrifice }\end{array}$ & $\begin{array}{l}\text { Protein } \\
\text { content of } \\
\text { homogenato } \\
(\mathrm{mg} / \mathrm{ml})\end{array}$ & $\begin{array}{c}\text { Terminal } \\
\text { MAO activity } \\
\text { umol kynuramine / } \\
\text { hr/mg protein }\end{array}$ \\
\hline $12 a-B$ & JNIVa & $250 \mathrm{mg} / \mathrm{kg}$ & $40 \mathrm{~min}$ & 3.00 & 3.6 \\
\hline $12 b-B$ & & i. p. & & 2.90 & 4.0 \\
\hline $13 a-B$ & & & & 3.00 & 3.1 \\
\hline $13 b-B$ & & & & 2.70 & 3.7 \\
\hline $14 a-B$ & & & & 2.60 & 3.2 \\
\hline $14 b-B$ & & & & 2.60 & 2. 9 \\
\hline $15 a-B$ & & 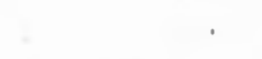 & & 2.30 & 3.2 \\
\hline $16 a-8$ & VEHICLE: & $1 \mathrm{ml} / \mathrm{kg}$ & 2 hours & 3.60 & 2.2 \\
\hline $16 b-B$ & carboxy - & i.p. & & 2.70 & 2.3 \\
\hline $17 a-B$ & methylcellulose & & & 3.25 & 3.5 \\
\hline $17 b-B$ & $(2 \%)$ & & & 3.10 & 3.7 \\
\hline $18 a-B$ & & & & 3.25 & 3.4 \\
\hline $18 b-B$ & & & & 3.25 & 2.5 \\
\hline $19 a-B$ & & & & 3.20 & 3.2 \\
\hline $19 b-B$ & & & & 2.50 & 4.6 \\
\hline $20 a-B$ & JNIVa & $250 \mathrm{mg} / \mathrm{kg}$, & 2 hours & 3.10 & 2.6 \\
\hline $20 b-B$ & . & i.p. & & 2.65 & 3.5 \\
\hline $21 a-B$ & & & & 3.00 & 2.5 \\
\hline $21 b-B$ & & & & 3.00 & 2. 9 \\
\hline $22 a-B$ & & & & 2.90 & 4.4 \\
\hline $22 b-B$ & & & & 2.50 & 3.5 \\
\hline $23 a-B$ & & & & 2.70 & 3.2 \\
\hline $23 b-B$ & & . & & 2.35 & 3.5 \\
\hline
\end{tabular}


TABLE IV

SUMMARY OF TABLE III

MONOAMINE OXIDASE ACTIVITY: IN VIVO DRUG ACTIVITY

A. RAT BRAIN HOMOGENATE

\begin{tabular}{|c|c|c|c|c|c|c|}
\hline & Group I & Group II & Group III & Group IV & Group V & Group VI \\
\hline \multicolumn{7}{|l|}{ Drug } \\
\hline treatment & phenelzine & $\begin{array}{l}\text { vehicle: } \\
\text { water }\end{array}$ & $\begin{array}{l}\text { vehicle: } \\
\mathrm{CMC}^{\mathrm{a}}\end{array}$ & JNIVa & $\begin{array}{l}\text { vehicle: } \\
\text { CMC }\end{array}$ & JNIVa \\
\hline Time & $2 \mathrm{hrs}^{\mathrm{e}}$ & 2 hrs. & 40 min. ${ }^{f}$ & $40 \mathrm{~min}$. & $2 \mathrm{hrs}$ & 2 hrs. \\
\hline$N^{b}$ & 8 & 8 & 6 & 7 & 8 & 8 \\
\hline$x \pm$ S.D. ${ }^{c}$ & G & $2.93 \pm .38$ & $3.10 \pm .20$ & $3.42 \pm .36$ & $3.2 \pm .81$ & 3. $31 \pm .58$ \\
\hline
\end{tabular}

\section{STATISTICAL COMPARISON OF GROUPS ${ }^{d}$}

\section{Comparison}

Group I, phenelzine vs: Group II, Vehicle; water.

Group II, Vehicle; water vs. Group III, Vehicle, CMC.

Group III, Vehicle, CMC vs. Group IV, JNIVa, T-40

Group IV, JNIVa, T-40 vs. Group VI, JNIVa, T-120

Group V, Vehicle; CMC vs. Group VI, JNIVa, T-120

a. carboxy-methylcellulose.

b. $N=$ number of animals per group.

c. Mean \pm Standard Deviation of MAO activity expressed in umol kynuramine/ $\mathrm{hr} / \mathrm{mg}$ protein. $\underline{\text { Result }}$

Sign.

N.S.

N.S.

N.S.

N.S.

d. Student's " $t$ " test, Snedecor, 1956.

e. 120 minutes duration of action.

f. 40 minutes duration of action. 
FIG. 1

THE EFFECTS OF JNIVA AND PHENELZINE ON TERMINAL MONOAMINE OXIDASE ACTIVITY. IN VIVO DRUG ACTIVITY.

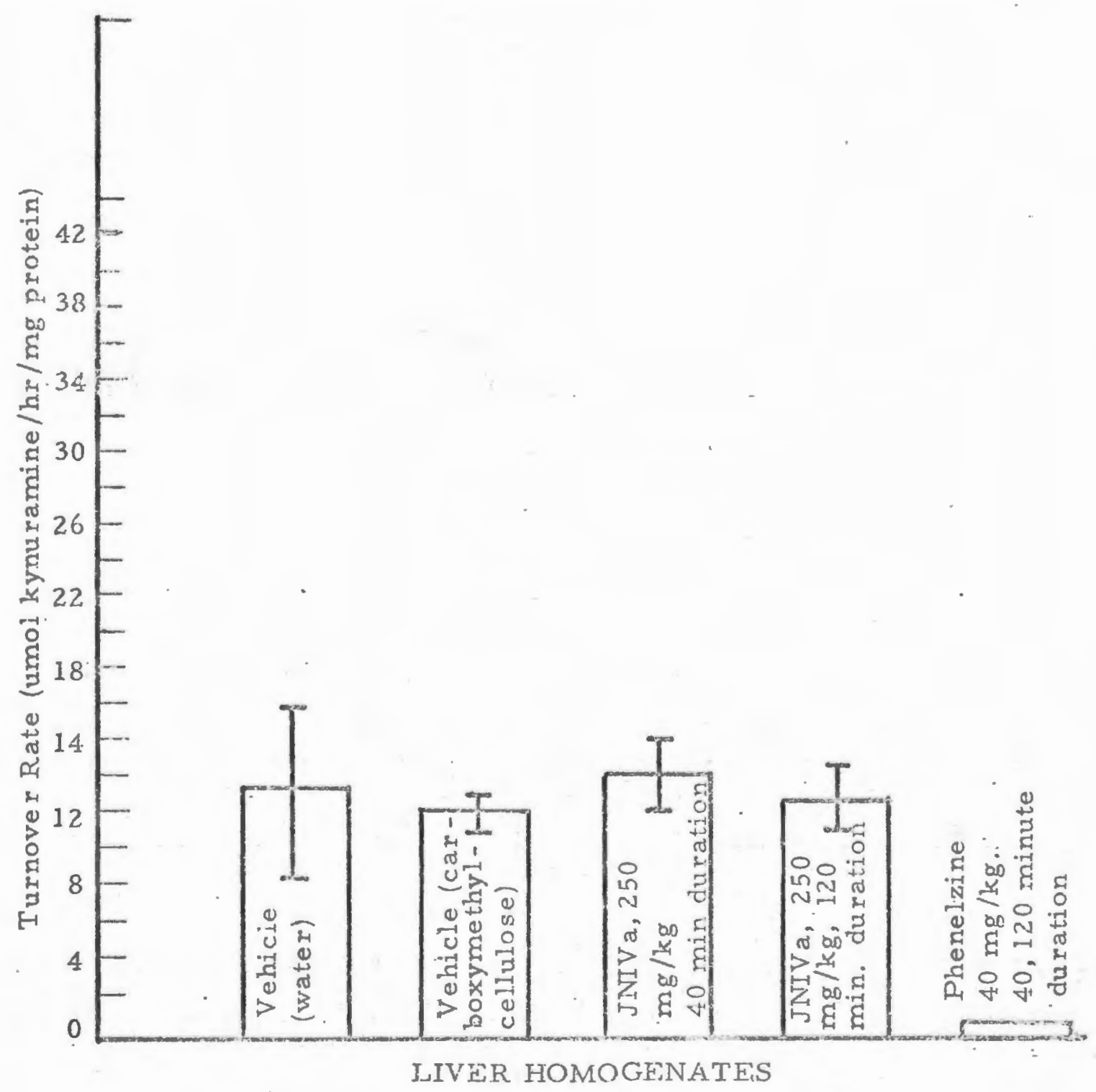

Each bar represents the mean $\pm S . D$. turnover rate of monoamine oxidase obtained from liver homogenates of rats pretreated with vehicle, JNIVa, or phenelzine.

Drug Treatment: Vehicle, CMC(carboxymethylcellulose) $1 \mathrm{ml} / \mathrm{kg}$, i.p.; Water, glass-distilled, $1 \mathrm{ml} / \mathrm{kg}$, i.p.; JNIVa, $250 \mathrm{mg} / \mathrm{kg}$, i p.; Phenelzine, $40 \mathrm{mg} / \mathrm{kg}$, i.p.

Time interval prior to sacrifice: 40 minutes and 120 minutes. 
FIG. 2 IN VIVO DRUG ACTIVITY. THE EFFECT OF JNIVA AND PHENELZINE ON TERMINAL MONOAMINE OXIDASE ACTIVITY.

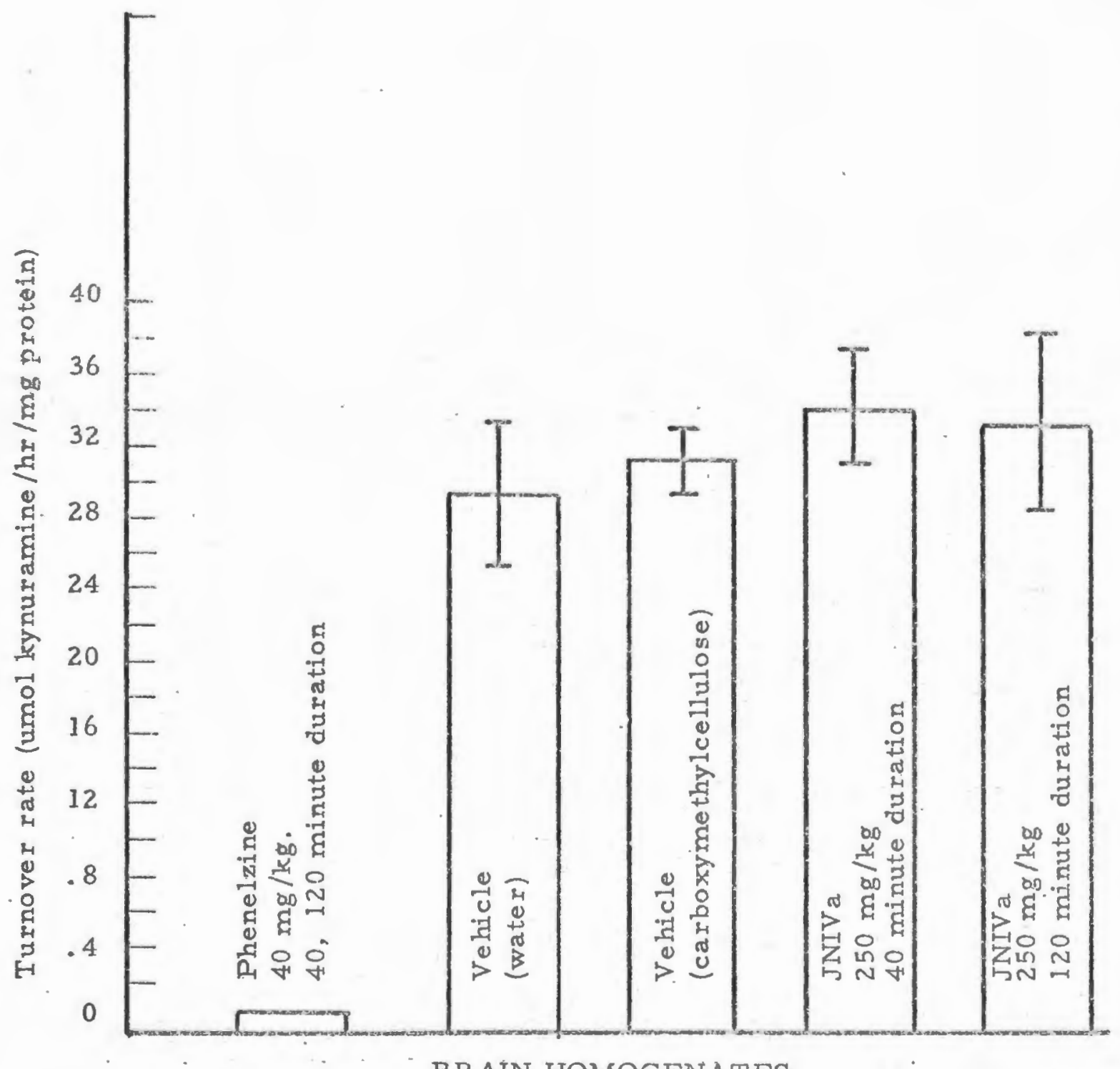

Each bar represents the mean $\pm S . D$. turnover rate of monoamine oxidase obtained from brain homogenates of rats pretreated with vehicle, JNIVa, or phenelzine.

Drug treatment: Vehicle, CMC(carboxymethylcellulose)

$1 \mathrm{ml} / \mathrm{kg}$, i. p.;

Wate r, glass-distilled, $1 \mathrm{ml} / \mathrm{kg}$, i.p. ; JNIVa, $250 \mathrm{mg} / \mathrm{kg} /$, i. p. ;

Phenelzine, $40 \mathrm{mg} / \mathrm{kg}$, i.p.

Time interval prior to sacrifice: 40 minutes and 120 minutes 


\section{TABLE V}

THE STABILITY OF

MITOCHONDRIAL MONOAMINE OXIDASE

OVER A FORTY-FIVE MINUTE PERIOD

POOLED RAT IIVER MITOCHONDRIA

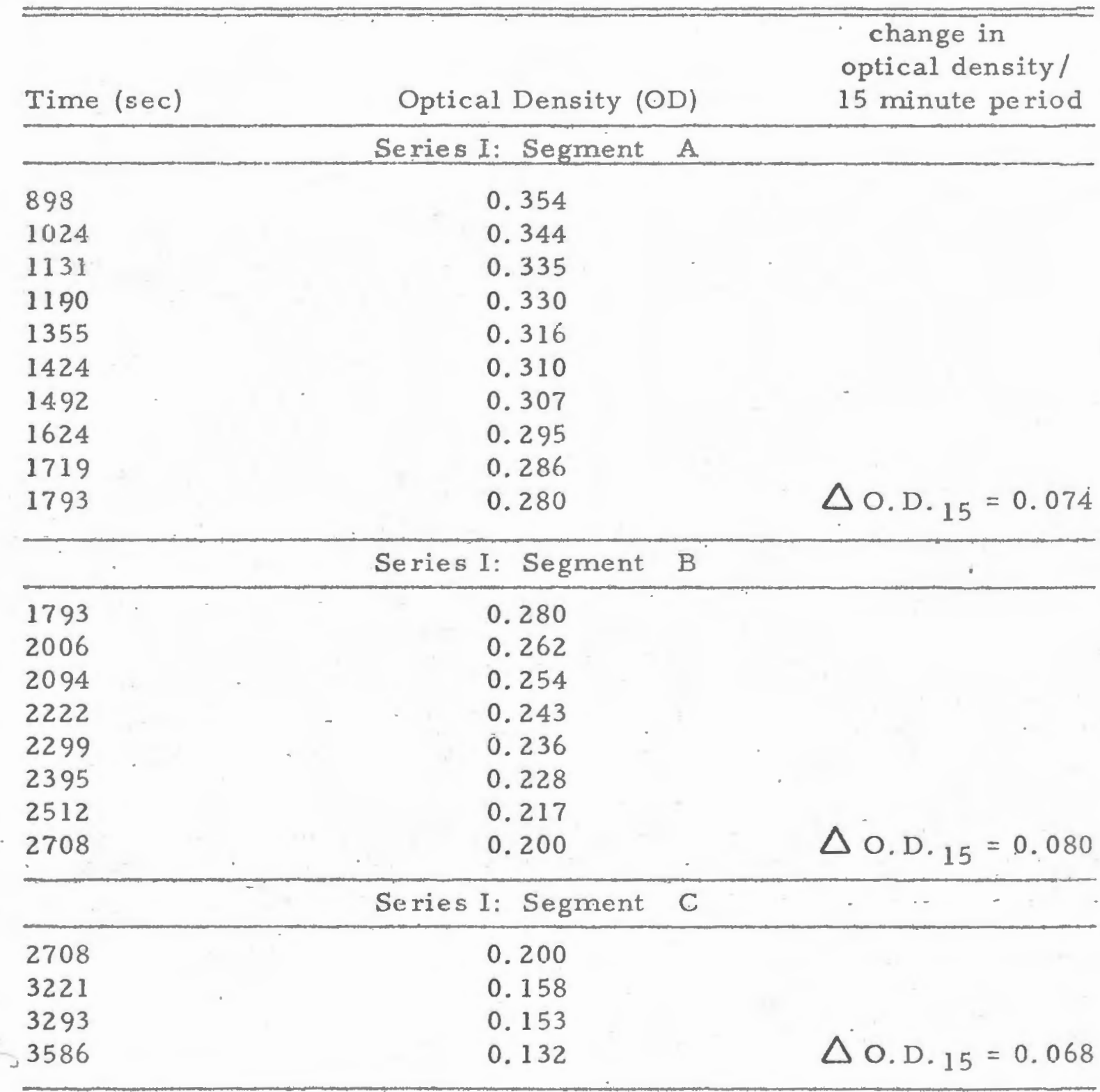


TABLE VI

THE STABILITY OF

MITOCHONDRIA

OVER A FORTY-FIVE MINUTE PERIOD

POOLED RAT LIVER MITOCHONDRIA

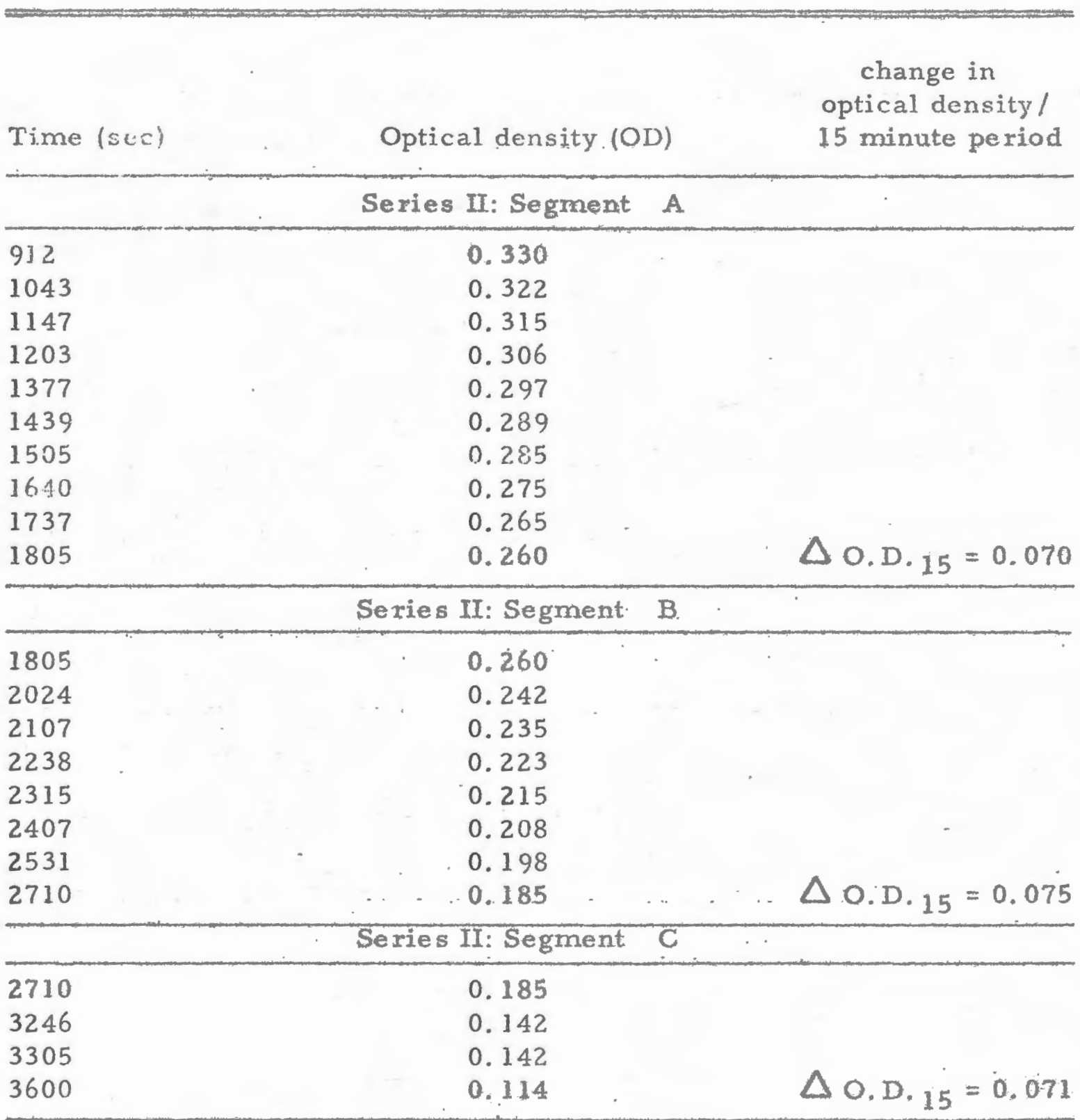


TABLE VII

THE STABILITY OF

MITOCHONDRIAL MONOAMINE OXIDASE

OVER A FORTY-FIVE MINUTE PERIOD

POOLED RAT LIVER MITOCHONDRIA

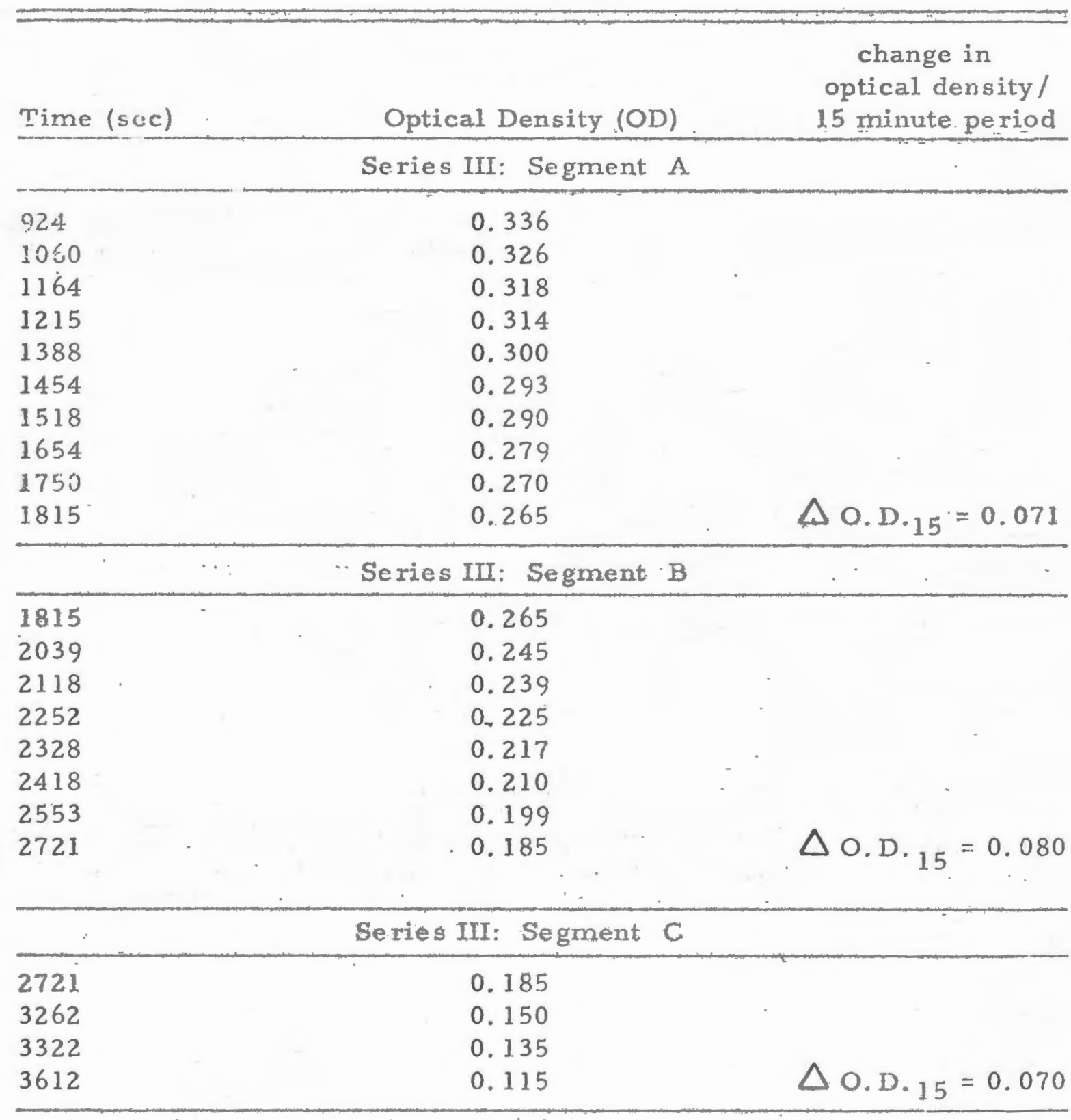


TABLE VIII

SUMMARY OF TABLES V, VI, AND VII

MITOCHONDRIAL MONOAMINE OXIDASE

OVER A FORTY-FIVE MINUTE PERIOD

POOLED RAT LIVER MITOCHONDRIA

\begin{tabular}{|c|c|c|}
\hline Sample & $\triangle$ O.D. $15^{\mathrm{a}}$ & \multirow[t]{2}{*}{$\mathrm{X} \pm$ S.D. ${ }^{\mathrm{b}}\left(\Delta O \mathrm{D}_{15}\right)$} \\
\hline & Series: I & \\
\hline Segmen: A & 0.074 & $0.074 \pm 0.006$ \\
\hline Segment B & 0.080 & \\
\hline \multirow[t]{2}{*}{ Segment $\quad$} & 0.068 & \\
\hline & Series: II & \\
\hline Segment A & 0.070 & \\
\hline Segment B & 0.075 & \\
\hline \multirow[t]{2}{*}{ Segment C } & 0.071 & $0.072 \pm 0.003$ \\
\hline & Series: III & \\
\hline Gegment A & 0.071 & \\
\hline Segment B & 0.080 & \\
\hline Segment C & 0.070 & $0.073 \pm 0.005$ \\
\hline
\end{tabular}

a. Change in optical density (absorbance) per 15 minute period.

b. Represents mean \pm S.D. of $\triangle$ O.D. 15 values obtained in each series.

c. 15 minute portion of overall reaction.

STATISTICAI, COMPARISON OF SERIES

Series Comparison

Series I vs. Series II

Series I vs. Series III

Series II vs. Series III
Result

N.S. ${ }^{\text {d }}$

N.S.

N.S.

d. N.S.; no significant diffe rence, 0.05. Comparisons made using Student's "t" test (Snedecor, 1956). 
TABLE IX

THE EFFECTS OF JNIVA AND FHENELZINE DLHYDROGEN SULFATE

ON MONOAMINE OXIDASE ACTIVITY. DOSE RESPONSE OF INHIBITORS AND DETERMINATION OF $I_{50}{ }^{2}$

\begin{tabular}{|c|c|c|c|}
\hline Drug & Concentration & $\%$ irthibition & $I_{50}$ value \\
\hline Phenelzine & $\begin{array}{l}3.14 \times 10^{-7} \underline{M} \\
6.28 \times 10^{-7} \mathrm{M} \\
7.85 \times 10^{-7} \mathrm{M} \\
9.40 \times 10^{-7} \mathrm{M} \\
1.36 \times 10^{-6} \mathrm{M} \\
1.57 \times 10^{-6} \mathrm{M}\end{array}$ & $\begin{array}{l}21.6 \pm \\
40.5 \\
44.6 \\
55.3 \\
71.3 \\
85.0\end{array}$ & $8.3 \times 10^{-7} \mathrm{M}$ \\
\hline JNIVa & $\begin{array}{l}1.55 \times 10^{-6} \mathrm{M} \\
3.10 \times 10^{-6} \mathrm{M} \\
4.71 \times 10^{-6} \mathrm{M} \\
6.27 \times 10^{-6} \mathrm{M} \\
7.75 \times 10^{-6} \mathrm{M} \\
9.42 \times 10^{-6} \mathrm{M}\end{array}$ & $\begin{array}{l}16.6 \\
23.8 \\
51.1 \\
59.0 \\
62.8 \\
81.7\end{array}$ & $5.4 \times 10^{-6} \mathrm{M}$ \\
\hline
\end{tabular}

a. The approximate concentration of drug at which 50 per cent inhibition of monoamine oxidase was observed. 
FIG, 3 THE EFFECTS OF JNIV a ON MONOAMINE OXIDASE ACTIVITY

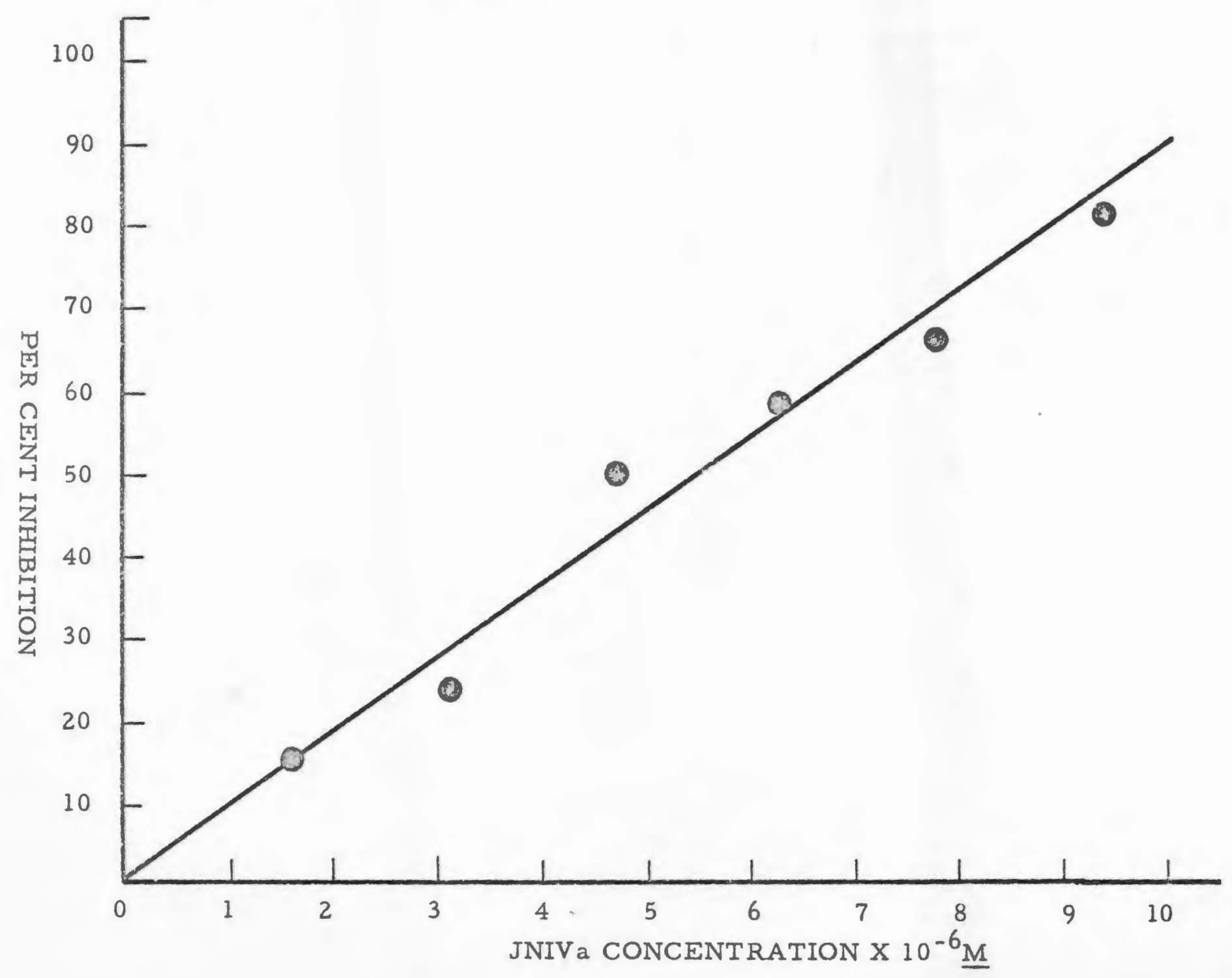


FIG. 4 THE EFFECTS OF PHENELIINE DIHYDROGEN SULFATE ON MONOAMINE OXIDASE
ACTIVITY

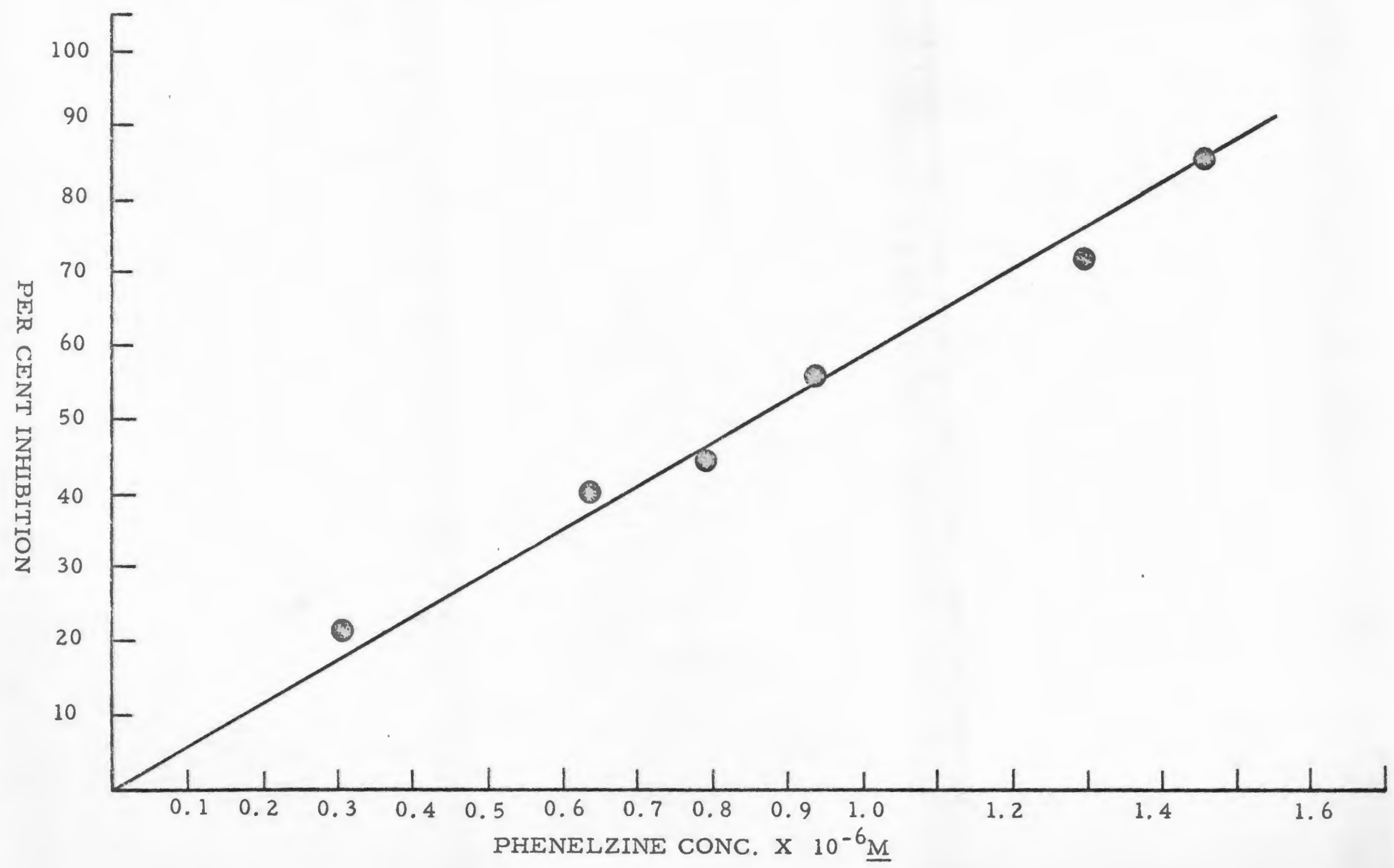


FIG. 5 THE EFEECT OF INCREASED PREINCUBATION TIME ON THE INHIBITION OF MONOAMINE

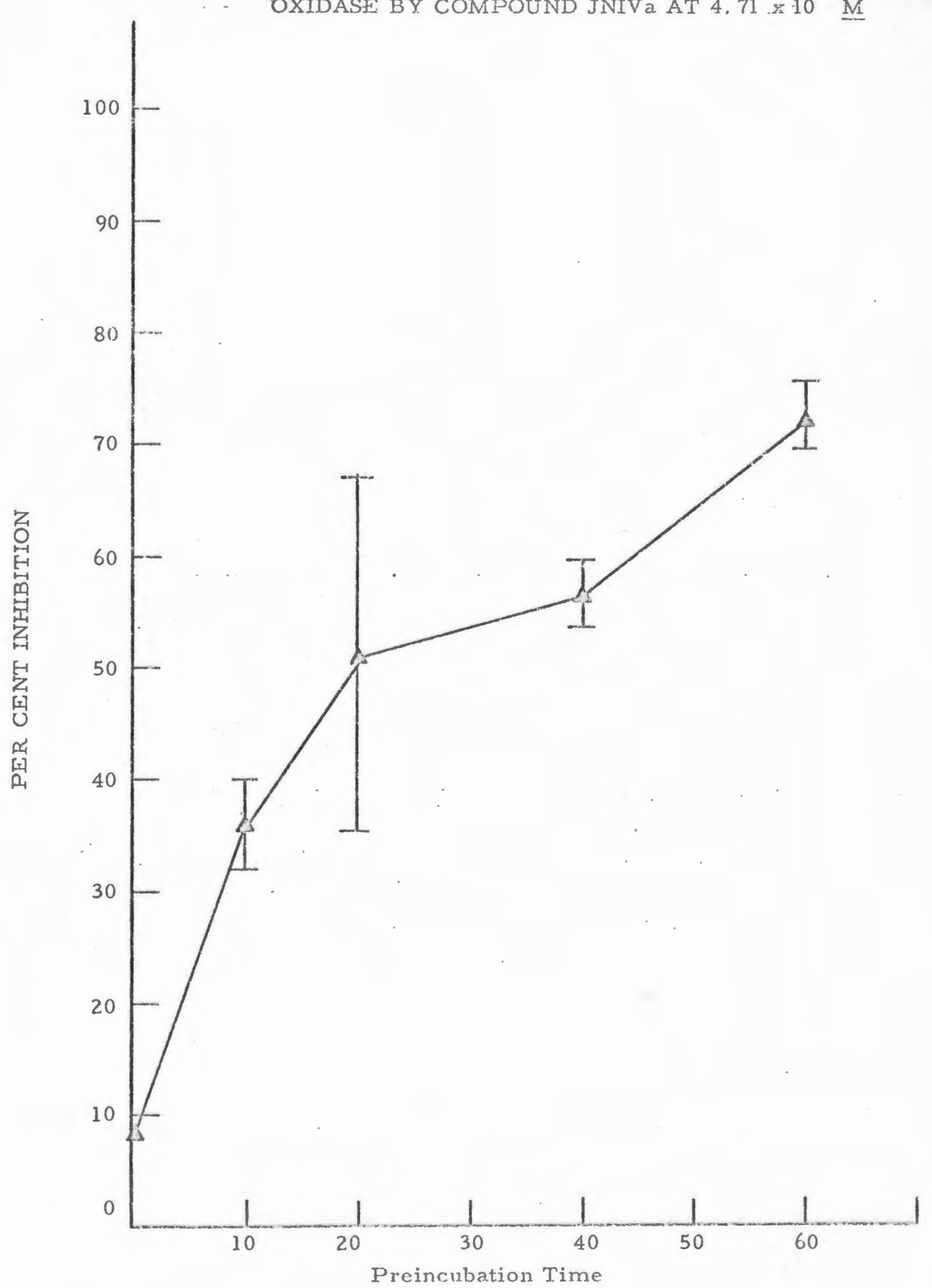


FIG. 6 ACTOPHOTOMETRIC RECORDING OF GROSS LOCOMOTOR ACTIVITY

MEAN CUMULATIVE

COUNTS

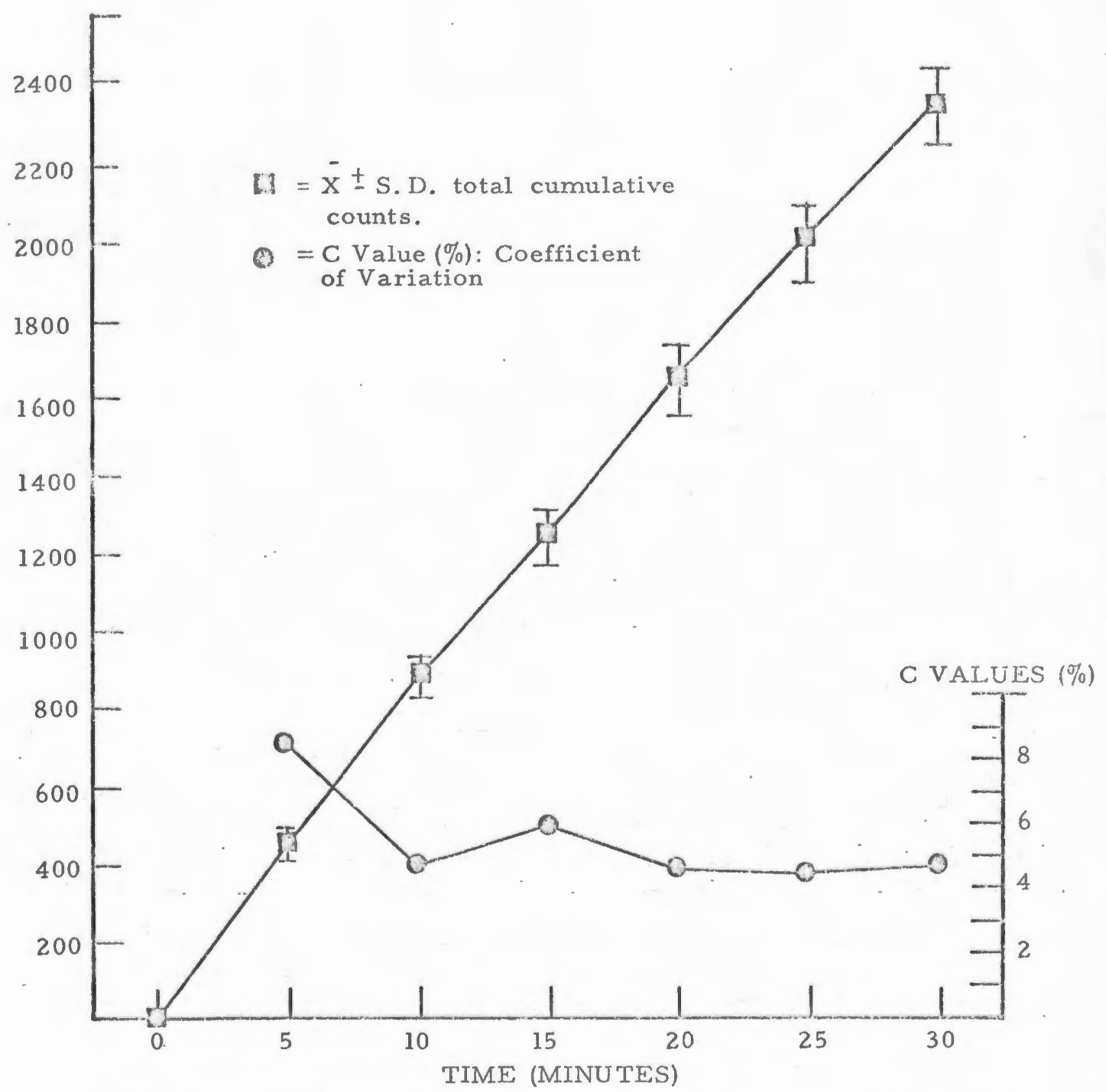

Graph represents mean cumulative counts per five minute increment generated by six groups of five vehicle-treated male albino mice over a period of thi rty minutes.

Drug treatment: Vehicle(carboxymethylcellulose), $1 \mathrm{ml} / \mathrm{kg}, \mathrm{i} . \mathrm{p}$.; 1 hour duration of action. 
FIG. 7 ACTOPHOTOMETRIC RECORDING OF GROSS LOCOMOTOR ACTIVITY

MEAN CUMULATIVE

COUNTS

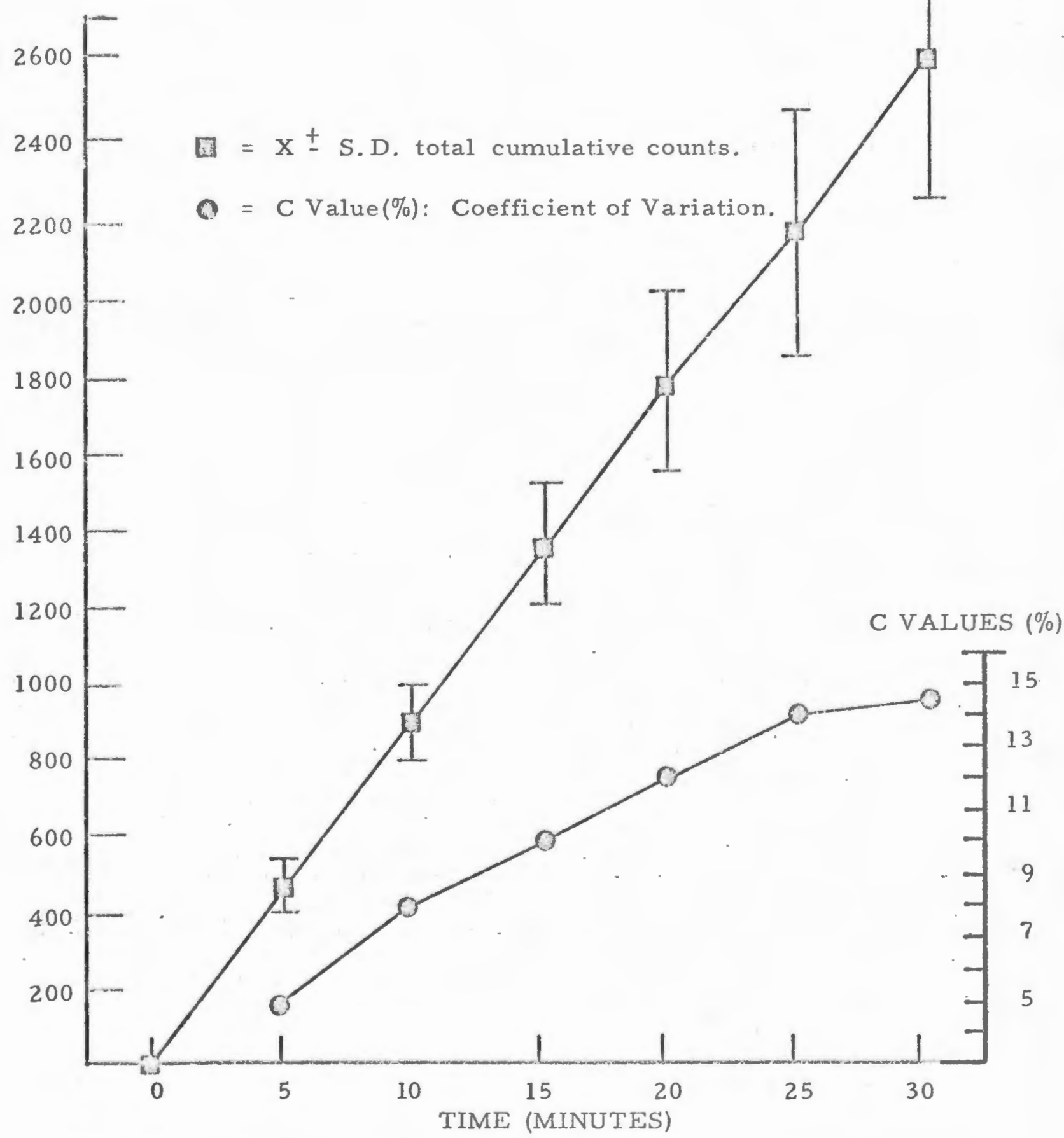

Graph represents mean cumulative counts per five minute increment generated by six groups of five phenelzine treated male albino mice measured over a period of thirty minutes.

Drug treatment: Phenelzine, $40 \mathrm{mg} / \mathrm{kg}$, i.p.; l hr. duration of action. 
FIG. 8 ACTOPHOTOMETRIC RECORDING OF GROSS LOCOMOTOR ACTIVITY

$$
\begin{aligned}
& {[=\dot{\bar{X}}-\text { S.D. total cumulative counts. }} \\
& \mathbf{O}=\mathrm{C} \text { Value }(\%) \text { : Coefficient of Variation. }
\end{aligned}
$$

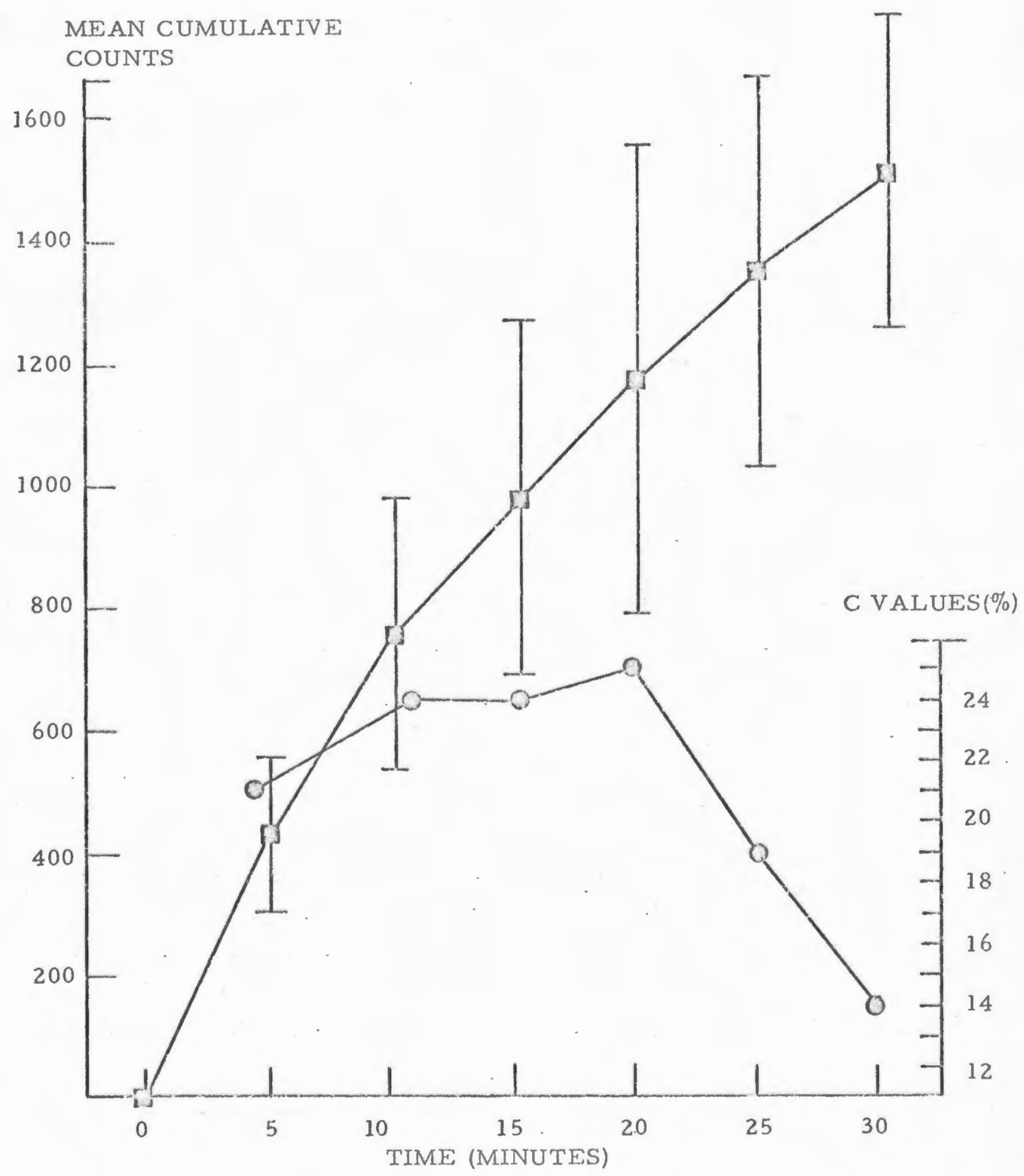

Graph represcnts mean cumulative counts per five minute increment generated by six groups of five JNIVa treated male albino mice measured over a period of thirty minutes.

Drug treatment: JNIVa, $150 \mathrm{mg} / \mathrm{kg}$, i.p. ; l hour duration of action. 
FIG. 9 ACTOPHOTOMETRIC RECORDING OF GROSS LOCOMOTOR ACTIVITY

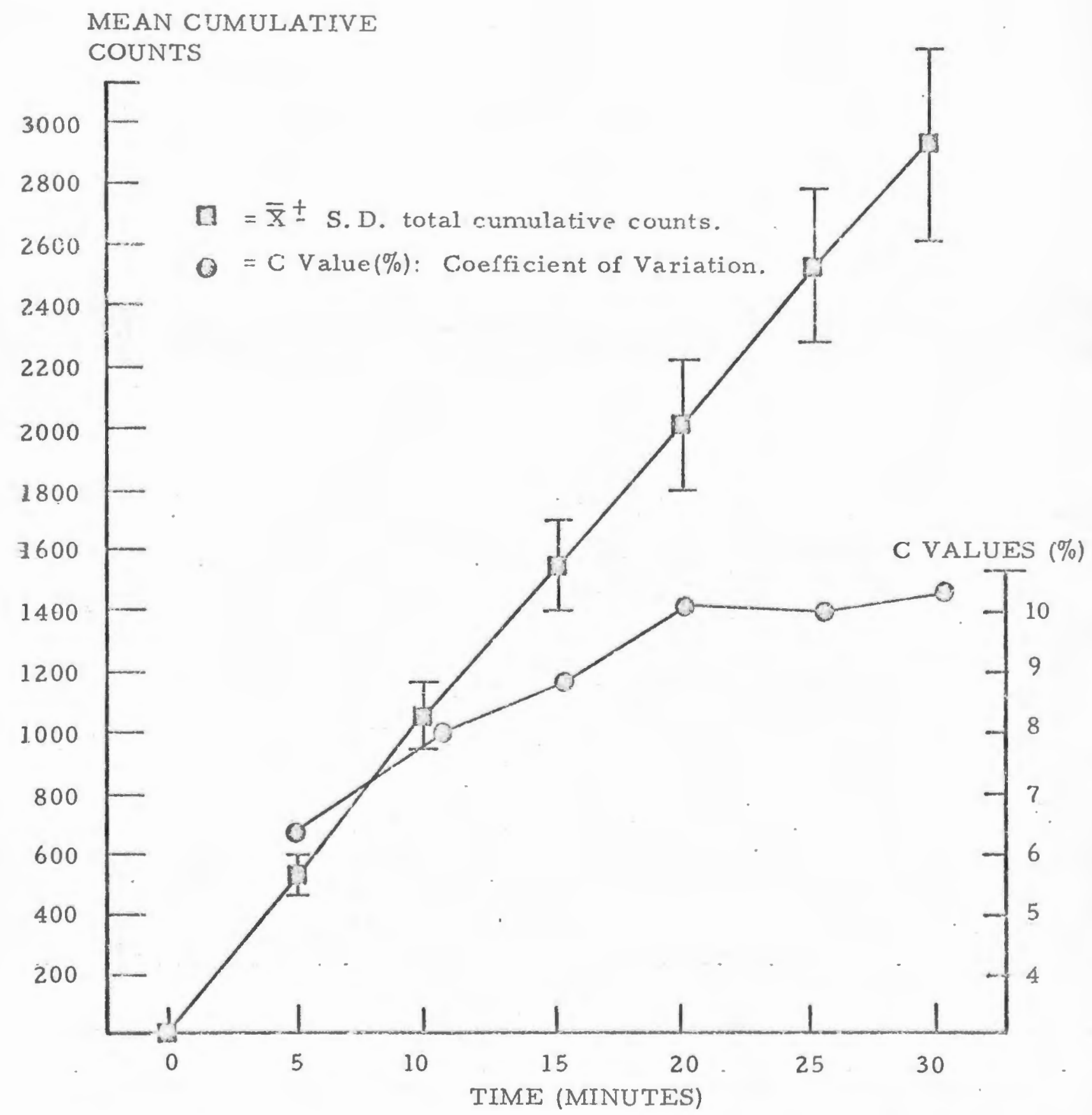

Graph represents mean cumulative counts per five minute increment generated by six groups of five phenelzine treated male albino mice measured over a period of thirty minutes.

Drug treatment: Phenelzine, $40 \mathrm{mg} / \mathrm{kg}$, i.p. $; 2.5$ hours duration of action. 
FIG. 10 ACTOPHOTOMETRIC RECORDING OF GROSS LOCOMOTOR ACTIVITY

MEAN CUMULATIVE COUNTS

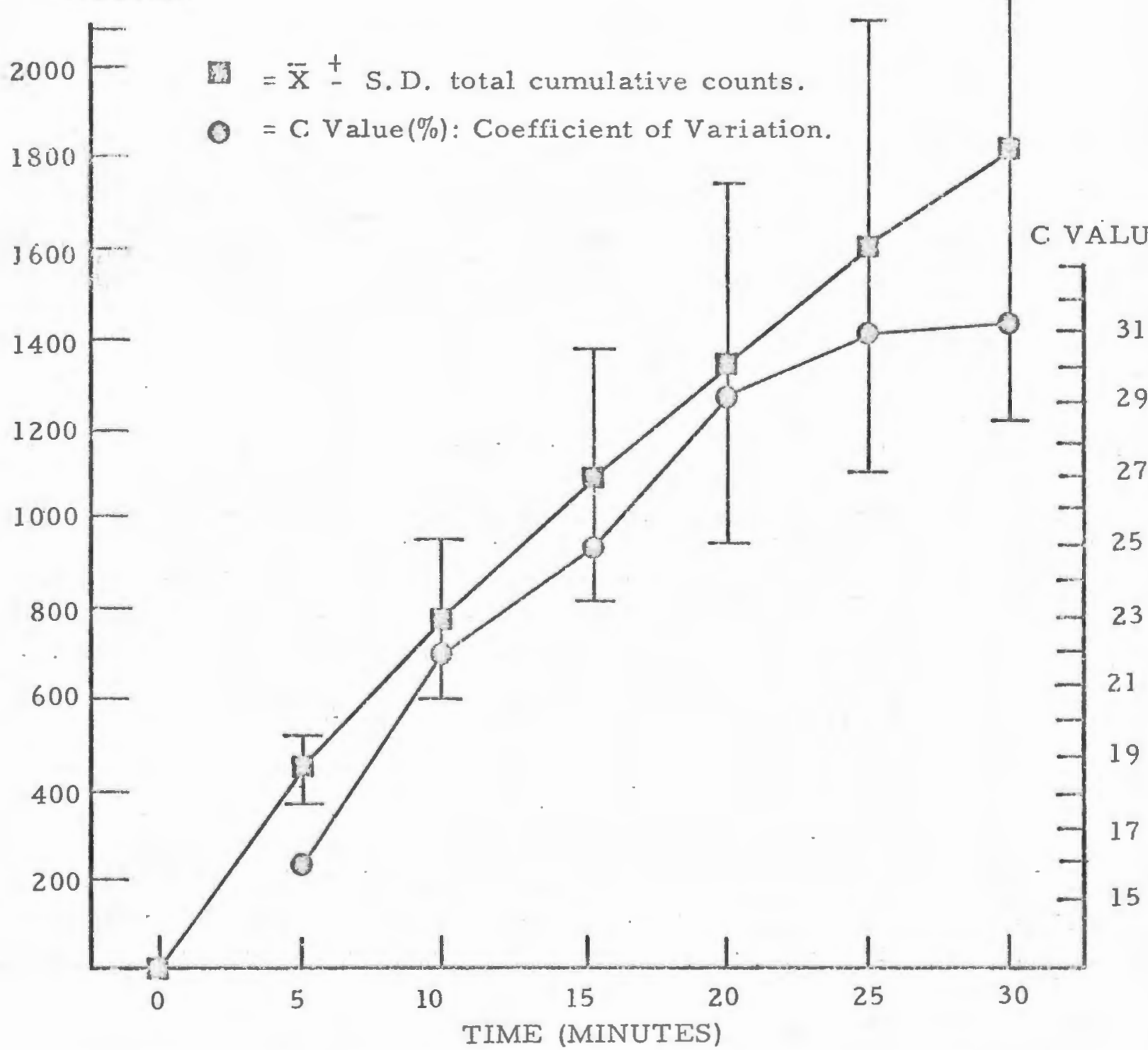

Graph represents mean $\pm S . D$. cumulative counts per five minute increment generated by six groups of five JNIVa treated male albino mice measured over a period of thirty minutes.

Drug treatment: JNIVa, $150 \mathrm{mg} / \mathrm{kg}$, i.p. ; 2.5 hours duration of action. 
FIG. 11 ACTOPHOTOMETRIC RECORDING OF GROSS LOCOMOTOR ACTIVITY

MEAN CUMULATIVE

COUNTS

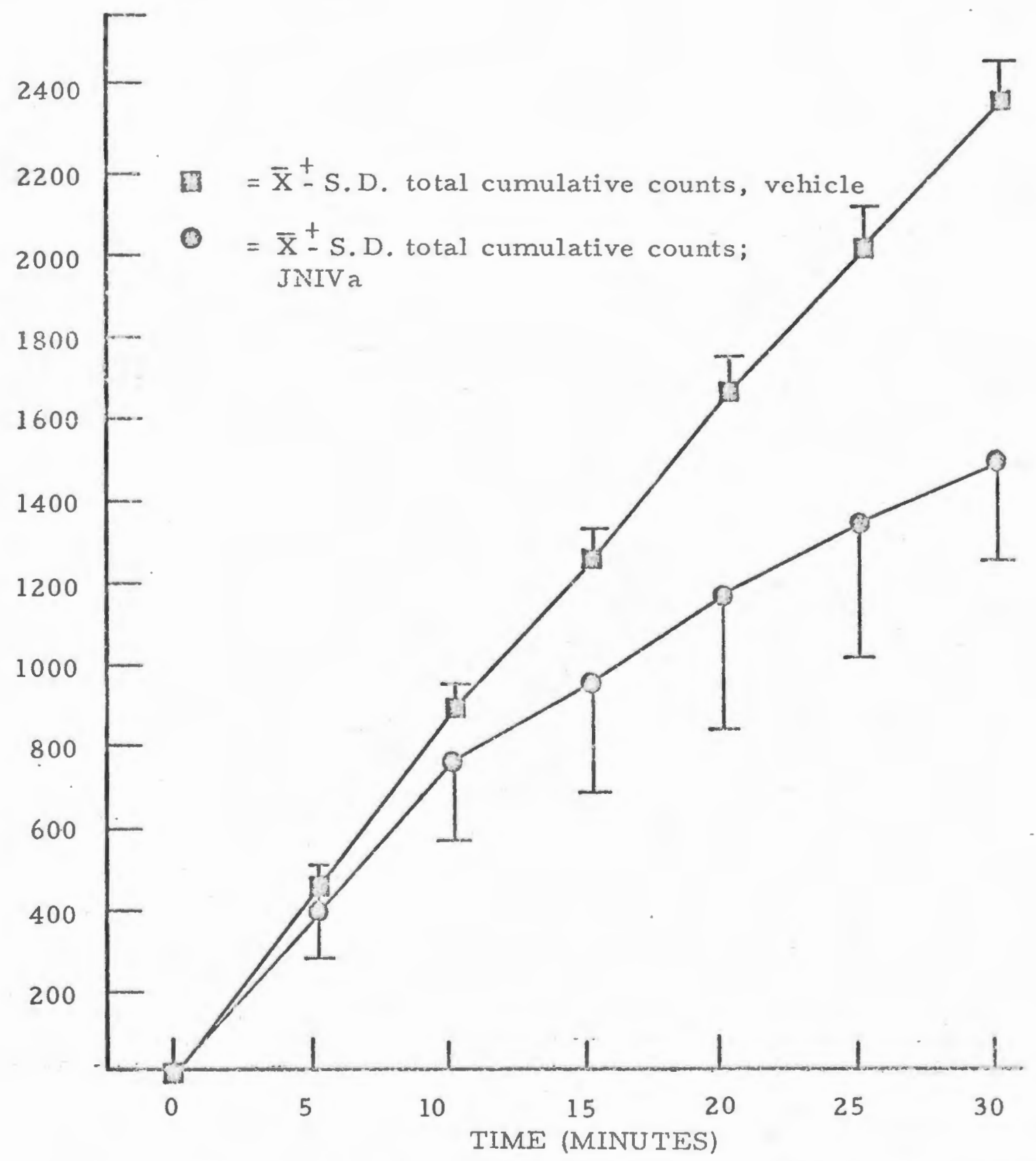

Graph-represents mean cumulative counts generated by six groups of five vehicle treated male albino mice versus six groups of five JNIVa treated mice.

Drug treatment: Vehicle(cárboxymethylcellulose) $1 \mathrm{ml} / \mathrm{kg}$, i.p., JNIVa, $150 \mathrm{mg} / \mathrm{kg}$, i. p.

Time interval prior to recording: 1 hour. 
FIG. 12 ACTOPHOTOMETRIC RECORDING OF GROSS LOCOMOTOR ACTIVITY

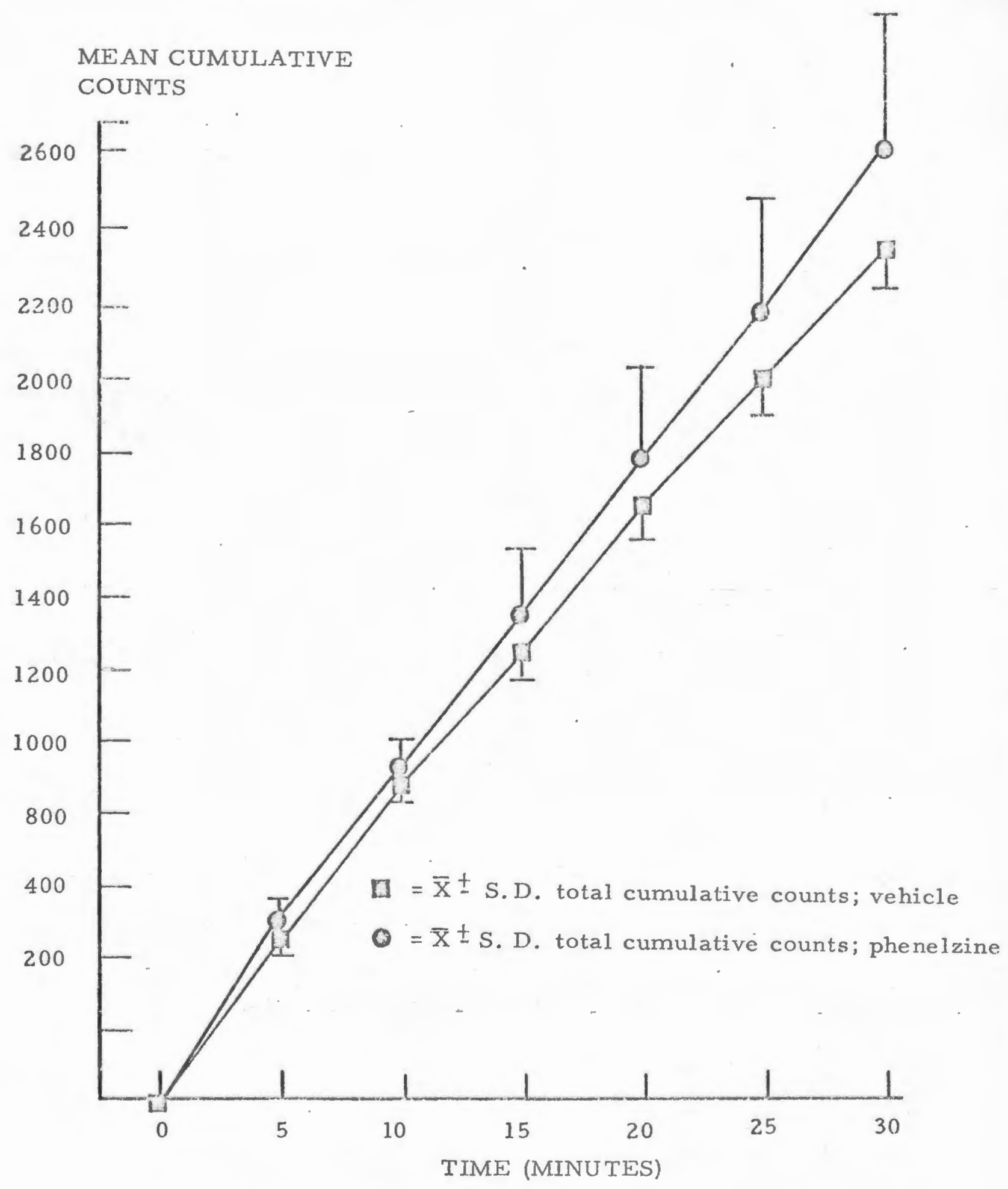

Graph represents mean cumulative counts generated by six groups of five vehicle treated male albino mice versus six groups of five phenelzine treated mice.

Drug treatment: Vehicle(carboxymethylcellulose) $1 \mathrm{ml} / \mathrm{kg}$, i. p. ; Phenelzine, $40 \mathrm{mg} / \mathrm{kg}$, i. p.

Time interval prior to recording: 1 hour 
FIG. 13 ACTOPHOTOMETRIC RECORDING OF GROSS LOCOMOTOR ACTIVITY

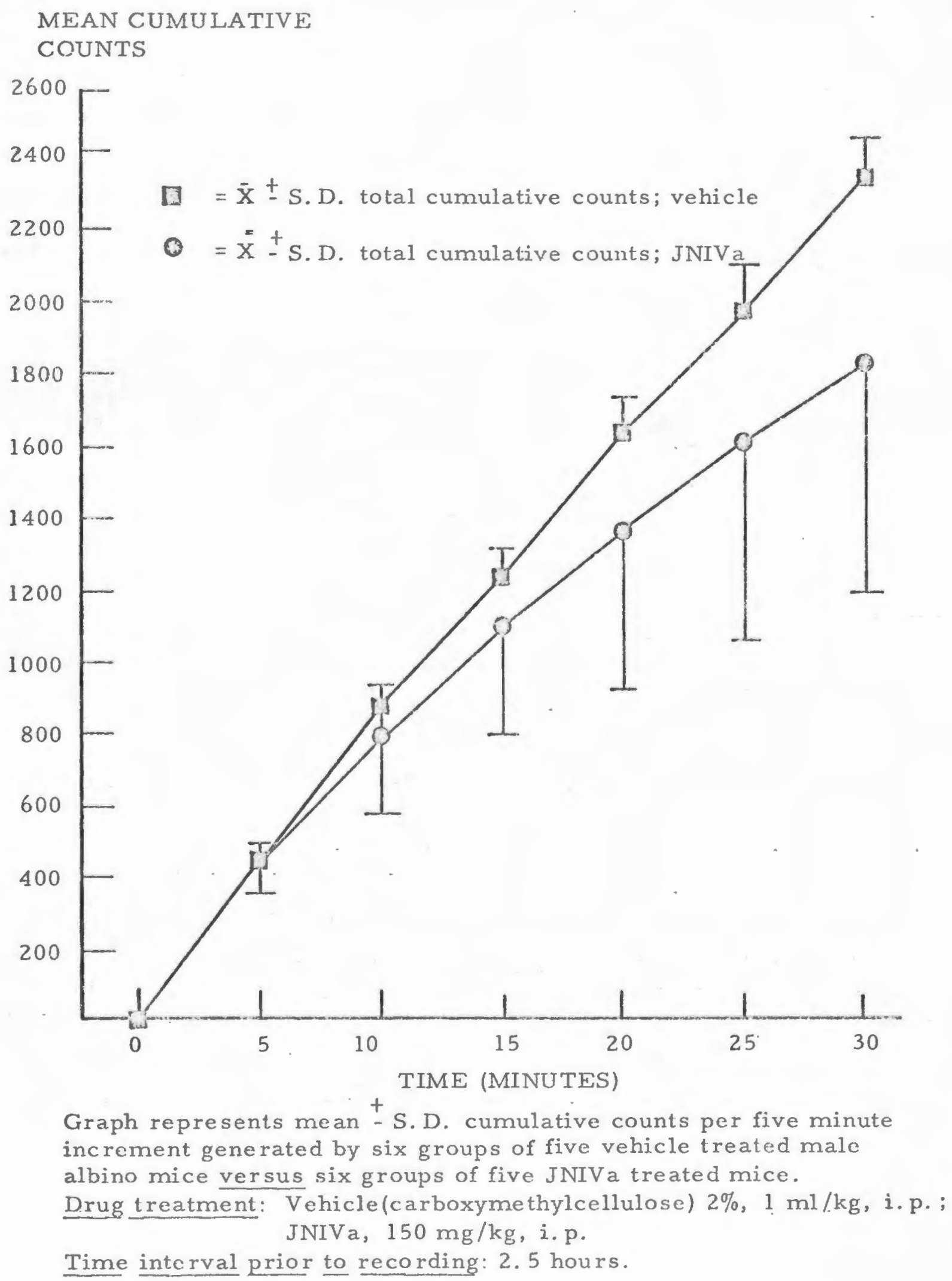


FIG. 14 ACTOPHOTOMETRIC RECORDING OF GROSS LOCOMOTOR ACTIVITY.

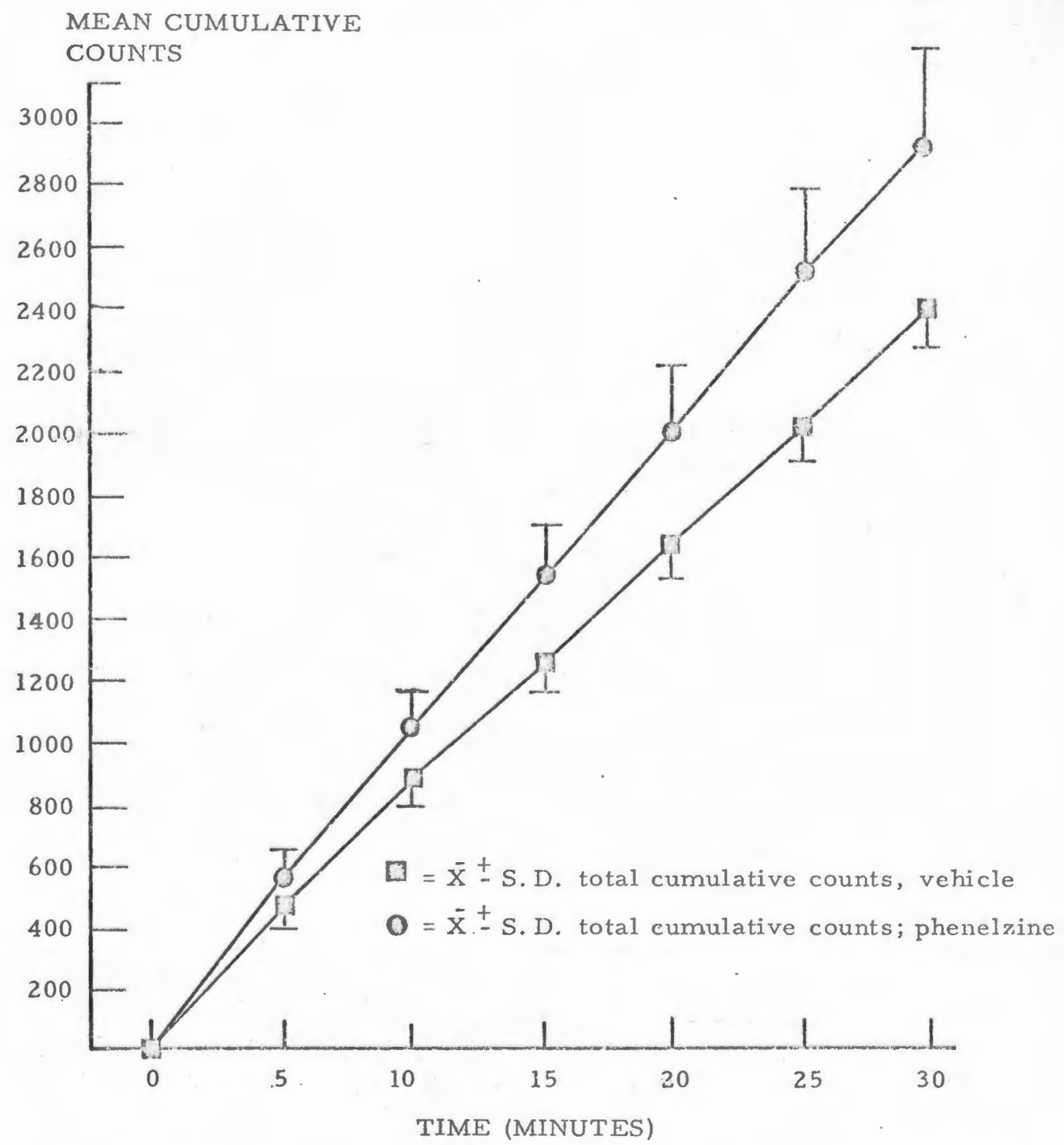

Graph represents mean cumulative counts per five minute increment generated by six groups of five vehicle treated male albino mice versus six groups of five phenelzine treated mice.

Drug treatment: Vehicle(carboxymethylcellulose; $2 \%, 1 \mathrm{ml} / \mathrm{kg}, \mathrm{i} . \mathrm{p}$. ; Phenelzine, $40 \mathrm{mg} / \mathrm{kg}$, i.p.

Time interval prior to recording: 2.5 hours. 
FIG. 15 ACTOPHOTOMETRIC RECORDING OF GROSS IOCOMOTOR ACTIVITY

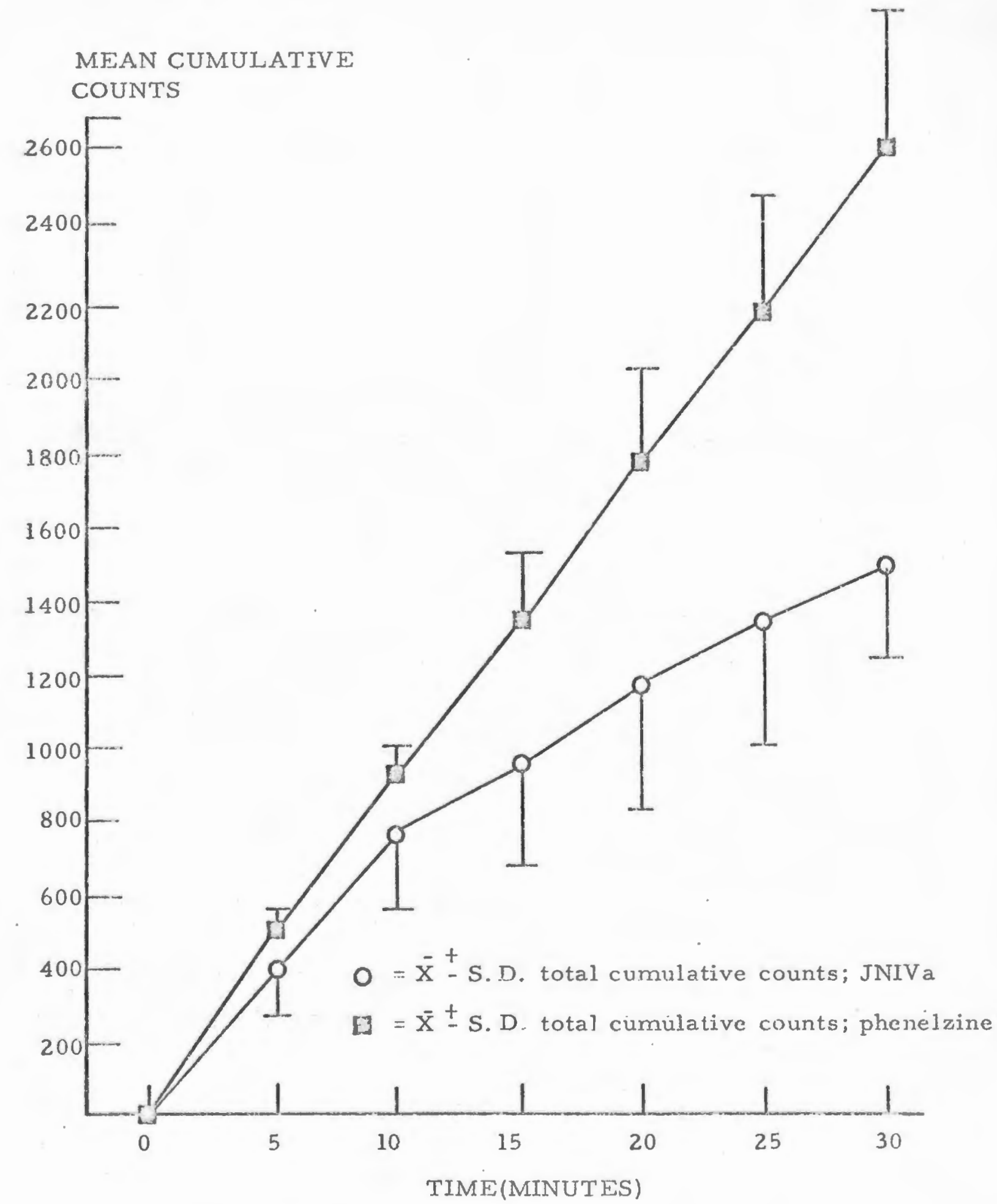

Graph represents mean \pm S. D. of cumulative counts per five minute increment gene rated by six groups of five JNIVa treated male albino mice versus six groups of five phenelzine treated micc.

Drug treatment: JNIVa, $150 \mathrm{mg} / \mathrm{kg}$, i.p. ; phenelzine, $40 \mathrm{mg} / \mathrm{kg}$, i. p. Time interval prior to recording: 1 hour. 
FIG. 16 ACTOPHOTOMETRIC RECORDING OF GROSS LOCOMOTOR ACTIVITY

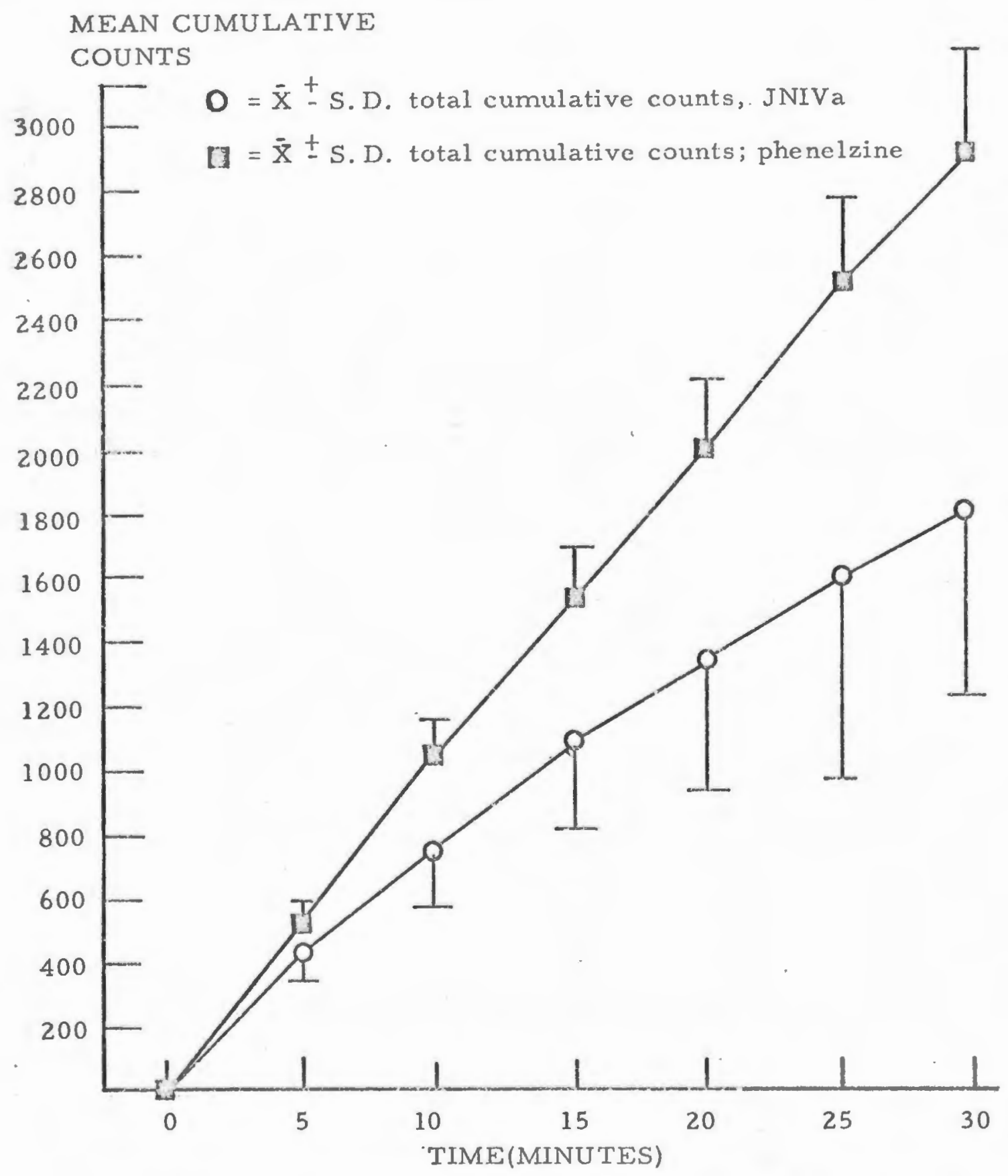

Graph represents mean $\pm S . D$. cumulative counts per five minute increment generated by six groups of five JNIVa treated male albino mice versus six groups of five phenelzine treated mice.

Drug treatment: JNIVa $150 \mathrm{mg} / \mathrm{kg}$, i.p.; phenelzine, $40 \mathrm{mg} / \mathrm{kg}$, i.p. Time interval prior to recording, 2.5 hours 
FIG. 17. ACTOPHOTOMETRIC RECORDING. OF GROSS LOCOMOTOR ACTIVITY.

MEAN CUMULATIVE

COUNTS

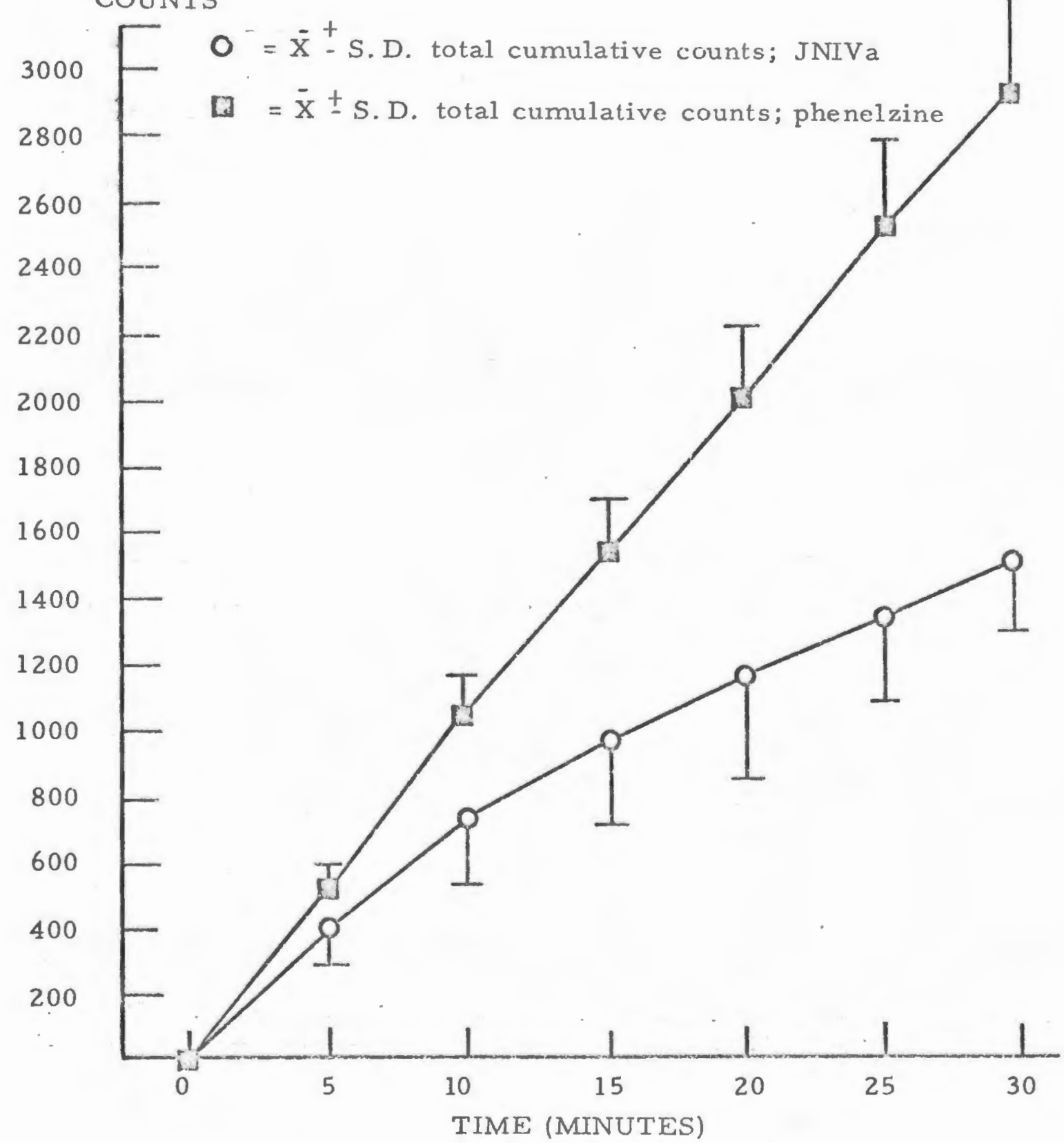

Graph represents mean cumulative counts per five minute increment generated by six groups of five JNIVa treated male albino mice versus six groups of five phenelzine treated mice.

Drug treatment: JNIVa $150 \mathrm{mg} / \mathrm{kg}$, i.p.; phenelzine $40 \mathrm{mg} / \mathrm{kg}$, i.p.

Time interval prior to recording: JNIVa: 1 hour

Phenelzine: 2.5 hours 
FIG. 18 ACTOPHOTOMETRIC RECORDING OF GROSS LOCOMOTOR ACTIVITY

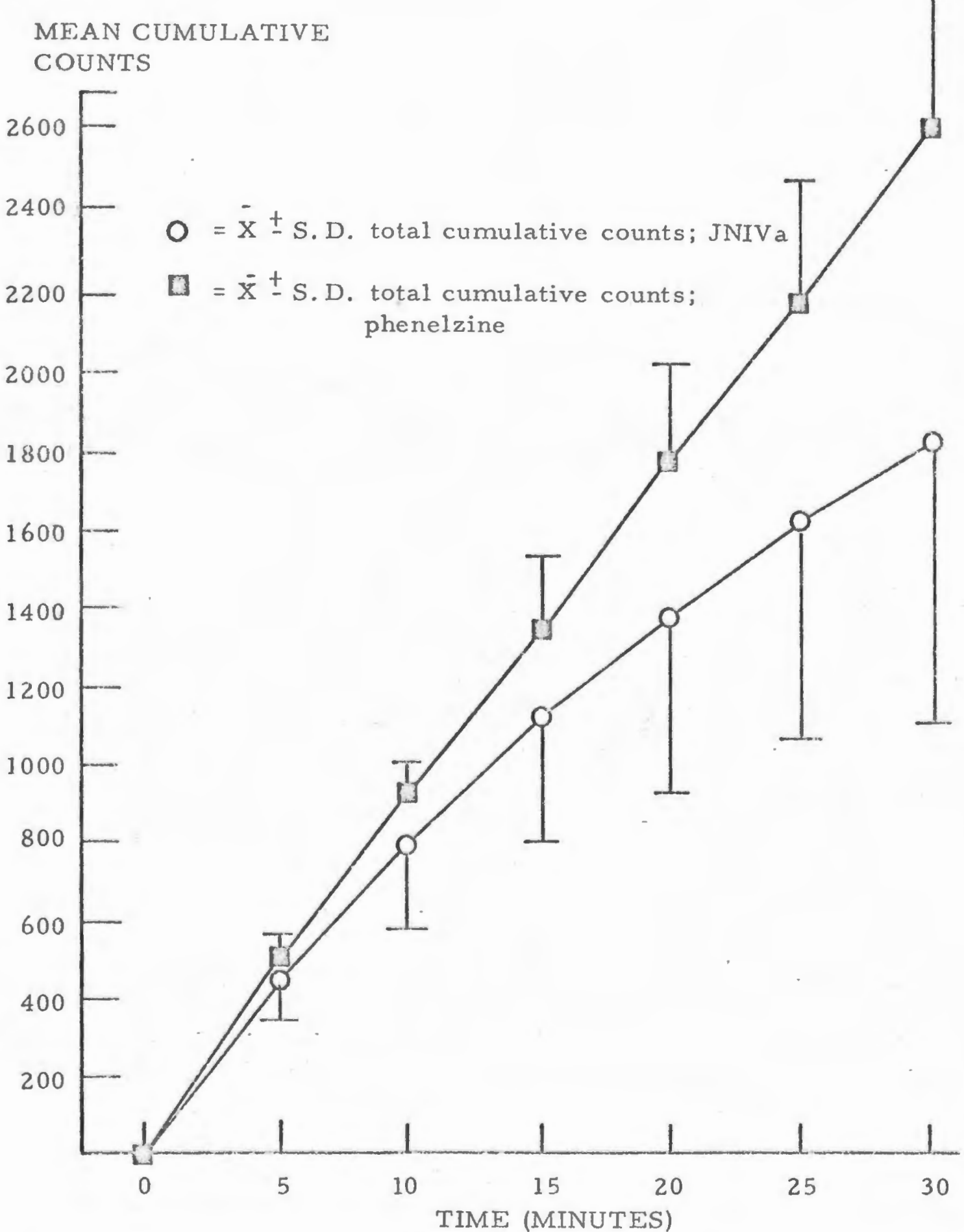

Graph represents mean \pm S.C. of mean cumulative counts per five minute increment generated by six groups of five JNIVa treated male albino mice versus six groups of five phenelzine treated mice.

Drug treatment: JNIVa, $150 \mathrm{mg} / \mathrm{kg}$, i. p. ; phenelzine, $40 \mathrm{mg} / \mathrm{kg}$, i. p.

Time interval prior to recording: JNIVa: 2.5 hours phenclzine: 1.0 hours 
FIG. 19 ACTOPHOTOMETRIC RECORDING OF GROSS LOCOMOTOR ACTIVITY

MEAN CUMULATIVE COUNTS

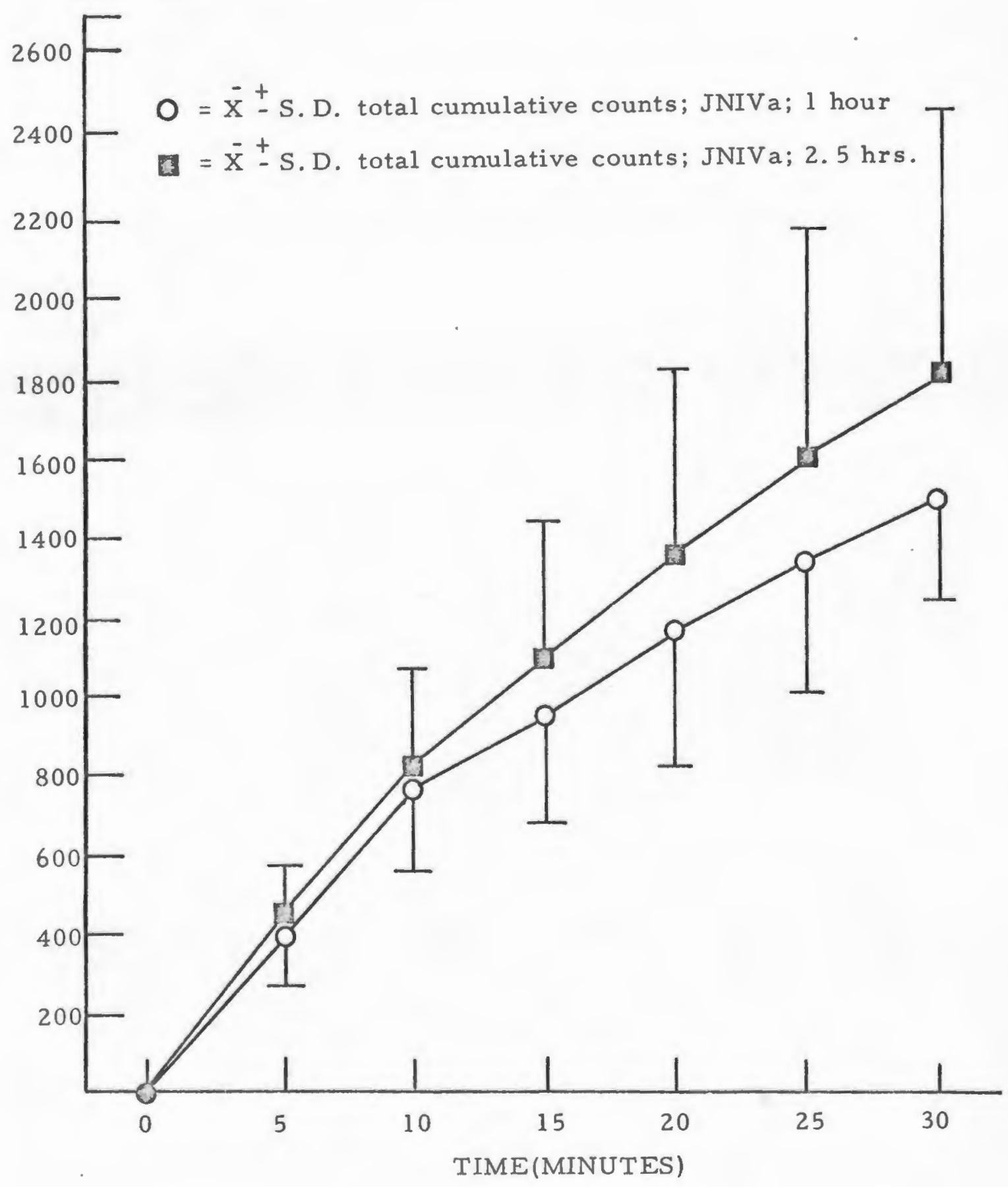

Graph represents mean $₫$ S. D. of mean cumulative counts per five minute inc rement generated by six groups of five JNIVa treated (1 hour) male albino mice versus six groups of five JNIVa treated (2.5 hours) mice.

Drug treatment: JNIVa, $150 \mathrm{mg} / \mathrm{kg}$, i. p.

Time interval prior to recording: 1 hour and 2.5 hours 
FIG. 20 ACTOPHOTOMETRIC RECORDING OF GROSS LOCOMOTOR ACTIVITY

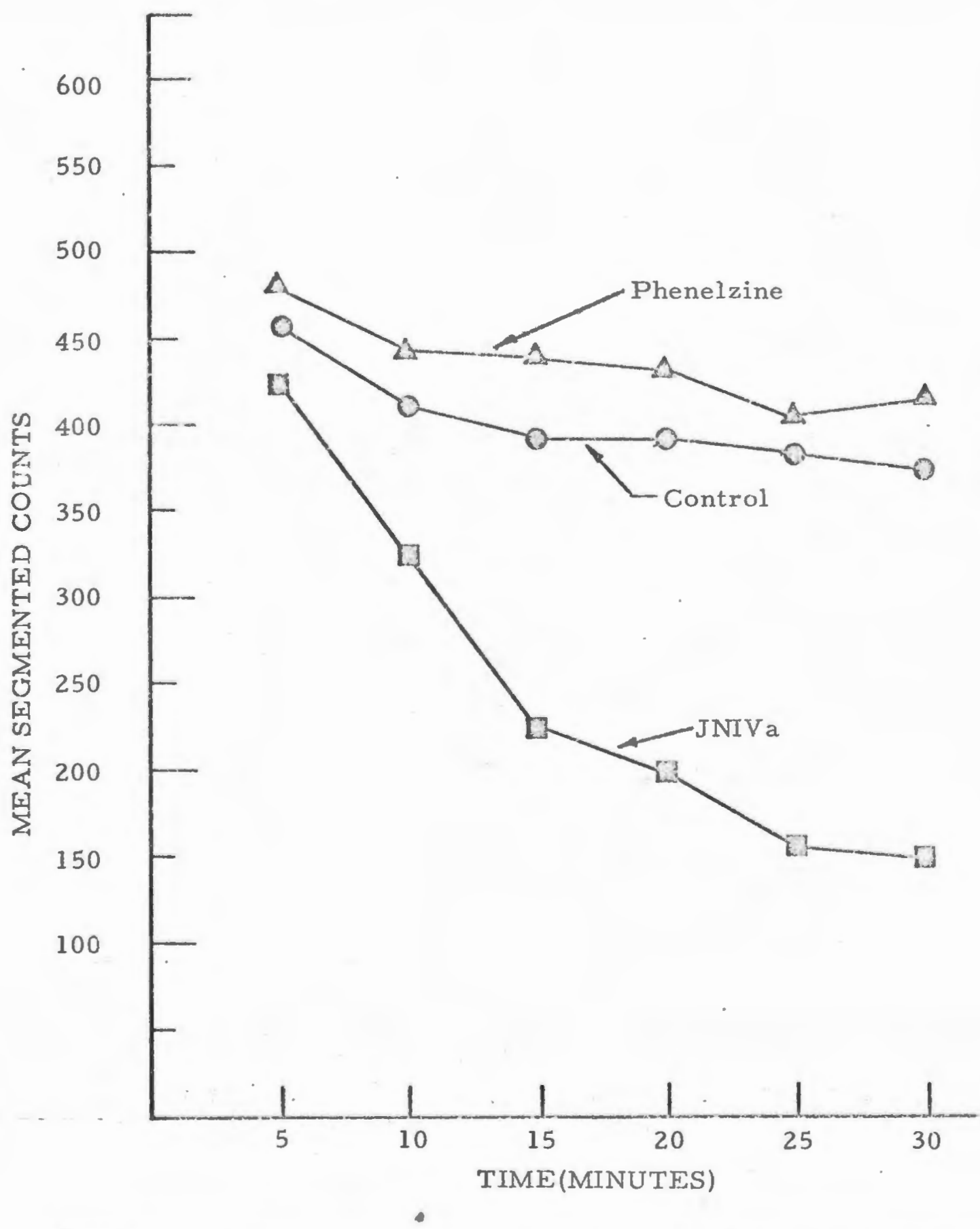

Graph represents mean segmented counts per five minute increment generated by six groups of vehicle-treated, JNIVa-treated and phenelzine-treated male albino mice over a period of thirty minutes.

Drug treatment: Vehicle, CMC(carboxymethylcellulose) $1 \mathrm{ml} / \mathrm{kg}$. , i. p. ; JNIVa, $150 \mathrm{mg} / \mathrm{kg}$, i. p. , phenelzine, $40 \mathrm{mg} / \mathrm{kg}$, i. p.

Time interval prior to recording: 1 hour 
FIG. 21 ACTOPHOTOMETRIC RECORDING OF GROSS LOCOMOTOR ACTIVITY

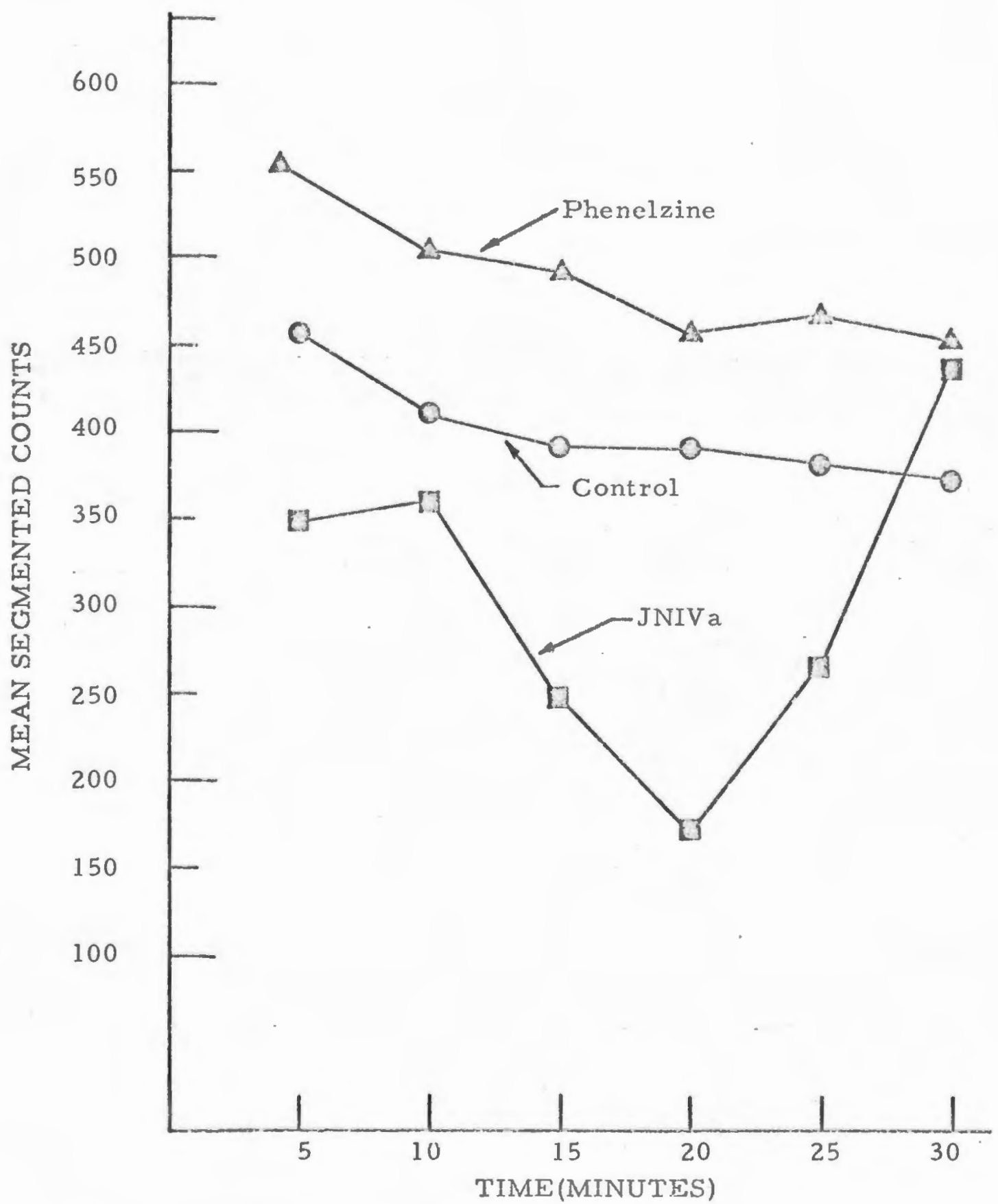

Graph represents mean segmented counts per five minute increment generated by six groups of vehicle-treated, JNIVa-treated and phenelzine-treated male albino.mice over a period of thirly minutes.

Drug treatment: Vehicle, CMC(carboxymethylcellulose) $1 \mathrm{ml} / \mathrm{kg}$, i.p. ; JNIVa, $150 \mathrm{mg} / \mathrm{kg}$, i.p.; phenelzine, $40 \mathrm{mg} / \mathrm{kg}$, i. p.

Time interval prior to recording: 2.5 hours 
FIG. 22 ACTOPHOTOMETRIC RECORDING OF GROSS

LOCOMOTOR ACTIVITY

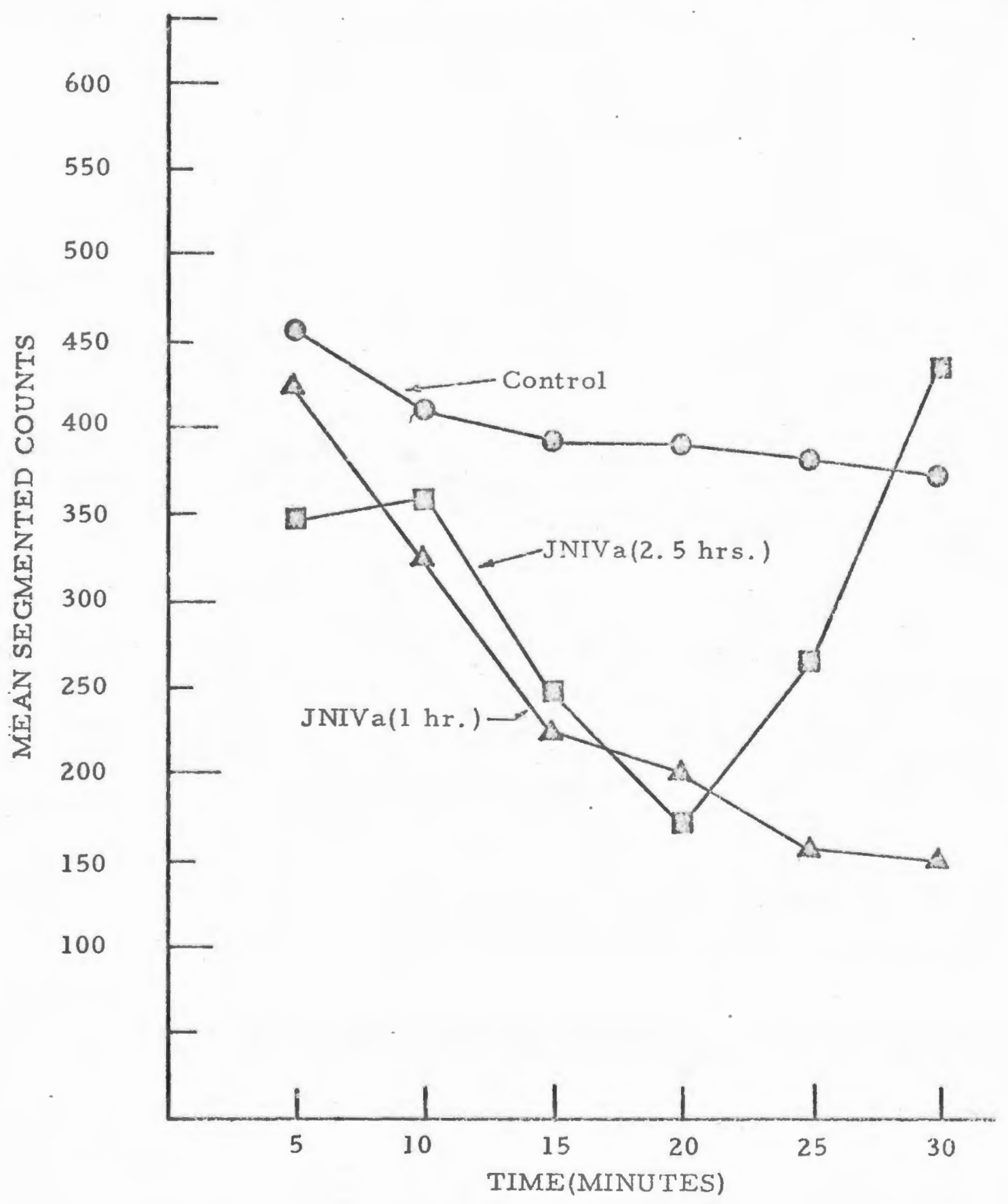

Graph represents mean segmented counts per five minute increment generated by six groups of vehicle-treated, JNIVa-treated ( 1 hour duration) and JNIVa-treated ( 2.5 hours duration) male albino mice over a period of thirty minutes.

Drig treatment: Vehicle, CMC(carboxymethylcellulose) $1 \mathrm{ml} / \mathrm{kg}$, i.p., JNIVa, $150 \mathrm{mg} / \mathrm{kg}$, i.p.

Time interval prior to recording: 1 hour and 2.5 hours 
FIG. 23 ACTOPHOTOMETRIC RECORDING OF GROSS LOCOMOTOR ACTIVITY.

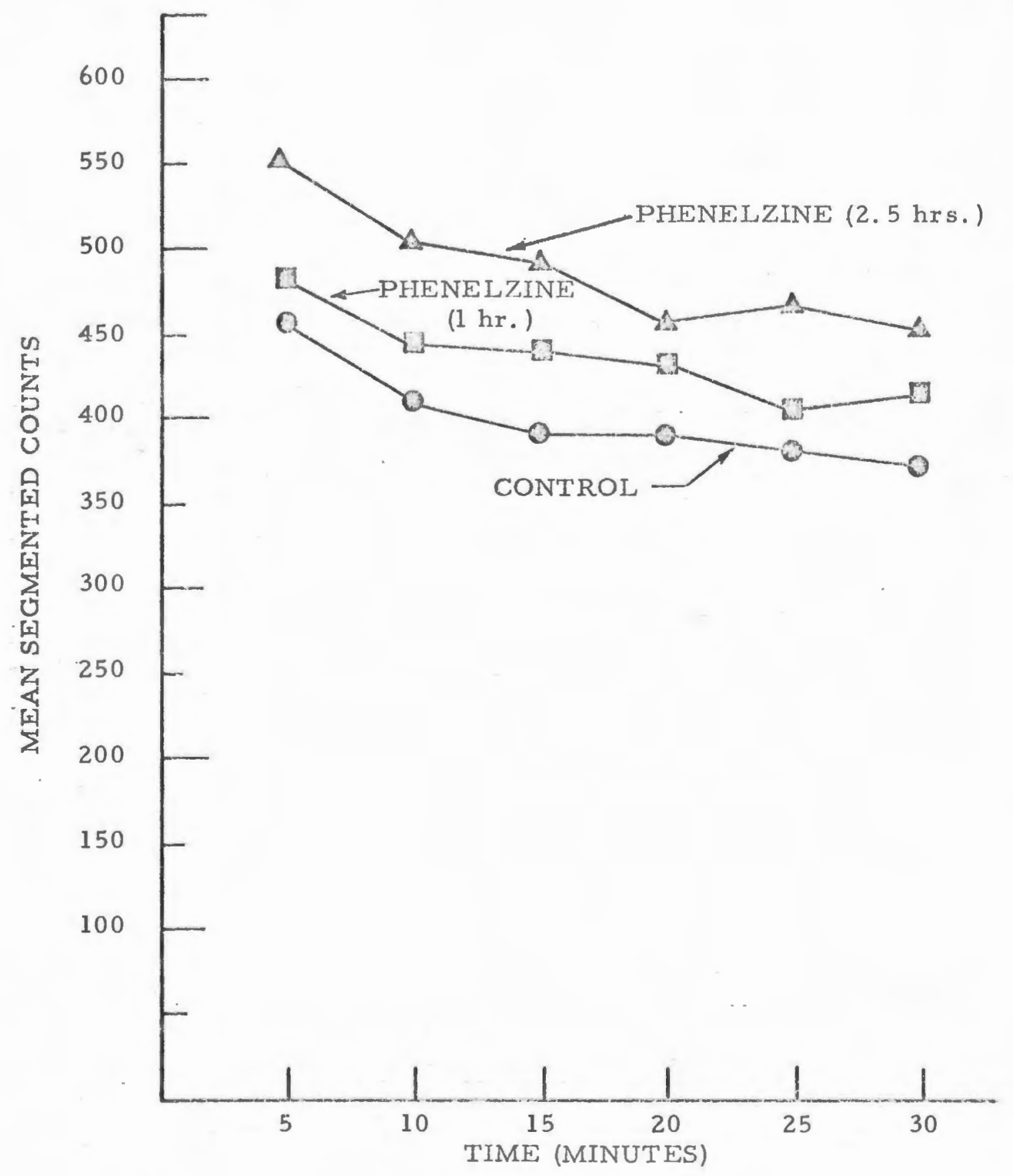

Graph represents mean segmented counts per five minute increment generated by six groups of vehicle-treated, phenelzine-treated ( 1 hour duration) and phenelzine-treated ( 2.5 hours duration) over a period of thirty minutes.

Drug treatment: Vehicle, CMC(carboxymethylcellulose) $1 \mathrm{ml} / \mathrm{kg}$, i.p., phenelzine, $40 \mathrm{mg} / \mathrm{kg}$, i.p.

Time interval prior to recording: 1 hour and 2.5 hours 


\section{TABLE X}

THE EFFECT OF JNIVA AND PHENEL,ZINE TREATMENT ON GROSS LOCOMOTOR ACTIVITY IN MALE ALBINO MICE

A. Incidence of significant difference between drug-treated and vehicle-treated groups of mice, using total segmented counts per five minute increment for a period of thirty minutes.

Series I: JNIVa versus control (vehicle)

\begin{tabular}{|c|c|c|c|c|}
\hline Time (min) & Control & vs. & Drug-treated & $\begin{array}{l}\text { Incidence of } \\
\text { significant } \\
\text { difference }\end{array}$ \\
\hline 5 & $\begin{array}{l}\bar{x} \pm \text { S.D. } \\
458 \pm 43\end{array}$ & & $\begin{array}{r}\overline{\mathrm{X}} \pm \text { S. D. } \\
425 \pm 91\end{array}$ & N.S. ${ }^{a}$ \\
\hline 10 & $416 \pm 18$ & & $326 \pm 104$ & N.S. \\
\hline 15 & $382 \pm 52$ & & $225 \stackrel{+}{-} 104$ & Sign. \\
\hline 20 & $385 \pm 43$ & & $198 \pm 75$ & Sign. \\
\hline 25 & $376 \pm 60$ & & $182 \pm 76$ & Sign. \\
\hline 30 & $364 \pm 45$ & & $177 \pm 53$ & Sign. \\
\hline
\end{tabular}

a. For a given five minute period, gross locomotor activity as measured by the actophotometer was not significantly (N.S.) diffe rent or,

b. significantly different (Sign.) as compared to the activity of vehicle-treated groups. $(P \leq 0.05)$

Drug treatment: Vehicle, CMC (carboxymethylcellulose) $1 \mathrm{ml} / \mathrm{kg}$, i.p. JNIVa, $150 \mathrm{mg} / \mathrm{kg}$, i.p.

Time interval prior to recording: 1 hour

The mean $\pm S . D$. of the total cumulative counts per five minute increment was computed. Comparisons between vehicle-treated and drug-treated groups were made by means of Student's "'t" test (Snedecor, 1956). All values were computed by use of the IBM Model 1620 Digital Computer (University of Rhode Island Computer Laboratory). 
TABLE XI

THE EFFECT OF JNIVA AND PHENELZINE TREATMENT ON GROSS LOCOMOTOR ACTIVITY IN MALE ALBINO MICE.

B. Incidence of significant difference between drug-treated and vehicle-treated groups of mice, using total counts per five minute increment for a period of thirty minutes.

Series II: JNIVa versus control (vehicle)

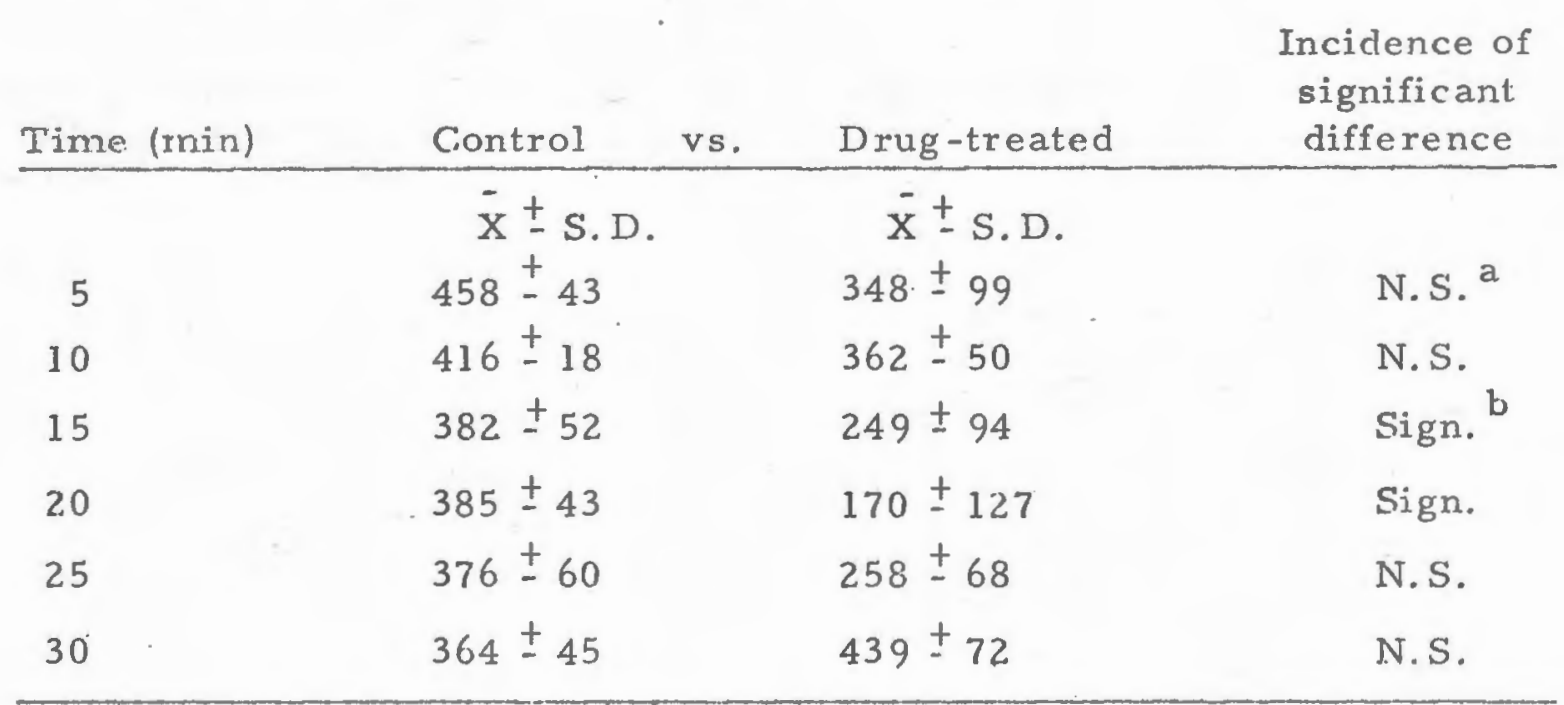

$\overline{\mathrm{X}}=$ Mean

S. D. =. Standard deviation

a. For a given five minute period, gross locomotor activity as measured by the actophotometer was not significantly (N.S.) diffe rent or,

b. significantly (Sign.) different as compared to activity of vehicletreated groups. (PS0.05)

Drug treatment: Vehicle, CMC (carboxymethylcellulose) $1 \mathrm{ll} / \mathrm{kg}$, i.p. JNIVa, $150 \mathrm{mg} / \mathrm{kg}$, i.p.

Time interval prior to recording: 2.5 hours

The mean \pm S.D. of the total counts per five minute increment was computed. Comparisons between vehicle-treated and drug-treated groups were made by means of Student's "t" test (Snedecor, 1956). All values were computed by use of the IBM Model 1620 Digital Computer (University of Rhode Island Computer Laboratory). 
TABLE XL

THE EFFECT OF JNIV A AND PHENELZINE TREATMENT.ON GROSS LOCOMOTOR ACTIVITY IN MALE ALBINO MICE.

C. Incidence of significant difference between drug-treated and vehicle-treated groups of mice, using total counts per five minute increment for a period of thirty minutes.

Series III: Phenelzine versus control (vehicle)

\begin{tabular}{|c|c|c|c|c|}
\hline Time (min) & Control & vs. & Drug-treated & $\begin{array}{c}\text { Incidence of } \\
\text { significant } \\
\text { difference }\end{array}$ \\
\hline 5 & $\begin{array}{l}\bar{X} \pm \text { S. D. } \\
458 \pm 43\end{array}$ & & $\begin{array}{l}\bar{X} \pm \text { S.D. } \\
480 \pm 25\end{array}$ & N. S. ${ }^{a}$ \\
\hline 10 & $416 \pm 18$ & & $440 \pm 58$ & N.S. \\
\hline 15 & $382 \pm 52$ & & $441 \pm 60$ & N.S. \\
\hline 20 & $385 \pm 43$ & & $434 \pm 94$ & N.S. \\
\hline 25 & $376 \pm 60$ & & $405 \pm 120$ & N.S. \\
\hline 30 & $364 \pm 45$ & & $414 \pm 87$ & N.S. \\
\hline
\end{tabular}

$\overline{\mathrm{X}}=$ Mean

S. D. $=\cdot$ Standard Deviation

a. For a given five minute period, gross locomotor activity as measured by the actophotometer was not significantly (N.S.) diffe rent.

Drug treatment: Vehicle, CMC (carboxymethylcellulose) $1 \mathrm{ml} / \mathrm{kg}$, i. p. Phenelzine, $40 \mathrm{mg} / \mathrm{kg}$, i. p.

Time interval prior to recording: 1.0 hour

The mean $\pm S$. D. of total counts per five minute increment was computed. Comparisons between vehicle-treated and drug-treated groups were made by means of Student's "t" test (Snedecor, 1956). All values were computed by use of the IBM Model 1620 Digital Computer (University of Rhode Island Computer Laboratory). 
TABLE XIII

THE EFFECT OF JNIV A AND PHENELZINE TREATMENT ON GROSS LOCOMOTOR ACTIVITY IN MALE ALBINO MICE

D. Incidence of significant difference between drug-treated and vehicle-treated groups of mice, using total counts per five minute increment for a period of thirty minutes.

Series IV: Phenelzine versus control (vehicle)

\begin{tabular}{|c|c|c|c|c|}
\hline Time (bxin) & Control & $\mathrm{vs}$ & Drug-treated & $\begin{array}{c}\text { Incicience of } \\
\text { significant } \\
\text { difference }\end{array}$ \\
\hline 5 & $\begin{array}{l}\bar{X} \pm \text { S. D. } \\
458 \pm 43\end{array}$ & & $\begin{array}{l}\bar{x} \pm \text { S.D. } \\
557 \pm 36\end{array}$ & Sign. ${ }^{b}$ \\
\hline 10 & $416 \pm 18$ & & $496 \pm 55$ & Sign. \\
\hline 15 & $382 \pm 52$ & & $489 \pm 57$ & Sign. \\
\hline 20 & $385 \pm 43$ & & $456 \pm 80$ & N.S. ${ }^{a}$ \\
\hline 25 & $376 \pm 60$ & & $469 \pm 65$ & Sign. \\
\hline 30 & $364 \pm 45$ & & $444 \pm 63$ & Sign. \\
\hline
\end{tabular}

$\overline{\mathrm{X}}=$ Mean

S.D. = Standard deviation

a. For a given five minute period, gross locomotor activity as measured by the actophotometer was not significantly (N.S.) diffe rent or,

b. significantly (Sign.) different as compared to activity of vehicletreated groups. $(P \leq 0.05)$

Drug treatment: Vehicle, CMC(carboxymethylcellulose) $1 \mathrm{ml} / \mathrm{kg}$, i.p. Phenelzine, $40 \mathrm{mg} / \mathrm{kg}$, i. $\mathrm{p}$.

Time interval prior to recording: 2.5 hours

The mean \pm S.D. of total counts per five minute increment was computed. Comparisons between vehicle-treated and drug-treated groups were made by means of Student's "t" test (Snedecor, 1956). All values were computed by use of the IBM Model 1620 Digital Computer (University of Rhode Island Computer Laboratory). 


\section{v. DISCUSSION}

Monoamine oxidase studies: In vitro system

The method of Weissbach et al., (1960) for the determination of monoamine oxidase activity was used throughout this portion of the study. Through preliminary studies, it was determined that the assay method was amenable to the use of mitochondrial suspensions as well as crude homogenates for a source of $M \dot{A O}$, for which the assay was originally designed.

All but two of the initial five compounds presented for research were eliminated following preliminary enzyme studies. Of the two remaining compounds, JNIV a was arailable in sufficient quantity to allow completion of additional studies.

Various authors (Hawkins, 1952; Davison, 1957) have indicated that the major activity of MAO is found in the mitochondria. Baudhuin et al., (1964) reported that $74 \%$ of the total MAO activity of crude rat liver homogenates was localized.in the mitochondria, with $24 \%$ in the microsomes. Inasmuch as Zeller et al, (1955) demonstrated that monoamine oxidase of tissue homogenates in considerably less sensitive than mitochondrial MAO to the actions of even relatively potent inhibitors such as iproniazid, frozen suspensions of lysed rat liver mitochondria were used as the enzyme source for.. all in vitro $\mathrm{MAO}$ assays 
Early work in this area (Zeller et al, 1955; Davison, 1956;

Green, 1962) has established the requisite for a pre-incubation period to effect maximal inhibition of mitochondrial MAO; indeed, the extent of enzyme inhibition has been observed to increase with longer incubation periods. In studies preliminary to the present one, an attempt was made to demonstrate the existence of a similar relationship between in vitro MAO inhibition and compound JNIVa. A concentration of $4.7 \times 10^{-6} \underline{M}$ JNIV a was found to be capable of effective inht bition of approximately $50 \%$ of mitochondrial MAO activity. Figure 5 represents graphically the results obtained when reaction mixtures were run, keeping the amount of enzyme and drug constant, while varying the length of the incubation period. With the same drug concentration, it was possible to alter the degree of enzyme inhibition from virtually none (a negligible amount) to over 70 per cent, by increasing the incubation period. The degree of enzyme inhibition rose rapidly during incubation periods extending to 20 minutes. At this point, a "plateau" region was reached, which extended from 20 to 40 minutes of incubation time. The plateau was followed by a second, relatively sharp increase in the degree of inhibition elicited by the test compound. This pattern for compound JNIVa was thus shown to be very similar to those of known in vitro MAO inhibitors. In this study, preincubation time was found to be a controlling factor, 
as is the case with such classic MAO inhibitors as iproniazid and phenyl-isopropylhydrazine (PIH). However, Zeller et al, (1955) reported that maximum MAO inhibition produced by iproniazid was reached between 6 and 12 minutes, whereas the degree of enzyme inhibition elicited by JNIVa was still increasing even after a 60 minute incubation period. If the assumption that preincubation periods are required for the biotransformation of the drug into an active inhibitor is valid, it would follow that a longer time interval may be required for the active moiety of compound JNIVa to be released. However, mechanism studies are needed to substantiate this hypothe sis.

The effects of the simultaneous addition of enzyme, substrate, and inhibitor to the reaction mixture correlated well with lite rature reports obtained from similar experiments using iproniazid. Under these conditions (no preincubation period), JNIVa was ineffective in Inhibiting MAO. This fact suggests that compound JNIVa could elicit its in vitro inhibition of MAO by acting as a competitive inhibitor, although substantiation of this idea awaits further studies.

Before any further in vitro enzyme studies were performed, a definite schedule for reaction mixtures had to be devised. An incubation interval was needed such that slight variations in the. . schedule would not appreciably affect the degree of enzyme inhibition, 
because preincubation time was shown to affect the inhibitory activity of JNIVa least significantly during the 20 to 30 minute incubation interval. A period of two minutes was required to remove the reaction cuvettes from the wate $\mathrm{r}$ bath, pipette $0.1 \mathrm{ml}$ of kynuramine into the media, cover with parafilm, and mix by vigorous shaking. At time when enzyme inhibition had been shown to be increasing rapidly with even small changes in time, this two-minute period could conceivably have a significant effect on the results. A period whereby the degree of inhibition was least affected by time would effectively guard against discrepancies caused by experimental technique. Therefore, it was decided that a preincubation time of 20 minutes would be suitable for this purpose.

Although JNIVa had seemingly decreased the rate of kynuramine oxidation taking place in mitochondrial as well as in crude rat liver homogenates, it was of primary importance to establish that a true, drug-induced inhibition and not a degradation of the enzyme itself was the causative agent in the observed decrease in substrate oxidation. A study was designed whereby the stability of the enzyme preparation, mitochondrial suspensions, would be determined. Three separate reaction mixtures containing no inhibitor were allowed to react for 50 minutes each. The change in optical density per 15 minute increment ( $0 . D .15)$ was determined by direct 
meașurement obtained from graphs produced by the DB-Spectrophotometer recording attachment previously described (See Methods section, page 28). Table VIII summarizes the results obtained from Series I, II, and III of this study. Statistical comparison of results obtained from each series demonstrated that no significant difference existed between the activity of mitochondrial MAO measured durirg the first 15 minutes of incubation at $30^{\circ} \mathrm{C}$, when compared to values obtained from the second and third 15-minute segments of the total reaction time. The integrity of the enzyme preparation was unaffected by incubation periods extending for over 50 minutes. In light of the se findings, it was assumed that the changes noted in enzyme activity following JNIVa must be attributed. to the action of the drug itself and not to any loss of enzyme integrity.

A separate study was used to determine the effect on the degree of enzyme inhibition under conditions of constant temperature brought about by varying enzyme concentration, drug concentration, and preincubation time. All enzyme reactions were run at $30^{\circ} \mathrm{C}$ using a preincubation time of 20 minutes. Figure 4 demonstrates the dose-response relationship obtained with phenelzine. A similar relationship was observed when compound JNIVa was used as the inhibitor. A dose-response curve was drawn by plotting the concentration of inhibitor on the abcissa and per cent inhibition on the 
ordinate. From this graph, it was then possible to determine the $I_{50}$ value (approximate concentration at which 50 per cent inhibition of enzyme is observed) for each drug. The $I_{50}$ value for phenelzine, a known inhibitor of monoamine oxidase in vivo and in vitro was found to be $8.3 \times 10^{-7} \underline{\mathrm{M}}$ as compared to $5.4 \times 10^{-6} \underline{\mathrm{M}}$, the $I_{50}$ value deterrminc for JNIVa. Table IX lists the various concentrations of each drug used in the determination of $I_{50}$ values. Based on the se data, it would appear that compound JNIVa exhibited significant: MAO inhibiting properties, when compared under similar-conditions, to the actions of pehnelzine, one of the more potent hydrazine MAO Inhibitors known at present.

In vivo MAO studies

The observation that hydrazide-type MAO inhibitors exhibiting potent inhibition in one system while being inactive in another has been well documented (Schayer and Smile, 1953; Weikel et al, 1963; Zeller et al, 1955). Consequently, the fact that compound JNIV a demonstrated rather potent MAO inhibitory properties in vitro by no means dictated that similar results were to be expected in vivo.

An in vitro measurement of in vivo drug activity was made by determining the extent to which liver and brain homogenates of treated rats could metabolize the substrate, kynuramine, using the Identical assay method for all measurements of enzyme activity. 
This part of the study was divided into two series, A and B. All animals in Series A were sacrificed 40 minutes after treatment; animals in Series B were sacrificed 120 minutes after treatment. During preliminary studies, it was found that treatment with vehicle, whether glass distilled water or 2 per cent carboxymethylcellulose, administered at eithe $r$ of these time periods, had no significant effect on enzyme activity. It was therefore decided to run one control for each vehicle at the 40 minute period, in order to decrease the number of animals sacrificed on the day tissue homogenates were to be prepared from treated groups.

During a separate preliminary stuay, it was noted that both rats and mice treated with $100 \mathrm{mg} / \mathrm{kg}$ JNIVa, intraperitoneally, showed profound symptoms of lethargy and developed ptosis, 30 to 45 minutes after drug administration. For this reason, a decision was made to sacrifice at least one entire series of drug-treated groups at a time when drug effects we re evident. Neither the sedative nor ptotic effect of JNIVa was as prominent after 90 minutes had elapsed from time of treatment; however, it was believed that at: least two hours should be allowed for any drug activity, particularly MAO inhibition, to become manifest.

Reports of almost total inhibition of brain and liver MAO following a single intraperitoneal injection of hydrazide MAO 
inhibitors are not uncommon. McNeill (1964) found that phenelzine $(30 \mathrm{mg} / \mathrm{kg})$ was capable of virtually complete inhibition $(97.5 \%)$ of brain MAO activity in rats treated with a single injection three hours prior:to sacrifice. Weikel et al, (1962) reported that one hour after a single intraperitoneal injection of iproniazid, $150 \mathrm{mg} / \mathrm{kg}$, 73 per cent of brain MAO and 100 per cent of liver MAO was inhibited. It became clear, then, that hydrazine MAO inhibitors are capable of significantly lowering MAO activity after single doses have been administered.

For the purpose of this study, experimental groups were divided in the manner previously described (See Methods section, page 26 ). Once the animals had been sacrificed and the tissue homogenates prepared, the actual measurement of MAO activity was performed exactly as in in vitro measurements, the only exception being that tissue homogenates from treated animals we re now used as the enzyme source for the assay. The protein content of each liver and brain homogenate sample was determined. Turnover rates, expressed as umoles kynuramine/hour/mg protein were calculated from these data. Table II summarizes the data obtained from analysis of turnover rates based upon MAO activity of livers obtained from treated rats. These results are represented graphically in Figure 1. The mean turnover rate for all phenelzine treated groups 
was zero, signifying that the drug had completely inhibited the enzyme present in both liver and brain. Conversely, compound JNIVa failed to bring about a significart change from the control value of the activity of liver or brain monoamine oxidase in rats treated 120 minutes prior to sacrifice. When compared to a mean control value of $11.81 \pm 1.23$, the activity of liver homogenates prepared from INIVa-treated animals showed a small but significant increase. Similarly, mean turnover rates of $3.42 \pm 0.36$ and $.3 .31 \pm 0.58$ are reported for groups treated with JNIVa 40 minutes and 120 minutes prior to sacrifice, respectively (Table IV). The enzyme activity of both JNIVa-treated groups was shown-to be raised above control values, though neither change was statistically significant. Certainly, the effects of JNIVa on an in vivo enzyme system demonstrated in this study, when considered in light of the in vitro enzyme activity ellcited by the drug, would not be expected to occur. Elucidation of this seeming anomaly must await additional study.

It is evident from this study that compound JNIVa failed to exhibit any significant in vivo inhibition of monoamine oxidase, an effect clearly demonstrated by this drug during in vitro enzyme studies using similar assay techniques. 


\section{Activity Studies}

Early in the activity studies, nume rous mechanical difficulties were encountered in the use of the Actophotometers in this laboratory. Once the instrument had been adjus ted, great care was required to maintain all six photoelectric circuits in functioning order. Following adjustment, the instrument proved to be a valuable tool in determining the temporal pattern of animal activity subsequent to drug treatment.

The extensive studies performed by Watzman et al, (1964) to determine in what way the actophotometric method of measuring gross locornotor activity could be employed most efficiently proved valuable in designing the present study. Watzman's work may be summarized as follows:

1. The lowest "C" values (Coefficient of Variation) and highest cumulative counts resulted from the use of five mice per experimental group.

2. Higher cumulative counts were generated by fasted mice as opposed to mice which had been fed prior to the recording period.

3. " $\mathrm{C}$ " values were found to be lowest during the first half-hour of the counting period.

4. Any "warmup" or equilibration period prior to recording would tend to increase the " $\mathrm{C}$ " values and decrease the total cumulative counts obtained during the study. 
Gylys and Muccia (1967) noted a biphasic action exhibited by Beveral hydrazine and non-hydrazine MAO inhibitors: either an increase or a slight depression in gross locomotor activity in mice appeared one hour after phenelzine treatment; however, after two hours, a very pronounced increase in activity was noted. In an attempt to estabiish a clearer picture of activity changes elicited by both phenalzine and JNIVa, two separate time intervals of 1. 0 hour and 2.5 hours following drug treatment were allowed prior to the recording period.

The total cumulative counts generated by each experimental group were recorded every five minutes for a total of thirty minutes. Only the initial thirty minute period following each group's introduction in the chamber was analyzed, because it was believed that this time period would produce the most meaningful results. The results obtained during this study were analyzed by two methods:

a) The Mean \pm Standard Deviation (S.D.) total cumulative counts per five minute increment was calculated for vehicle-treated and drug-treated groups. "C" yalues were determined.

b) The Mean \pm Standard Deviation (S.D.) segmented counts per five minute increment were determined for both vehicle-treated and drug-treated groups. Statistical comparisons of the above group were made and the incidence of significant difference between groups 
was determined.

Figures 6 - 10 represent the means \pm standard deviations of the total cumulative counts generated by six groups of vehicle-treated animals. Included are the " $\mathrm{C}$ " values for each five minute increment For vehicle-treated groups, the number of counts increased linearly with tirue throtighout the thirty-minute recording period. Further, the " $C$ " value for each five-minute increment was found to be significantly lower in comparison to corresponding " $\mathrm{C}$ " values from. drug-treated groups. After ten minutes had elapsed, the "C" values dropped to approximately 5 per cent and varied only slightly during the remainder of the recording period. It was evident from this control study that any drug-induced changes in locomotor activity would be easily discernible by the method employed.

Graphs of the data from phenelzine-treated groups showed linearity similar to the graphs of the activity of vehicle-treated groups. However, total cumulative counts generated by phenelzine groups treated 1.0 hour prior to recording were slightly above control values (Figure 12). Experimental groups treated with phenelzine 2.5 hours prior to recording (Figure 14) also showed similar increased activity. "C" values for both phenelzine-treated groups were higher than those for vehicle-treated groups. Values ranging from 5 per cent to 14 per cent for phenelzine-treated, as compared 
to a range of 5 per cent to 9 per cent for vehicle-treated groups, were noted. The total mean count per thirty minutes for phenelzinetreated groups at the 1.0 hour and 2.5 hour intervals was 2600 and 2900 counts, respectively, as compared to 2300 counts generated by vehicle-treated groups.

During the thirty-minute recording period, JNIVa groups treated at the 1.0 hour and 2.5 hour intervals generated a total of 1500 and 1800 counts, respectively, as compared to a mean control value of 2300 counts. This significantly decreased locomotor activity experienced by JNIVa-treated groups was accompanied by large " $C$ " values for all six readings observed during the thirty minute recording period (Figures 8 and 10, Results section). "C" values ranging from 16 to 31 per cent were reported for the six JNIVa groups treated 2.5 hours prior to recording. The depressed locomotor activity evident in the first series of JNIVa-treated mice was less prominent 2.5 hours following drug treatment. "C"! values within this series increased steadily throughout the recording period. It is possible that the depressive effect initially elicited by JNIV a was now ebbing. Varying durations of drug activity caused primarily by normal intraspecies variation could conceivably account for the extremely high " $\mathrm{C}$ " values noted during this series. Interestingly, Steinberg et al., (1964) reported that rats of the same strain, sex, 
and litter often demonstrate widely varying responses to several MAO inhibitors.

Figures 6 through 9 represent the total cumulative counts generated by drug-treated groups as opposed to vehicle-treated groups. Both phenelzine-treated groups generated significantly higher counts as compared to control values. When compared to these same corirol values, JNIVa-treated groups generated fewer counts at both the 1.0 hour and 2.5 hour intervals.

Measuring the activity of drug-treated groups at both the 1.0 hour and 2.5 hour intervals made it possible to determine whether any changes in drug effects had occurred between the two. time intervals. In addition, qualitative changes in gross locomotor activity elicited by phenelzine and JNTVa could be observed at both time intervals. The results of this study are represented in Figures 15-19. After 30 minutes, a mean total of 2600 counts and 2900 counts was generated by rats treated with phenelzine, 1.0 hour and 2.5 hours, respectively, prior to recording of activity. Under identical conditions, JNIVa-treated groups generated 1500 counts after one hour and 1800 counts after 2.5 hours. These results would indicate that the stimulation experienced by phenelzinetreated groups 1.0 hour following drug treatment had increased in intensity 1.5 hours after the initial reading. In contrast, the 
depression of locomotor activity evidenced in JNIVa-treated rats 1. 0 hour after treatment was not as apparent at the 2.5 hour interval.

In order to obtain a more concise picture of the dissimilar locomotor alterations experienced by the phenelzine - and JNIVatreated groups, mean segmented counts of the se groups were analyzed. Tables $\mathrm{X}-\mathrm{XIII}$ list the occurrence of significant differences ( $P$ 0.5) in gross locomotor activity between drugtreated and vehicle-treated groups. The data are represented graphically in Figures $20-23$. At the 1.0 hour time interval, significant differences occurred at the $15,20,25$, and 30 minute segments during studies on JNIVa-treated groups. At the 2.5 hour interval, only the 14 and 20 minute segments were statistically different from control groups. In contrast, no significant differences occurred between phenelzine - and vehicle-treated groups at the 1. 0 hour time interval. However, at the 2.5 hour interval, all except the 20 minute segment proved significantly different from control values. The profiles of both phenelzine groups were very similar (Figure 23), whereas those of JNIVa-treated groups demonstrated considerable variation when measured at two separate time intervals. At the 1.0 hour interval, a steadily increasing depression of locomotor activity was noted; however, a decrease followed by a correspondingly rapid increase in activity rising above control value 
occurred during the 30 minute recording period at the 2.5 hour interval: All phenelzine-treated groups demonstrated an elevation in locomotor activity. The intensity of this apparent stimulation remained relatively stable throughout the recording period. 


\section{SUMMARY AND CONCLUSIONS}

A study of certain biochemical and pharmacological properties of one member of a series of dihydrazides is presented. This compound possesses a close structural relationship to known inhibitors of monoaraine oxidase. Consequently, the present study was designed to elucidate any pharmacological properties of the dehydrazide correlating with several properties inherent in hydrazide-type MAO inhibitors.

A. Preliminary blood pressure studies were performed, utilizing both direct and indirect measurements. Compound JNIVa (imidazole4,4-dicarboxylic acid, di-2-methylhydrazide) and JNII (imidazole-4, 5-dicarboxylic acid, di-2-dimethylhydrazide), administered intravenously, did not significantly alter systemic blood pressure. Similarly, compounds JNII and JNIVa failed to alter systemic blood pressure when administered intraperitoneally at doses of 5,20 , and $40 \mathrm{mg} / \mathrm{kg}$ daily for 21 days.

B. The monoamine oxidase assay of Weissbach et al (1960) was employed throughout all enzyme studies. Phenelzine dihydrogen sulfate, a potent hydrazine-type MAO inhibitor, was used as the standard for both in vivo and in vitro enzyme studies. Terminal MAO activity measured in brain and liver was not affected by pretreatment with JNIVa administered 1.0 hour and 2.5 hours prior to sacrifice. 
Under identical conditions, phenelzine completely inhibited MAO activity in both live $\mathrm{r}$ and brain.

C. A concentration of $4.7 \times 10^{-6} \underline{M}$ JNIVa was found to inhibit approximately 50 per cent of mitochondrial monoamine oxidase. The degree of inhibition for any given inhibitor concentration was found to be directly related to the duration of the pre-incubation period. D. Gross locomotor activity in mice was measured by the actophotometric method. Recordings of exploratory activity of animals pretreated with phenelzine or JNIVa were taken 1.0 hour or 2.5 hours following drug administration. Phenelzine was shown to increase activity at the 1.0 hour level; after 2.5 hours, the initial stimulation increased in intensity. Compound JNIVa significantly depressed exploratory activity at the 1.0 hour level; however, this decrease was not as apparent at the 2.5 hour level. "C" values were significantly higher in JNIVa-treated groups at both time intervals. The mechanism of this depression is not known. Inasmuch as the results of the present study delineate the inability of JNIVa to inhibit MAO in vivo, it is possible that the depression of exploratory behavior caused by the drug is unrelated to any MAO-inhibition property of this drug. 


\section{REFERENCES}

Aebi, H.: Mitochondrial structure as a cortrolling factor of monoamine oxidase activity and the action of amine oxidase inhibitors. Biochem. Pharmacol. 9: 135, 1962.

Assali, N. S. and Kanakbeena, D.: Hypotensive effects of iproniazid and carboxazid. J. Am. Med. Assoc. 173: 1549, 1960.

Biel, J. H., Nuhfer, P.A. and Conway, A. C.: Structure and activily relationships of monoamine oxidase inhibitors. Ann. N.Y. Acad. Sci. 80: 568, 1959.

Brimblecomive, R. W.: Effects of psychotropic drugs on open-field behavior in rats. Psychopharmacologia 4: 139, 1963.

Brodie, B. B., Spector, S. and Shore, P. A.: Interaction of drugs with norepinephrine in the brain. Pharmacol.Rev. 11: 548, 1959.

Chessin, M., Dubnick, B., Lesson, G. and Scott, C.: Biochemical and pharmacological studies of B-phenylethylhydrazine and selected related compounds. Ann. N. Y. Acad. Sci. 80: 597, 1959.

Davey, M. D., Farmer, J. B. and Reinert, H.: The effects of nialamide on adrenergic functions. Brit. J. of Pharmacol. 20: 121, 1963.

Davison, A. N.: The mechanism of the irreversible inhibition of rat-liver monoamine oxidase by iproniazid (Marsilid). Biochem. J. 67: 316, 1957.

Davison, A. N.: Physiological role of monoamine oxidase. Physiol. Rev. 38: 729, 1958.

Dubnick, B., Leeson, G. A. and Phillips, G. E.: In vivo inhibition of se rotonin synthesis in mouse brain by B-phenylethylhydrazine, an inhibitor of monoamine oxidase. Fed. Proc. 18: 218, 1959.

Feldstein, A: MAO inhibition and anti-depressant activity. Intern. J. Neuropsychiat. 1: 384, 1965.

Furgiuele, A. : Central effects of b-phenylisopropyl hydrazine and iproniazid, J. Pharmacol. Exptl. Therap. 138: 356, 1962 
Garattini, S., Giacalone, E. and Valzelli, L. : Isolation, aggres siveness and brain 5-hydroxytryptamine turnover. J. Pharm. Pharmac. 19: 338; 1967 .

Gertner, S. B.: Ganglionic block and monoamine oxidase inhibitors. Nature 173: 750, 1959.

Gertner, S. B.: The effects of monoamine oxidase inhibitors on ganglionic transmission. J. Pharmacol. Exptl. Therap. $131: 223,1961$.

Gessa, G. L., Cuenca, E. and Costa, E.: On the mechanism of hypotensive effects of MAO inhibitors. Ann. N. Y. Acad. Sci. 107: $935,1963$.

Goldberg, Leon I., and DaCosta, Francis M.: Selective depression of sympathetic transmission by intravenous administration of iproniazid and harmine. Proc. Soc. Exptl. Biol. Med. 105: 223, 1960.

Green, H. : Effect of repcated oral administration of monoamine oxidase inhibitors on rat brain amines. Proc. Soc. Exptl. Biol. Med. 109: 347, 1962.

Greig, M. E., Seay, P. H. and Freyburger, W. A.: The pharmacology of etryptamine. J. Neuropsychiat. 2: S131, 1961.

Greismer, E. C. and Wells, J. A.: Abolition of epinephrineinactivating properties of liver by inhibiters of moroamine oxidase. J. Pharmaco1. Exp. Theraf. 116: 282, 1956.

Gylys, J. A. and Muccia, P. M. : Modaline and locomotor activity in the mouse. Arch. Int. Pharmacody1. 166: 449, 1967.

Hall, C. S.: Emotional behaviour in the rat: I. Defecation and urination as measures of individual differences in emotionality. J. comp. Psychol. 18: 385, 1934.

Hawkins, J.: The localization of amine oxidase in the liver cell. Biochem. J. 50: 577, 1952 .

Horita, A.: The antagonism of monoamine oxidase (MAO) inhibitors by the red blood cell and its constituents. Toxic. Appl. Pharmacol. 7: 97,1965 . 
Koechlin, A. and Iliev, J.: The metabolism of iproniazid. Ann. N. Y. Acad. Sci. 80: 864, 1959.

Kopin, I. J., Fischer, J. E., Musacchid, J. M., Horst, W. D. and Weisr, V.: False neurochemical transmitters and the mechanism of sympathetic blockade by monoamine oxidase inhibitors. J Pharmacol. Exptl. Therap. 147: 176, 1965.

Latz, A., Bain, G., Goldman, M. and Kornetsky, C.: Maze learning after the administration of antidepressant drugs. J. Pharmacol. Exptl. Therap. 156: 76, 1967.

Maitre. I..: Monoamine oxidase inhibiting properties of SU-11,739 in the rat. Comparison with pargyline, tranylcypromine and iproniazid. J. Pharmacol. Exptl. Therap. 157: 81, 1967.

Maling, H. M., Highman, B. and Spector, S.: Neurologic, neuropathologic, and neurochemical effects of prolonged administration of phenylisopropylhydrazine (JB-516), phenylisobutylhydrazine (JB-835), and other monoamine oxidase inhibitors. J. Pharmacol. Expt1. The rap. 137: 334, 1962.

Marriott, A. S. and Spencer, P. S. J.: Effects of centrally acting drugs on exploratory behavior in rats. Brit. J. Pharmacol. 25: $432,1965$.

Nair, V.: The fate of ${ }^{14} \mathrm{C}-$ labeled iproniazid in the rat. Biochem. Pharmacol. 3: 78, 1959.

Pare, C.M.B.: The role of brain amines in the antidepressant action of monoamine oxidase inhibitors in the human. Proceedings of the Fifth International Congress of the Collegium Internationale Neuropsycho-pharmacologicum, pp. 335-338. Neuropsychopharmacology. The Netherlands: Morton \& Co. 196.

Pletscher, A.: Monoamine oxidase inhibitors. Pharmacol. Rev. 18: $121,1966$.

Plummer, A. J., and Furness, P. A.: Biological estimation of the intensity and duration of action of monoamine oxidase inhibjtors. Ann. N. Y. Acad. Sci. 107: 865, 1963.

Randell, L. and Bagdon, R. E.: Pharmacology of iproniazid and other amine oxidase inhibitors. Ann. N.Y. Acad. Sci. 80: 626, 1959. 
Schayer, R. W.: In vivo inhibition of monoamine oxidase studied with radioactive tryptamine. Proc. Soc. Exptl. Biol. Med. 84: 60, 1953.

Schayer, R.. W. and Smiley, R. L.: The metabolism of epinephrine containing isotopic carbon. IIl. J. Biol. Chem. 202: 425, 1953.

Schwartz, M. A. : Monoamine oxidase inhibition by isocarboxazid. J. Pharmacol. Expt. Therap. 135: 1, 1962.

Seiden, L. S. and Westley, J.: Mechanism of iproniazid inhibition of brain nur oamine oxidase. Arch. Int. Pharmacodyn. $146: 145,1963$.

Sjoerdsma, Albert: Newer biological approaches to the treatment of hypertension. Ann. N. Y. Acad. Sci. 88: 933, 1960.

Sjoerdsma, A.: Relationships between alterations in amino metabolism and blood pressure. Circulation Res. 9: 734, 1961.

Sjoerdsma, A.: Catecholamine-drug interactions in man. Pharmacol. Rev. 18: 673, 1966.

Smith, T. E., Weissbach, M. and Udenfriend, S.: Studies on monoamine oxidase by iproniazid. Biochemistry 2: 746, 1963.

Spector, S., Shore,.P. and Brodie, B.: Biochemical and pharmacological effects of the monoamine oxidase inhibitors, iproniazid, 1-phenyl-3-hydrazinepropane (JB-516) and 1-phenyl-3-hydrazinobutane (JB-835). J. Pharmacol. Exptl. Therap. 128: 15, 1960.

Watzman, N., Barry, H. and Kinnard, W. J. : Influence of aggregation and other parameters on drug response in the mouse as measured in the actophotometer. Fed. Proc. 23: 197, 1964.

Weissbach, H., Smith, T. E., Daly, J. W., Witcop, B. and Udenfriend, S.: A rapid spectrophotometric assay of monoamine oxidase based on the rate of disappearance of kynuramine. J. Biol. Chem. 235: 1160, 1960 .

Zeller, E. A. and Barsky, J.: In vivo inhibition of liver and brain monoamine oxidase by 1 -isonicotinyl-2-isopropylhydrazine. Proc. Soc. Exptl. Biol. Med. 81: 459, 1952. 
Zeller, E. A., Barsky, J. and Berman, E. R.: XI. Inhibition of monoamine oxidase by 1 -isonicotinyl-2-isopropylhydrazine. $J$. Biol. Chem. 214: 267, 1955.

Zeller, E. A., Barsky, J., Fouts, J. R., Kircheimer, F. A. and Van Orden, L. S. : Iniluence of isonicotinic acid hydrazide (INH) and 1 -iso-nicotinyl-2-isopropylhydrazide (I IH) on bacterial and mammalian enzymes. Experientia 8: 17, 1952. 